I NTER NATIONAL MONETARY FUND

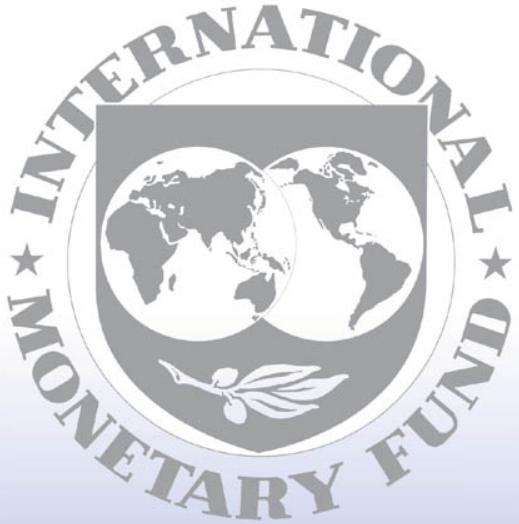

Staff

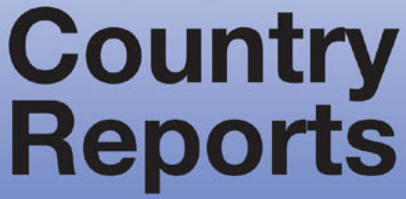




\section{Georgia: Report on Observance of Standards and Codes-Data Module}

This Report on the Observance of Standards and Codes on Data Module for Georgia was prepared by a staff team of the International Monetary Fund as background documentation for the periodic consultation with the member country. It is based on the information available at the time it was completed on March 7, 2012. The views expressed in this document are those of the staff team and do not necessarily reflect the views of the government of Georgia or the Executive Board of the IMF.

The Response by the Authorities to this report and the Detailed Assessments Using the Data Quality Assessment Framework (DQAF) are also included.

The policy of publication of staff reports and other documents by the IMF allows for the deletion of market-sensitive information.

Copies of this report are available to the public from

International Monetary Fund • Publication Services

700 19th Street, N.W. • Washington, D.C. 20431

Telephone: (202) 6237430 • Telefax: (202) 6237201

E-mail: publications@imf.org • Internet: http://www.imf.org

\section{International Monetary Fund Washington, D.C.}




\title{
GEORGIA
}

\section{Report on the Observance of Standards and Codes (ROSC)—Data Module Volume I}

\author{
Prepared by the Statistics Department
}

Approved by Adelheid Burgi-Schmelz and Ahmed Masood

March 7, 2012

The Report on the Observance of Standards and Codes (ROSC) - Data Module provides an assessment of Georgia's macroeconomic statistics against the Special Data Dissemination Standard (SDDS) complemented by an assessment of data quality based on the IMF's Data Quality Assessment Framework (DQAF) July 2003. The DQAF lays out internationally accepted practices in statistics, ranging from good governance in data-producing agencies to practices specific to datasets.

The datasets covered in this report are national accounts, consumer and producer price indices, government finance, monetary and balance of payments statistics. The agencies that compile the datasets assessed in this report are the National Statistics Office of Georgia, Ministry of Finance and National Bank of Georgia.

The datasets to which this report pertains can be accessed in print and on the Internet:

Ministry of Finance (MOF): http://www.mof.gelen/home

National Bank of Georgia (NBG): http://www.nbg.gov.ge

National Statistics Office of Georgia (GEOSTAT): http://geostat.ge

This report is based on information provided prior to and during a staff mission from October 4-17, 2011 and publicly available information. The mission team was headed by Ms. Wipada Soonthornsima and included Ms. Nataliya Ivanyk, Ms. Yutong Li, Messrs. Jose Carlos Moreno-Ramirez and Farid Talishli, (all STA), Ms. Betty Gruber and Mr. Kari Manninen (experts). 


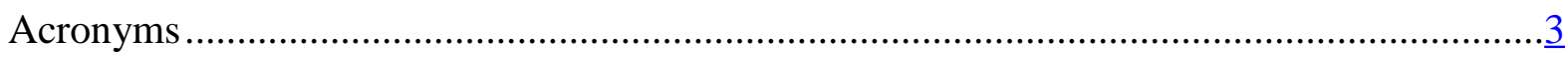

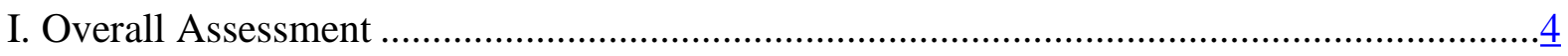

II. Assessment by Agency and Dataset ..........................................................................

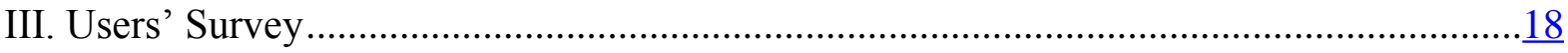

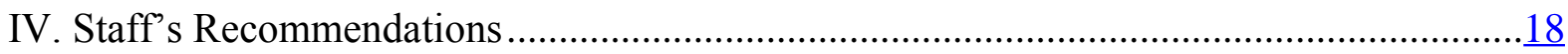

Tables

1. Data Quality Assessment Framework July 2003-Summary Results...............................

2a. Assessment of Data Quality-Dimensions 0 and 1-National Statistics Office of Georgia (GEOSTAT) ………….............................................................

2b. Assessment of Data Quality —Dimensions 0 and 1-Ministry of Finance .......................10

2c. Assessment of Data Quality—Dimensions 0 and 1-National Bank of Georgia ............11

3a. Assessment of Data Quality—Dimensions 2 to 5-National Accounts...........................12

3b. Assessment of Data Quality—Dimensions 2 to 5-Consumer Price Index ......................13

3c. Assessment of Data Quality-Dimensions 2 to 5-Producer Price Index .......................14

3d. Assessment of Data Quality—Dimensions 2 to 5-Government Finance Statistics .......15

3e. Assessment of Data Quality—Dimensions 2 to 5-Monetary Statistics...........................16

3f. Assessment of Data Quality—Dimensions 2 to 5-Balance of Payments Statistics .......17

Appendixes

I. Practices Compared to the SDDS Coverage, Periodicity, and Timeliness of Data...........21 


\section{ACRONYMS}

1993 SNA

BPM5

COFOG

COICOP

CPI

DQAF

DSBB

GDDS

GDP

GEOSTAT

GFS

GFSM 2001

GFSY

HBS

IFS

IMF

IPSAS

ITRS

LEPL

MFSM

$\mathrm{MOF}$

NBG

NPI

ODC

OFC

PPI

ROSC

SDDS

SNA

STA
System of National Accounts 1993

Balance of Payments Manual, fifth edition

Classification of Functions of Government

Classification of Individual Consumption by Purpose

Consumer Price Index

Data Quality Assessment Framework

Dissemination Standards Bulletin Board

General Data Dissemination System

Gross Domestic Product

National Statistics Office of Georgia

Government Finance Statistics

Government Finance Statistics Manual 2001

Government Finance Statistics Yearbook

Household Budget Survey

International Financial Statistics

International Monetary Fund

International Public Sector Accounting Standard

International Transactions Reporting System

Legal Entity of Public Law

Monetary and Financial Statistics Manual

Ministry of Finance

National Bank of Georgia

Nonprofit Institutions

Other Depository Corporation

Other Financial Corporation

Producer Price Index

Report on the Observance of Standards and Codes

Special Data Dissemination Standard

System of National Accounts

IMF Statistics Department 


\section{Overall AsSESSMent}

1. This Report on the Observance of Standards and Codes (ROSC) - Data Module is a reassessment of the exercise conducted in July 2002, using the IMF's Data Quality Assessment Framework (DQAF July 2003). It covers national accounts, consumer (CPI) and producer price indices (PPI), government finance, monetary, and balance of payments statistics. The Georgian agencies that compile and disseminate these datasets are: the National Statistics Office of Georgia (GEOSTAT) for national accounts and prices, the Ministry of Finance (MOF) for government finance statistics (GFS), and the National Bank of Georgia (NBG) for monetary and balance of payments statistics.

2. Following the 2002 ROSC mission, Georgia has continued to make impressive improvements in statistical compilation and dissemination in all areas of statistics covered by the Data ROSC. It participated in the General Data Dissemination System (GDDS) in 2006. The commendable progress achieved allowed Georgia to subscribe to the Special Data Dissemination Standard (SDDS) on May 17, 2010. Since its SDDS subscription, Georgia has been in observance of the SDDS, meeting the specifications for coverage, periodicity, timeliness, and the dissemination of advance release calendars. It uses flexibility options on periodicity and timeliness for the production index and employment and unemployment statistics. Appendix I provides an overview of Georgia's dissemination practices compared to the SDDS.

3. The ROSC - Data Module contains the following main observations. Georgia's macroeconomic statistics are generally of high quality and adequately meet users' needs. Since 2002, Georgia has made tangible improvements on the legal, institutional, methodological, and dissemination aspects of data quality. Nevertheless, areas for further improvements include increase staff resources of GEOSTAT, compilation system for GDP by expenditure approach in real terms, extension of the coverage to include the expenditure pattern of the whole population in the CPI weights, classification of board money, and enhancement of accuracy of c.i.f./f.o.b. prices on imports on a sound method. Since the 2002 ROSC, major improvements are the enactment of the Law of Georgia on Official Statistics in December 2009, followed by the establishment of an independent statistical office- the GEOSTAT - in 2010; the adoption in 2008 of the classifications of the Government Finance Statistics Manual 2001 (GFSM 2001) as the budget classification; a new compilation system for balance of payments statistics; the significant increase in the scope of macroeconomic statistics produced and disseminated by the three agencies to the public; and the explicit declared commitment by senior management to work toward international standards of data quality.

4. In applying the IMF's DQAF July 2003, the remainder of this section presents the mission's main conclusions. The presentation follows the DQAF's quality dimensions, by agency for the first two dimensions and across datasets for the remaining four.

5. Regarding prerequisites of quality, the responsibilities of the GEOSTAT, MOF, and NBG to compile and disseminate the corresponding statistics are clearly specified in the relevant laws governing them. However, the Law of Georgia on Official Statistics does not include mandatory reporting and sanctions (penalties) for nonreporting or misreporting, 
hence, some data producing agencies face significant challenges to improve source data, with the strongest impact on national accounts and price statistics. While management of each of the three agencies clearly demonstrates the commitment to improve data quality through collaboration, there is no arrangement for regular meetings of technical staff responsible for macroeconomic statistics. Such meetings provide a comprehensive arena for exchanging information on current and forthcoming projects for statistical development, promoting cross-sectoral data consistency crucial for macro-economic policy making, and coordinating work programs to avoid duplication of effort, ensure coherent application of methodology at all stages of data collection, and enhance effectiveness. Nevertheless, these agencies have several bilateral meetings and arrangements for collaboration on data issues e.g. MOF and NBG on GDP estimates, GEOSTAT and NBG on data sources for balance of payments statistics. However, there is no regular venue for the price users to discuss the issues related to the price statistics and their developments. All three data producing agencies seek to maintain a high level of transparency in the compilation and dissemination of their statistics. Especially, the management of the newly established GEOSTAT conducts intensive outreach activities with users to build trust and increase the credibility of statistics

6. Staff, computing, and financial resources are adequate to compile GFS, monetary and balance of payments statistics. However, staff resources of the GEOSTAT are not adequate for performing current programs. The remuneration of the GEOSTAT staff is not competitive compared to similar job positions in other data producing agencies in Georgia. This creates difficulties in attracting and retaining experienced staff. Hardware and software facilities of the GEOSTAT are not up to date for implementation of the medium-term program. All agencies, except the MOF, have systematic arrangements in place to obtain feedback from external users.

7. Regarding assurances of integrity, staff of the GEOSTAT, MOF, and NBG uphold high standards of professionalism, transparency, and ethical conduct in producing macroeconomic statistics. The basic principles governing the statistical compilation and dissemination practices include professional independence, objectivity, confidentiality of statistical data, and efficiency. Recruitment and promotion of staff are based on relevant skills and performances in accordance with the Law of Georgia on the Public Service (No. 1022 of October 31, 1997). Professionalism is promoted through well-established procedures including participation in training and seminars. Advance notice of major changes in methodology, source data, and statistical techniques is provided, except for monetary and balance of payments statistics. Arrangements with the NBG and GEOSTAT for internal government access to GFS prior to their data releases are not publicly identified by the MOF.

8. Regarding methodological soundness, the macroeconomic statistics are generally based on sound methods. All datasets broadly follow international statistical standards, namely the System of National Accounts, 1993 (1993 SNA), international manuals for the CPI and PPI, GFSM 2001, Monetary and Financial Statistics Manual (MFSM), and Balance of Payments Manual, fifth edition (BPM5). Methodological deviations exist in most datasets. Volume measures of GDP by the expenditure approach are not compiled. The scope of the consumer price index is limited to only urban areas while the treatment of owner-occupied housing is conceptually imprecise. The structure of PPI relies on turnover rather than output concept while product based PPIs are not compiled. For GFS, impressive progress has been 
achieved in the implementation of the GFSM 2001, as part of the ongoing reform of public sector accounting. The reform includes the implementation of accrual accounting by 2020 . However, there are deficiencies in sectorization of Legal Entities of Public Law (LEPLs) and securities are not recorded at market value in central government debt. For monetary statistics, classification and sectorization mainly follow international guidelines, except for: i) the definition of broad money; ii) classification of other financial corporations (OFCs) and nonprofit institutions (NPI) in other depository corporations (ODCs) survey; iii) classification of accrued interest together with the outstanding amounts of assets and liabilities for some financial instruments; and iv) recording financial derivatives in the balance sheet of the NBG and commercial banks.

9. The accuracy and reliability of the macroeconomic statistics for most datasets could benefit from further improvements. National accounts face serious source data deficiencies owing to: absence of an economic census; under-reporting in the business survey and household budget survey (HBS); shortcomings in the business register; and incomplete coverage of some activities (trade, other community, social and personal activities). Also, a better method could be used to benchmark quarterly national accounts data to annual estimates. The export and import price indices are not compiled. The accuracy of the CPI and PPI weights, with respect to actual household consumption and market turnover, suffers from the same HBS and business register shortcomings as the national accounts. The imputation methods for both CPI and PPI, while recently improved, need to be enhanced to ensure coherent long-term treatment of seasonal goods. Monetary and balance of payments statistics rely on adequate and timely source data. However, the source data for monetary statistics do not give a clear definition of residency for legal entities consistent with the recommendations of the MFSM. Some data sources for balance of payments need strengthening, notably the International Transactions Reporting System (ITRS) and the private nonfinancial external debt compilation program. For the balance of payments, statistical techniques are adequate, except for the calculation of the c.i.f./f.o.b. adjustment to imports. For national accounts and balance of payments, limited revision studies and analyses are carried out but not documented.

10. Serviceability of macroeconomic statistics is adequate, with all macroeconomic datasets exceeding timeliness requirements of the SDDS. All datasets meet the periodicity requirements of the SDDS. The CPI, PPI, and GFS receive excellent assessments in all elements of serviceability. All macroeconomic statistics fulfill adequately the consistency parameters within each dataset and over time. Although the serviceability of balance of payments statistics is generally sound, users are neither informed when data are revised nor provided with detailed explanations of the revisions. In addition, the revision cycle of the national accounts follows a regular schedule, determined on the basis of the availability of source data and the timing of revisions to related datasets; however, the public is not informed about the revision policy.

11. Regarding accessibility, most datasets meet the standard in terms of presentational format and dissemination media, provision of advance release calendars, and simultaneous release of data. While national accounts have comprehensive references to international guidelines on the GEOSTAT website, the information on data sources and methods for compilation of national accounts and price statistics, applied in Georgia, is limited. Brief 
metadata for CPI are disseminated, but for the PPI the GEOSTAT does not currently disseminate either analysis of recent index movements or any metadata apart from the SDDS metadata on the IMF website. Consistent long-term index series for the CPI and PPI are not disseminated monthly, although they are available in the quarterly publications. Most datasets provide contact information and compilers are responsive to queries as confirmed by the independent users' survey. However, the MOF do not provide contact details or material suitable to help raise awareness of the use of GFS for the general public. Data and metadata for monetary and balance of payments statistics, and the international investment position are available to the public on the NBG website.

12. Section II provides a summary assessment by agency and dataset based on a four-part scale. This is followed by users' survey in Section III and staff recommendations in Section IV. The authorities' response to this report and a volume of detailed assessments are presented in separate documents.

\section{Assessment B y AgenCy AND Dataset}

13. Assessments of the quality of six macroeconomic datasets - national accounts, CPI, PPI, government finance, monetary, and balance of payments statistics - were conducted using the DQAF July 2003. In this section, the results are presented at the level of the DQAF elements and using a four-point rating scale (Table 1). Assessments of the prerequisites of data quality and the assurances of integrity (Dimensions " 0 " and " 1 " of the DQAF) are presented in Tables $2 \mathrm{a}-\mathrm{c}$. For each dataset, the assessment of methodological soundness, accuracy and reliability, serviceability, and accessibility (Dimensions "2" to " 5 " of the DQAF) are shown in Tables 3a-f. 
Table 1. Data Quality Assessment Framework July 2003—Summary Results

Key to symbols: $\mathrm{O}=$ Practice Observed; $\mathrm{LO}=$ Practice Largely Observed; $\mathrm{LNO}=$ Practice Largely Not Observed;

$\mathrm{NO}=$ Practice Not Observed; NA $=$ Not Applicable

\begin{tabular}{|c|c|c|c|c|c|c|}
\hline $\begin{array}{lc} & \text { Datasets } \\
\text { Dimensions/Elements } & \\
\end{array}$ & $\begin{array}{l}\text { National } \\
\text { Accounts }\end{array}$ & $\begin{array}{c}\text { Consumer } \\
\text { Price Index }\end{array}$ & $\begin{array}{c}\text { Producer } \\
\text { Price Index }\end{array}$ & $\begin{array}{c}\text { Government } \\
\text { Finance } \\
\text { Statistics }\end{array}$ & $\begin{array}{c}\text { Monetary } \\
\text { Statistics }\end{array}$ & $\begin{array}{c}\text { Balance of } \\
\text { Payments } \\
\text { Statistics }\end{array}$ \\
\hline \multicolumn{7}{|l|}{ 0. Prerequisites of quality } \\
\hline 0.1 Legal and institutional environment & LO & $\mathrm{LO}$ & LO & $\mathrm{LO}$ & LO & $\mathrm{LO}$ \\
\hline 0.2 Resources & LNO & LNO & LNO & $\mathrm{O}$ & $\mathrm{O}$ & $\mathrm{O}$ \\
\hline 0.3 Relevance & $\mathrm{O}$ & LO & LO & LO & $\mathrm{O}$ & $\mathrm{O}$ \\
\hline 0.4 Other quality management & $\mathrm{O}$ & $\mathrm{O}$ & $\mathrm{O}$ & $\mathrm{O}$ & $\mathrm{O}$ & $\mathrm{O}$ \\
\hline \multicolumn{7}{|l|}{ 1. Assurances of integrity } \\
\hline 1.1 Professionalism & $\mathrm{O}$ & $\mathrm{O}$ & $\mathrm{O}$ & $\mathrm{O}$ & $\mathrm{O}$ & $\mathrm{O}$ \\
\hline 1.2 Transparency & $\mathrm{O}$ & $\mathrm{O}$ & $\mathrm{O}$ & LO & LO & LO \\
\hline 1.3 Ethical standards & $\mathrm{O}$ & $\mathrm{O}$ & $\mathrm{O}$ & $\mathrm{O}$ & $\mathrm{O}$ & $\mathrm{O}$ \\
\hline \multicolumn{7}{|l|}{ 2. Methodological soundness } \\
\hline 2.1 Concepts and definitions & $\mathrm{O}$ & $\mathrm{O}$ & LO & $\mathrm{O}$ & $\mathrm{O}$ & $\mathrm{O}$ \\
\hline 2.2 Scope & LO & LO & LO & $\mathrm{O}$ & $\mathrm{O}$ & $\mathrm{O}$ \\
\hline 2.3 Classification/sectorization & LO & $\mathrm{O}$ & $\mathrm{O}$ & LO & LO & $\mathrm{O}$ \\
\hline 2.4 Basis for recording & $\mathrm{LO}$ & $\mathrm{O}$ & $\mathrm{O}$ & LO & $\mathrm{O}$ & $\mathrm{O}$ \\
\hline \multicolumn{7}{|l|}{ 3. Accuracy and reliability } \\
\hline 3.1 Source data & LNO & LO & LO & $\mathrm{O}$ & $\mathrm{LO}$ & LO \\
\hline 3.2 Assessment of source data & $\mathrm{O}$ & $\mathrm{O}$ & $\mathrm{O}$ & $\mathrm{O}$ & $\mathrm{O}$ & $\mathrm{O}$ \\
\hline 3.3 Statistical techniques & LO & LO & LO & $\mathrm{O}$ & $\mathrm{O}$ & LO \\
\hline & \\
\hline data and statistical outputs & $\mathrm{O}$ & $\mathrm{O}$ & $\mathrm{O}$ & $\mathrm{O}$ & $\mathrm{O}$ & $\mathrm{O}$ \\
\hline 3.5 Revision studies & $\mathrm{LO}$ & $\mathrm{O}$ & $\mathrm{O}$ & $\mathrm{O}$ & $\mathrm{O}$ & LO \\
\hline \multicolumn{7}{|l|}{ 4. Serviceability } \\
\hline 4.1 Periodicity and timeliness & $\mathrm{O}$ & $\mathrm{O}$ & $\mathrm{O}$ & $\mathrm{O}$ & $\mathrm{O}$ & $\mathrm{O}$ \\
\hline 4.2 Consistency & $\mathrm{O}$ & $\mathrm{O}$ & $\mathrm{O}$ & $\mathrm{O}$ & $\mathrm{O}$ & $\mathrm{O}$ \\
\hline 4.3 Revision policy and practice & LO & $\mathrm{O}$ & $\mathrm{O}$ & $\mathrm{O}$ & $\mathrm{O}$ & LO \\
\hline \multicolumn{7}{|l|}{ 5. Accessibility } \\
\hline 5.1 Data accessibility & $\mathrm{O}$ & $\mathrm{O}$ & LO & $\mathrm{O}$ & $\mathrm{O}$ & $\mathrm{O}$ \\
\hline 5.2 Metadata accessibility & LO & LO & LNO & LO & $\mathrm{O}$ & $\mathrm{O}$ \\
\hline 5.3 Assistance to users & $\mathrm{O}$ & $\mathrm{O}$ & $\mathrm{O}$ & LO & $\mathrm{O}$ & $\mathrm{O}$ \\
\hline
\end{tabular}

Practice observed: Current practices generally meet or achieve the objectives of DQAF internationally accepted statistical practices without any significant deficiencies. Practice largely observed: Some departures, but these are not seen as sufficient to raise doubts about the authorities' ability to observe the DQAF practices. Practice largely not observed: Significant departures and the authorities will need to take significant action to achieve observance. Practice not observed: Most DQAF practices are not met. Not applicable: Used only exceptionally when statistical practices do not apply to a country's circumstances.

(CInternational Monetary Fund. Not for Redistribution 
Table 2a. Assessment of Data Quality—Dimensions 0 and 1—National Statistics Office of Georgia (GEOSTAT)

\section{Prerequisites of quality}

Legal and institutional environment. The GEOSTAT is a legal entity of public law established by the Law of Georgia on Official Statistics for producing official statistics and disseminating statistical information (Article. 1 of the Charter of the National Statistics Office of Georgia, approved by the Presidential Decree \#72 of February 1, 2010). With this legal provision, GEOSTAT is responsible for the compilation of national accounts and price statistics. According to the legislation, the administrative bodies shall be obliged to provide the GEOSTAT with the information, however, no sanctions (penalties) for nonreporting or misreporting are stipulated by the Law. Arrangements to promote consistency of methods and results are set up by the Board of the GEOSTAT. However, meetings among technical staff levels with other data producing agencies to promote coordination and ensure consistency of macroeconomic statistics are not conducted on a regular basis.

Resources. Staff resources are not sufficient for performing the current and upcoming tasks, in particular for national accounts, as well as for trade and price statistics. The GEOSTAT faces problems with staff turnover and uncompetitive remuneration. Hardware and software facilities are not quite up to date for implementation of the medium-term program.

Relevance. The management has an intensive outreach activity with users on building trust and increasing the credibility of the statistics. However, there is no procedure to consult all types of users on a regular basis (e.g. annually) to ensure that current statistics meet needs of CPI and PPI data users. The users'

feedback is encouraged via GEOSTAT website.

Other quality management. The GEOSTAT commitment to quality is stipulated by the Law and well publicized. Quality policy is based on the provisions of national and EU legislation, Strategy of National Statistics Offices, European Statistics Code of Practice, user needs and expectations. It defines overall intentions and directions of institution related to quality. The GEOSTAT regularly reviews and plans improvements to their internal processes.

\section{Assurances of integrity}

Professionalism. The basic principles governing the collection, processing, and dissemination of statistics in Georgia include professional independence, objectivity, reliability, confidentiality of statistical data, and efficiency.

GEOSTAT staff is free from political or other influences in choosing the most appropriate sources and methods. The Board of the GEOSTAT nominates the Executive Director who is appointed for a term of 4 years and may be dismissed by the President of Georgia.

Transparency. The terms and conditions governing the collection of statistics are published in the Law on Statistics and in the Charter of GEOSTAT, which are widely available to the public, including from the GEOSTAT website.

Products of the GEOSTAT are clearly identified as such by its name and logo. The national accounts tables disseminated in the NBG's publications identify the GEOSTAT as the source. There is no prior access by government officials to data before their release.

Ethical standards. Ethical standards set up in the UN Fundamental Principles of Official Statistics are at core in the GEOSTAT operations. New staff are made aware of the ethical standards when they join the GEOSTAT. 
Table 2b. Assessment of Data Quality-Dimensions 0 and 1-Ministry of Finance

\section{Prerequisites of quality}

Legal and institutional environment. The responsibility for compiling and disseminating GFS and budget execution data is clearly specified in laws and decrees. The task of compiling and disseminating GFS is assigned to the Fiscal Forecasting Department of the MOF.

Arrangements exist for the exchange of data with other data producing agencies, the NBG and GEOSTAT. However, meetings of the technical staff of the data producing agencies do not follow a regular schedule, such as one per year, which would address data requirements and understanding and ensure the consistency of macroeconomic statistics.

The Law of Georgia on Official Secrecy identifies data that are considered confidential. There are legal and administrative provisions for collecting the information necessary for the compilation of budget execution reports.

Resources. The human resources seem to be adequate for current operations. Physical, and computer resources allocated to compiling GFS and budget execution data are adequate. Knowledge of the GFSM 2001 is very good.

Relevance. Users indicated that the fiscal data were sufficiently relevant for their use. However, there are no systematic arrangements in place at the MOF to obtain feedback from external users.

Other quality management. The GFS are compiled from accounting data which are subject to budget law, accounting standards, and audit. The MOF monitors the quality of GFS. The ongoing accounting reform includes the full implementation of the GFSM 2001 methodology.

\section{Assurances of integrity}

Professionalism. MOF staff responsible for GFS compilation and dissemination have a strong culture of professionalism, transparency, and ethica conduct. Fiscal data are compiled under budget laws for the purposes of budget monitoring and fiscal policy analysis, and for reporting to international organizations in accordance with international standards. The procedures established under the laws and standards ensure the production of fiscal data on an impartial basis.

Transparency. The laws and regulations governing the compilation and dissemination of GFS and budget execution data are available to the public. Arrangements with the NBG and GEOSTAT for internal government access to GFS prior to release are not publicly identified.

Ethical standards. All state employees are governed by a code of conduct according to the Law of Georgia on Public Service, which includes penalties for violations. The Law was disseminated to all employees when promulgated. Employees are referred to the existence of the law when signing their employment contracts. The MOF has its own internal code of conduct (The Home Rule of Central Apparatus of the Ministry of Finance of Georgia) approved under the decree of the Minister of Finance of October 10, 2007. 


\section{Prerequisites of quality}

Legal and institutional environment. The Organic Law on the National Bank of Georgia $(N B G)$ in its Article 3, paragraph 3, mandates the compilation and dissemination of Georgia's monetary and balance of payments statistics. The legal provisions included in Article 20, paragraph 1 of the Organic Law on the $N B G$ protect the confidentiality of information. Article 45 requires both public and private sectors to provide statistical, financial, and other data, including confidential information that the NBG may request. The NBG is authorized to request statistical and accounting reports from the financial system (Article 33 of the $N B G$ Organic Law). Data sharing and coordination in compiling statistics between NBG departments are adequate. However, meetings among technical staff with other data producing agencies to promote coordination and ensure consistency of macroeconomic statistics are not conducted on a regular basis.

Resources. The number of staff assigned to compile monetary and balance of payments statistics is adequate. Staff responsible for monetary and balance of payments statistics have attended courses organized by other central banks and international organizations. Computing and financial resources are adequate to carry out statistical programs.

Relevance. The NBG conducts annual users surveys of monetary and balance of payment statistics to ensure that MFS and balance of payment statistics meet the needs of users.

Other quality management. The NBG recognizes the importance of quality of statistical data. Compilers of monetary and balance of payments statistics review data at the collection, processing, and dissemination stages. The work programs of NBG's statistical divisions are focused on high quality statistics by extensive use of international standards.

\section{Assurances of integrity}

Professionalism. According to the NBG Organic Law, Article 4, paragraph 1, the NBG is independent in its activity. NBG's independence is strengthened by a similar provision in the Constitution of the Republic of Georgia (Article 95 , paragraph 4). These provisions guarantee professional independence of the NBG, ensuring that monetary and balance of payments statistics are compiled following strict technical criteria without outside interference. Recruitment and promotions are based on relevant skills and expertise and are conducted on a competitive basis. Professionalism is further promoted through participation in seminars and workshops, training courses, and visits to other central banks. The NBG tracks media coverage of its data and comments publicly on misuse of its statistics.

Transparency. The NBG disseminates the terms and conditions for conducting statistical work in the NBG's website. No government officials outside the NBG have access to the data before their release to the public. Statistics that are included in NBG's publications but compiled by other agencies carry appropriate attribution. However, there is no advance notice on changes in the methodology, source data, or statistical techniques.

Ethical standards. NBG's Staff Manual identifies rules and standards of ethical conducts for NBG's staff. The Manual is available to all employees and establishes rights, responsibilities, and disciplinary actions for failure to meet standards prescribed by the Manual. 
Table 3a. Assessment of Data Quality-Dimensions 2 to 5-National Accounts

\begin{tabular}{|c|c|c|c|}
\hline 2. Methodological soundness & 3. Accuracy and reliability & 4. Serviceability & 5. Accessibility \\
\hline $\begin{array}{l}\text { Concepts and definitions. National accounts statistics } \\
\text { are compiled based on the } 1993 \text { SNA conceptual } \\
\text { framework. } \\
\text { Scope. GDP estimates by production and expenditure } \\
\text { are compiled and disseminated annually and quarterly } \\
\text { for the total economy. Volume measures of GDP are } \\
\text { available only by the production approach. GDP by } \\
\text { expenditure approach at constant prices is not compiled } \\
\text { due to the absence of the export/import price indexes } \\
\text { and problems in deflation of consumption. In addition, } \\
\text { annual input/output tables are compiled, and the } \\
\text { sequence of accounts up to the financial account for the } \\
\text { total economy. From 2007, the seasonally adjusted } \\
\text { time-series were introduced. } \\
\text { Classification/sectorization. National Accounts use } \\
\text { the Georgian national classification of economic } \\
\text { activities (GNC 001-2004) based on Statistical } \\
\text { Classification of Economic Activities in the European } \\
\text { Community (NACE rev 1.1). Classifications of } \\
\text { Individual Consumption by Purpose (COICOP) and } \\
\text { Classifications of the Functions of Governments } \\
\text { (COFOG) are used to classify household consumption } \\
\text { and the functions of government, respectively. There } \\
\text { are deficiencies in recording transactions of Legal } \\
\text { Entities of Public Law (LPEL.) } \\
\text { Basis for recording. Market output and output for own } \\
\text { final use are valued at basic prices and at equivalent } \\
\text { market prices, respectively. Intermediate consumption } \\
\text { and final uses are valued at purchasers' prices, } \\
\text { including levied sales/excise taxes and value added } \\
\text { taxes, with the deductible part excluded. Total exports } \\
\text { and imports are valued at free on board (f.o.b) prices. } \\
\text { General government data on a cash basis are not } \\
\text { adjusted to an accrual basis. Transactions between } \\
\text { establishments within the same enterprise are not } \\
\text { recorded on a gross basis. }\end{array}$ & $\begin{array}{l}\text { Source data. Data sources have been noticeably improved over } \\
\text { recent years, but continue to be generally inadequate. No } \\
\text { economic census has been conducted in observable past; business } \\
\text { survey and HBS are affected by underreporting, maintenance of } \\
\text { business register needs improvement. Coverage of the some } \\
\text { activities is considered incomplete (trade, other community, } \\
\text { social and personal activities). Data for the government sector } \\
\text { and the balance of payments are obtained from MOF and NBG, } \\
\text { respectively. However, consolidated budget data by are not } \\
\text { considered detailed enough to properly estimate intermediate } \\
\text { consumption. Various ad hoc sample surveys are conducted to } \\
\text { support main data collection. Source data are available on a } \\
\text { timely basis except the NBG data for insurance companies. } \\
\text { Assessment of source data. Appropriate measures are taken to } \\
\text { validate source data. } \\
\text { Statistical techniques. Surveys conducted by GEOSTAT } \\
\text { employ sound statistical techniques. The GEOSTAT makes } \\
\text { significant efforts to ensure the exhaustiveness of the GDP } \\
\text { estimates. NOE activities are separately identified in the } \\
\text { accounts. There are deficiencies in volume measures of trade and } \\
\text { taxes; coefficients for measuring work in progress in agriculture } \\
\text { need to be updated. Denton technique is not applied for } \\
\text { benchmarking quarterly accounts to annual estimates. } \\
\text { Assessment and validation of intermediate data and } \\
\text { statistical outputs. Intermediate data are validated using time- } \\
\text { series analysis combined with the cross checking with } \\
\text { independent data sources such as employment statistics and tax } \\
\text { data from Revenue Service. } \\
\text { Revision studies. GEOSTAT analyses direction and magnitude } \\
\text { of revisions between preliminary and final data, but there is no } \\
\text { documentation of the sources of errors, omissions, and } \\
\text { fluctuations in the data. }\end{array}$ & $\begin{array}{l}\text { Periodicity and timeliness. } \\
\text { GEOSTAT publishes the } \\
\text { quarterly GDP estimates on } \\
\text { the 80th day after the end of } \\
\text { the quarter. } \\
\text { Consistency. Consistent } \\
\text { quarterly and annual time } \\
\text { series are maintained } \\
\text { from 2003. Discrepancies } \\
\text { between the independent } \\
\text { estimates of GDP by } \\
\text { production and expenditure } \\
\text { are kept at reasonably low } \\
\text { levels. The national accounts } \\
\text { statistics are reconcilable } \\
\text { with those from balance of } \\
\text { payments and GFS. } \\
\text { Revision policy and } \\
\text { practice. The revision cycle } \\
\text { of the national accounts } \\
\text { follows a regular schedule, } \\
\text { determined on the basis of } \\
\text { the availability of source } \\
\text { data and the timing of } \\
\text { revisions to related datasets, } \\
\text { however public is not well } \\
\text { informed about the revision } \\
\text { policy. }\end{array}$ & $\begin{array}{l}\text { Data accessibility. In recent } \\
\text { years there have been a lot of } \\
\text { improvements in data } \\
\text { dissemination in terms of } \\
\text { scope and format of presented } \\
\text { data. Data are initially } \\
\text { disseminated via a press } \\
\text { release and subsequently } \\
\text { posted on the website in Excel } \\
\text { format. Quarterly GDP data } \\
\text { are available since } 2003 \text {. Main } \\
\text { aggregates include GDP, Net } \\
\text { Domestic Product, Gross } \\
\text { National Income, Net } \\
\text { National Income, Gross } \\
\text { Disposable Income, and } \\
\text { Consumption of fixed Capital, } \\
\text { Net Saving, and Net } \\
\text { Lending/Net Borrowing. The } \\
\text { deflators of GDP are } \\
\text { published, including the } \\
\text { chain-linked time series. } \\
\text { Metadata accessibility. } \\
\text { Limited documentation is } \\
\text { available on sources and } \\
\text { methods for compiling the } \\
\text { national accounts statistics. } \\
\text { Assistance to users. A } \\
\text { catalog of publications is } \\
\text { available on the website and } \\
\text { updated annually. Contact } \\
\text { information is provided in } \\
\text { publications. }\end{array}$ \\
\hline
\end{tabular}


Table 3b. Assessment of Data Quality-Dimensions 2 to 5-Consumer Price Index

\begin{tabular}{|c|c|c|c|}
\hline 2. Methodological soundness & 3. Accuracy and reliability & 4. Serviceability & 5. Accessibility \\
\hline $\begin{array}{l}\text { Concepts and definitions. Generally, the } \\
\text { compilation of the CPI applies the concepts } \\
\text { and definitions that follow international } \\
\text { standards given in the } 1993 \text { SNA and the } \\
\text { international CPI manual. } \\
\text { Scope. The CPI scope covers only urban } \\
\text { resident households and their total monetary } \\
\text { consumption expenditure. The treatment of } \\
\text { owner-occupied housing is currently } \\
\text { conceptually imprecise, being included in } \\
\text { the price survey but excluded from the } \\
\text { weights. } \\
\text { Classification/sectorization. The CPI is } \\
\text { based on the Classification of Individual } \\
\text { Consumption by Purpose (COICOP). The } \\
\text { market basket for the index consists of } 266 \\
\text { goods and services classified into the twelve } \\
\text { major groups of COICOP. } \\
\text { Basis for recording. The prices collected } \\
\text { correspond to market prices paid by } \\
\text { households by direct payment (excluding } \\
\text { credit charges and including all taxes levied } \\
\text { on the products). }\end{array}$ & $\begin{array}{l}\text { Source data. The HBS and regional price survey } \\
\text { provide a sound basis for the CPI but relying solely } \\
\text { on these sources may not be the most effective and } \\
\text { accurate way of covering certain expenditure } \\
\text { classes, for both the weights structure and price } \\
\text { changes. The HBS suffers from nonsampling errors } \\
\text { that are not accounted for and the inclusion of } \\
\text { owner-occupied housing is ambiguous. } \\
\text { Assessment of source data. Accuracy of the CPI } \\
\text { source data is routinely assessed, both with respect } \\
\text { to the HBS and the Price Survey. The prices data } \\
\text { are validated by field supervisors independently of } \\
\text { the original collection if there is any suspicion that } \\
\text { there may be reporting problems in a particular } \\
\text { region for a certain product or outlet. } \\
\text { Statistical techniques. The CPI compilation } \\
\text { techniques have been recently improved by } \\
\text { enhancing the previous imputation method for } \\
\text { seasonal products. However, few issues still remain } \\
\text { in order to implement international best practices } \\
\text { regarding the imputation of missing prices and } \\
\text { adjusting for quality changes. } \\
\text { Assessment and validation of intermediate data } \\
\text { and statistical outputs. Explanations for large } \\
\text { changes at detailed and aggregate level are } \\
\text { followed up to identify the underlying reasons for } \\
\text { change. } \\
\text { Revision studies. The CPI is final when first } \\
\text { released. }\end{array}$ & $\begin{array}{l}\text { Periodicity and timeliness. The } \\
\text { CPI is published on a monthly } \\
\text { basis five days after the } \\
\text { reference month, meeting the } \\
\text { SDDS requirements. } \\
\text { Consistency. Time series at the } \\
\text { aggregate and group level are } \\
\text { compiled from individual 12- } \\
\text { month annual CPI series. The } \\
\text { CPI is internally consistent and } \\
\text { longer time-series are derived by } \\
\text { chain-linking annual index series } \\
\text { together. } \\
\text { Revision policy and practice. } \\
\text { The CPI is final upon its first } \\
\text { release. The market basket items } \\
\text { are updated annually. }\end{array}$ & $\begin{array}{l}\text { Data accessibility. Data are } \\
\text { disseminated monthly on the } \\
\text { GEOSTAT website with various } \\
\text { formats. Simple long index time series } \\
\text { is missing and may be difficult for } \\
\text { some users to derive from the existing } \\
\text { series. The GEOSTAT website } \\
\text { launched recently is relatively } \\
\text { informative and user friendly and has } \\
\text { improved the data dissemination } \\
\text { significantly. } \\
\text { Metadata accessibility. The main } \\
\text { available metadata is the SDDS } \\
\text { metadata on dsbb.imf.org. The } \\
\text { GEOSTAT website includes only a } \\
\text { brief description of the CPI practice. } \\
\text { Assistance to users. The GEOSTAT } \\
\text { website includes central telephone } \\
\text { number and email address for users to } \\
\text { contact. }\end{array}$ \\
\hline
\end{tabular}


Table 3c. Assessment of Data Quality-Dimensions 2 to 5-Producer Price Index

\begin{tabular}{|c|c|c|c|}
\hline 2. Methodological soundness & 3. Accuracy and reliability & 4. Serviceability & 5. Accessibility \\
\hline $\begin{array}{l}\text { Concepts and definitions. Generally, the } \\
\text { compilation of the PPI applies the } \\
\text { concepts and definitions that follow } \\
\text { international standards given in the } 1993 \\
S N A \text { and the PPI manual. However, } \\
\text { industry turnover is used instead of } \\
\text { production value. Only primary activity } \\
\text { products included. } \\
\text { Scope. The core PPI activities cover } \\
\text { Mining and quarrying; Manufacturing } \\
\text { (except production of nuclear fuel and } \\
\text { manufacture of aircraft); Electricity, gas } \\
\text { and water supply. The PPI has also been } \\
\text { extended to Construction and Freight } \\
\text { transport industries. However, product } \\
\text { PPIs are not produced. } \\
\text { Classification/sectorization. The PPI } \\
\text { follows the European NACE activity } \\
\text { classification and accordingly the CPA } \\
\text { product classification, even though } \\
\text { product indices are not compiled. } \\
\text { Basis for recording. The prices } \\
\text { correspond to prices at the factory gate, } \\
\text { including excise and similar tolls; VAT } \\
\text { and transport expenses are excluded. }\end{array}$ & $\begin{array}{l}\text { Source data. The PPI relies on Business } \\
\text { Register and a monthly regional price } \\
\text { survey. Generally they provide an adequate } \\
\text { basis for the compilation of the PPI, but the } \\
\text { completeness of the Business Register } \\
\text { behind the sample may not, especially for } \\
\text { some industries, provide an up-to-date } \\
\text { source. The reliance of a standard paper } \\
\text { questionnaire for all industries makes it } \\
\text { possibly difficult to capture different and } \\
\text { changing pricing policies across industries. } \\
\text { Assessment of source data. The source } \\
\text { data validation is generally adequate; } \\
\text { follow-up checks are undertaken, the prices } \\
\text { inspected by Head Office prices staff } \\
\text { independently of the original collection. } \\
\text { Large price changes are confirmed with the } \\
\text { respondents and effort made to maintain } \\
\text { the product specifications unchanged. } \\
\text { Statistical techniques. Statistical } \\
\text { techniques are mostly adequate but certain } \\
\text { practices fall behind the international } \\
\text { standards. The data collection method } \\
\text { relies solely on the simple questionnaire } \\
\text { and methods to treat quality changes and } \\
\text { missing prices need updating. } \\
\text { Assessment and validation of } \\
\text { intermediate data and statistical outputs. } \\
\text { Explanations for large changes at detailed } \\
\text { and aggregate level are followed up to } \\
\text { identify the underlying reasons for change. } \\
\text { Revision studies. The PPI is final when } \\
\text { first released. }\end{array}$ & $\begin{array}{l}\text { Periodicity and timeliness. The PPI } \\
\text { is published on a monthly basis } 15 \text { days } \\
\text { after the reference month, meeting the } \\
\text { SDDS requirements. } \\
\text { Consistency. Time series at the } \\
\text { aggregate and } 16 \text { sub-group levels are } \\
\text { compiled from individual } 12 \text {-month } \\
\text { annual PPI series. The PPI is internally } \\
\text { consistent and longer time-series are } \\
\text { derived by chain linking annual index } \\
\text { series together. } \\
\text { Revision policy and practice. The PPI } \\
\text { is final upon its first release. The market } \\
\text { basket items are updated annually. }\end{array}$ & $\begin{array}{l}\text { Data accessibility. The GEOSTAT } \\
\text { website is relatively informative and } \\
\text { user friendly but any analysis of the } \\
\text { recent PPI movements is missing. } \\
\text { Data are disseminated monthly on the } \\
\text { GEOSTAT website but consistent } \\
\text { long index time series are difficult to } \\
\text { locate since they are not disseminated } \\
\text { together with the monthly data. } \\
\text { Metadata accessibility. There are no } \\
\text { PPI metadata available apart from the } \\
\text { SDDS metadata on dsbb.imf.org. } \\
\text { Assistance to users. The GEOSTAT } \\
\text { website includes central telephone } \\
\text { number and email address for users to } \\
\text { contact. }\end{array}$ \\
\hline
\end{tabular}




\section{Table 3d. Assessment of Data Quality_Dimensions 2 to 5-Government Finance Statistics}

\begin{tabular}{|c|c|c|c|}
\hline 2. Methodological soundness & 3. Accuracy and reliability & 4. Serviceability & 5. Accessibility \\
\hline $\begin{array}{l}\text { Concepts and definitions. GFS are } \\
\text { compiled broadly in accordance with the } \\
\text { guidelines of the GFSM } 2001 \text {. } \\
\text { Scope. The fiscal statistics cover } \\
\text { budgetary central government, local } \\
\text { governments, and the consolidated } \\
\text { general government. } \\
\text { Classification/sectorization. The budget } \\
\text { classification follows the GFSM } 2001 \\
\text { economic and functional classifications. } \\
\text { The classification by institutional sector } \\
\text { of the entities set up by government as } \\
\text { LEPL needs to be reviewed and updated. } \\
\text { Basis for recording. The cash basis is } \\
\text { used for recording transactions. Accrual } \\
\text { accounting is planned by } 2020 \text { as part of } \\
\text { the ongoing accounting reform. Central } \\
\text { government debt, including securities, is } \\
\text { recorded at nominal value. }\end{array}$ & $\begin{array}{l}\text { Source data. Comprehensive and timely } \\
\text { source data are provided from } \\
\text { administrative systems for central and local } \\
\text { governments operations and central } \\
\text { government debt. } \\
\text { Assessment of source data. The budget } \\
\text { classification is the economic classification } \\
\text { of the GFSM } 2001 \text {. It also includes } \\
\text { COFOG. Central government debt source } \\
\text { data meet the requirements of the } \\
\text { GFSM } 2001 \text {. } \\
\text { Statistical techniques. Data are compiled } \\
\text { from administrative records. Preliminary } \\
\text { data are replaced by final audited data. } \\
\text { Assessment and validation of } \\
\text { intermediate data and statistical outputs. } \\
\text { Validation is done against the original } \\
\text { source data. } \\
\text { Revision studies. Discrepancies between } \\
\text { GFS and original source data, which rarely } \\
\text { occur, are assessed and investigated. After } \\
\text { compilation, GFS data are compared with } \\
\text { the previous period to identify unusual } \\
\text { trends, for which explanations are then } \\
\text { obtained and documented internally. }\end{array}$ & $\begin{array}{l}\text { Periodicity and timeliness. The } \\
\text { periodicity and timeliness of fiscal } \\
\text { statistics exceed SDDS } \\
\text { requirements. } \\
\text { Consistency. Data are internally } \\
\text { consistent within a dataset. Fiscal } \\
\text { statistics are broadly consistent or } \\
\text { reconcilable with other } \\
\text { macroeconomic datasets. } \\
\text { Revision policy and practice. The } \\
\text { dissemination of preliminary and } \\
\text { final data follows a regular schedule. } \\
\text { Final data are identified in a } \\
\text { footnote. }\end{array}$ & $\begin{array}{l}\text { Data accessibility. GFS are } \\
\text { presented monthly, quarterly, and } \\
\text { annually and central government } \\
\text { debt quarterly. Data tables and the } \\
\text { advance release calendar are } \\
\text { available on the MOF's website. } \\
\text { More detailed data are available } \\
\text { on request. } \\
\text { Metadata accessibility. The } \\
\text { methodology is included in the } \\
\text { budget laws which are available } \\
\text { on the MOF's website. The GFS } \\
\text { metadata are available on the } \\
\text { IMF's Dissemination Standards } \\
\text { Bulletin Boards (DSBB) website. } \\
\text { Assistance to users. The MOF } \\
\text { provides prompt and } \\
\text { knowledgeable service and } \\
\text { support to users. However, no } \\
\text { contact person is publicized and } \\
\text { no material is available to raise } \\
\text { awareness on the use of GFS. }\end{array}$ \\
\hline
\end{tabular}


Table 3e. Assessment of Data Quality-Dimensions 2 to 5-Monetary Statistics

\begin{tabular}{|c|c|c|c|}
\hline 2. Methodological soundness & 3. Accuracy and reliability & 4. Serviceability & 5. Accessibility \\
\hline $\begin{array}{l}\text { Concepts and definitions for } \\
\text { compiling monetary statistics are } \\
\text { consistent with MFSM. } \\
\text { Scope of the depository corporations } \\
\text { survey (DCS) comprises commercial } \\
\text { banks only. However, data on credit } \\
\text { unions which account for a small } \\
\text { portion of total depository } \\
\text { corporations' assets are not included } \\
\text { in the coverage of the DCS (their } \\
\text { share is less than } 1 \% \text { of the total } \\
\text { assets of the financial system). } \\
\text { Classification/sectorization. } \\
\text { Classification is broadly consistent } \\
\text { with the MFSM except: i) some } \\
\text { deposits (Debit cards, check book, } \\
\text { credit guarantee) are not classified as } \\
\text { Deposits Included in Broad Money; } \\
\text { ii) accrued interest is not classified } \\
\text { together with the outstanding amount } \\
\text { of assets or liabilities for all financial } \\
\text { instruments; iii) OFCs and NPIs are } \\
\text { classified together with ONFC in } \\
\text { ODCS; and iv) financial derivatives } \\
\text { are recorded off- balance sheet. } \\
\text { Basis for recording of accounting } \\
\text { rules are broadly consistent with the } \\
\text { IFRS. Asset and liability items, } \\
\text { which are denominated in foreign } \\
\text { currency, are converted into Georgian } \\
\text { Lari (GEL) at the official exchange } \\
\text { rate. }\end{array}$ & $\begin{array}{l}\text { Source data. Data included in the Central } \\
\text { Bank Survey are based on balance sheet of the } \\
\text { NBG compiled by the Finance and } \\
\text { Accounting Department. Balance sheets and } \\
\text { supplemental report forms provided by } \\
\text { commercial banks form the basis for } \\
\text { compilation ODCS. Data are available on a } \\
\text { timely basis and with sufficient detail for } \\
\text { compiling monetary accounts. However, the } \\
\text { definition of residency in the source data for } \\
\text { monetary statistics is based on the Tax Code } \\
\text { and is not consistent with recommendations of } \\
\text { the } M F S M \text {. } \\
\text { Assessment of source data. Automated and } \\
\text { manual assessments, validations of source } \\
\text { data and statistical outputs, are performed. } \\
\text { Statistical techniques. MFS are based on the } \\
\text { balance sheets of the NBG and ODCs. } \\
\text { Assessment and validation of intermediate } \\
\text { data and statistical outputs. The NBG } \\
\text { balance sheet data are cross-checked between } \\
\text { Monetary Statistics Division and Finance and } \\
\text { Accounting Department of the NBG. In } \\
\text { addition, automated and manual assessment of } \\
\text { intermediate data is performed. Procedures are } \\
\text { in place to investigate discrepancies in the } \\
\text { intermediate data, classification, and } \\
\text { sectorization errors. Data issues are } \\
\text { investigated. } \\
\text { Revision studies. As a policy monetary } \\
\text { statistics are final upon release. }\end{array}$ & $\begin{array}{l}\text { Periodicity and timeliness. Data for } \\
\text { the analytical accounts of the central } \\
\text { bank and the analytical accounts of } \\
\text { banking sector (DCS) are compiled on } \\
\text { a monthly basis and meet the SDDS } \\
\text { requirements for periodicity and } \\
\text { timeliness. } \\
\text { Consistency. Monetary data are } \\
\text { disseminated in consistent historical } \\
\text { series. Data on the NBG and ODCs } \\
\text { are internally consistent. The } \\
\text { monetary statistics are reconciled with } \\
\text { balance of payments statistics and } \\
\text { with GFS. Methodological notes } \\
\text { explaining differences are posted on } \\
\text { the NBG's website. } \\
\text { Revision policy and practice. The } \\
\text { NBG has established a revisions } \\
\text { policy and practice for monetary } \\
\text { statistics. Any revision in the data } \\
\text { series and the methodology are } \\
\text { explained in footnotes and NBG's } \\
\text { statements. }\end{array}$ & $\begin{array}{l}\text { Data accessibility. All NBG's } \\
\text { publications are posted on the } \\
\text { NBG website. Monetary } \\
\text { statistics are disseminated } \\
\text { through the NBG's monthly } \\
\text { Bulletin of Monetary and } \\
\text { Banking Statistics (available } \\
\text { from the Research and } \\
\text { Publications page on the NBG's } \\
\text { website). Monetary statistics are } \\
\text { presented in clearly structured } \\
\text { tables. Monetary statistics are } \\
\text { released simultaneously to all } \\
\text { users in accordance with the } \\
\text { advance release calendar. } \\
\text { Metadata accessibility. } \\
\text { Comprehensive methodological } \\
\text { notes are published in the NBG's } \\
\text { Bulletin of Monetary and } \\
\text { Banking Statistics. Georgia has } \\
\text { posted its metadata on the IMF's } \\
\text { Dissemination Standards } \\
\text { Bulletin Boards (DSBB). } \\
\text { Assistance to users. A contact } \\
\text { person is identified to address } \\
\text { users' queries. }\end{array}$ \\
\hline
\end{tabular}

CInternational Monetary Fund. Not for Redistribution 
Table 3f. Assessment of Data Quality-Dimensions 2 to 5-Balance of Payments Statistics

\begin{tabular}{|c|c|c|c|}
\hline 2. Methodological soundness & 3. Accuracy and reliability & 4. Serviceability & 5. Accessibility \\
\hline $\begin{array}{l}\text { Concepts and definitions } \\
\text { Data are compiled broadly in } \\
\text { accordance with the definitions set } \\
\text { out in the fifth edition of the } \\
\text { Balance of Payments Manual } \\
\text { (BPM5) and elements of BPM6. } \\
\text { Scope } \\
\text { The balance of payments statistics } \\
\text { include the transactions of } \\
\text { institutional units resident in } \\
\text { Georgia with the rest of the world. } \\
\text { Data do not cover territories of } \\
\text { Abkhazian Autonomous Republic } \\
\text { and Tskhinvali Region, a part of } \\
\text { Georgian territory not controlled by } \\
\text { the central authorities. } \\
\text { Classification/sectorization } \\
\text { The classification and sectorization } \\
\text { of the balance of payments data } \\
\text { closely follows BPM5. } \\
\text { Basis for recording } \\
\text { FDI and portfolio investment are } \\
\text { valued at market prices. Book value } \\
\text { is used when market value is not } \\
\text { available. Other investment } \\
\text { transactions are valued at nominal } \\
\text { value. Recording is on accrual } \\
\text { basis. }\end{array}$ & $\begin{array}{l}\text { Source data } \\
\text { Source data used for compiling the balance of } \\
\text { payments are generally adequate and timely. } \\
\text { However, some data sources need strengthening, } \\
\text { notably the ITRS and the private nonfinancial } \\
\text { external debt compilation program. } \\
\text { Assessment of source data } \\
\text { Source data-including censuses, sample } \\
\text { surveys, and administrative records-are } \\
\text { routinely assessed, for coverage, sample error, } \\
\text { response error, and nonsampling error. } \\
\text { Statistical techniques } \\
\text { Several measures are established to control } \\
\text { quality and conduct appropriate and timely } \\
\text { verification of the survey information. } \\
\text { Coefficients for adjusting c.i.f. to f.o.b. valuation } \\
\text { on imports are not based on a sound method, } \\
\text { such as a survey among major importers to } \\
\text { estimate transportation and insurance costs. } \\
\text { Assessment and validation of intermediate } \\
\text { data and statistical outputs } \\
\text { Statistical discrepancies in the intermediate data } \\
\text { are assessed and investigated. FDI transactions } \\
\text { are followed through the financial press. Series } \\
\text { are cross-checked with related series/indicators. } \\
\text { Revision studies } \\
\text { Revision studies and analyses are carried out but } \\
\text { not documented. }\end{array}$ & $\begin{array}{l}\text { Periodicity and timeliness } \\
\text { The periodicity and timeliness of } \\
\text { balance of payments meet SDDS } \\
\text { requirements. } \\
\text { Consistency } \\
\text { The statistics are consistent within } \\
\text { the dataset. The NBG continuously } \\
\text { revises methodology, procedures, } \\
\text { and output in order to ensure the } \\
\text { internal consistency of the statistics. } \\
\text { The balance of payments statistics } \\
\text { are reconcilable with monetary and } \\
\text { fiscal statistics and with data on the } \\
\text { external debt. } \\
\text { Revision policy and practice } \\
\text { There is a formal revisions policy. } \\
\text { Revisions follow a regular and } \\
\text { transparent schedule. Preliminary } \\
\text { data are identified in footnotes. } \\
\text { However, users are not always } \\
\text { informed whenever data are revised. }\end{array}$ & $\begin{array}{l}\text { Data accessibility } \\
\text { Quarterly balance of payments } \\
\text { statistics are disseminated on the } \\
\text { NBG website. The annual } \\
\text { balance of payments publication } \\
\text { includes charts, graphics, and } \\
\text { explanatory notes, related to IIP, } \\
\text { balance of payments, and } \\
\text { external debt, and contains } \\
\text { commentaries on current period } \\
\text { developments. } \\
\text { The balance of payments } \\
\text { advance release calendar is } \\
\text { accessible on the NBG website. } \\
\text { Metadata accessibility } \\
\text { Notes on data sources and } \\
\text { compilation methods are } \\
\text { available on the website of NBG } \\
\text { and the Annual Report on the } \\
\text { Balance of Payments of Georgia. } \\
\text { Assistance to users } \\
\text { Statistics users have available a } \\
\text { contact number on the NBG } \\
\text { website. New publications are } \\
\text { announced via press releases on } \\
\text { the NBG website. }\end{array}$ \\
\hline
\end{tabular}

CInternational Monetary Fund. Not for Redistribution 


\section{USERS' SURVEY}

14. To complement the assessment of the macroeconomic datasets conducted using the DQAF framework, the ROSC mission elicited the views of selected users of the statistics. With the assistance of the Georgian authorities, the mission conducted a users' survey (over 70 survey questionnaires were sent and 23 responses were received) and held discussions with key users. In general, users acknowledged and complimented the significant progress statistical agencies have made over recent years. A majority of the users were satisfied with data coverage, periodicity, timeliness, accessibility, serviceability, and to a great extent dissemination practices (with the exception of revision practice). While recognizing the authorities' limited resources, users wanted further improvements on coverage of data; user friendliness in terms of metadata especially using presentations easy to understand by nonspecialists; more detailed explanations for revisions to the data; and easier access to longer time series. They indicated satisfaction with the responsiveness of the statistical agencies to users' queries. Particularly in areas of prices statistics and national accounts, users expressed a need for improvement in level of detail, soundness of methodology, and availability of data. Finally, about 60 percent of the respondents considered Georgia's official statistics to be of the same or better quality than those from other countries in the region.

\section{STAFF's RECOMMENDATIONS ${ }^{1}$}

15. Based on the review of Georgia's statistical practices, discussions with the data producing agencies, and responses from data users (see Appendix III of the Detailed Assessments volume), the mission has developed a set of recommendations. They are designed to increase further Georgia's adherence to internationally accepted statistical practices and would, in the mission's view, enhance the analytical usefulness of Georgia's statistics. Some additional technical suggestions are included in the Detailed Assessments Volume III.

\section{Cross-cutting}

- Enact appropriate amendments to the Law of Georgia on Official Statistics to reinforce mandatory reporting of statistical data and ensure application of sanctions for nonreporting.

- Conduct pre-established, regular meetings, such as one per year, to improve communication among technical data compilers of macroeconomic statics at the NBG, GEOSTAT, and MOF. Such meetings provide a comprehensive arena, discussing issues of common interest, exchanging information on current and forthcoming projects for statistical development to avoid duplication of efforts, and ensure the consistency of macroeconomic statistics crucial for macroeconomic policy making (national accounts, monetary, fiscal, and external sector.)

\footnotetext{
${ }^{1}$ High priority recommendations are identified in bold.
} 
- Augment staff and IT resources in the GEOSTAT. Ensure proper training for the staff and implement measures to retain experienced staff.

National accounts

- Set up the compilation system for GDP by expenditure approach in real terms.

- Conduct an economic census of nonfinancial corporations and update the register.

- Develop and disseminate detailed documentation on data sources and methods for compilation of national accounts in Georgia.

- Set up the compilation of export/import price indices.

- $\quad$ Conduct revision studies and enhance communication with users about revisions.

Consumer price index

- Improve the imputation method of seasonal products to ensure long-term coherence between the index and price data over index weight revisions.

- Improve the CPI weight estimates to better represent actual household expenditure of the entire country and inform the users of these improvements. This action would in fact extend to coverage beyond the five cities of the entire country.

- Implement a consistent treatment of owner-occupied housing in the CPI.

- $\quad$ Pay additional attention to the collection of prices for complex goods and services to better account for quality changes and seek for alternative sources to reflect consumer behavior.

- $\quad$ Establish a users' advisory group for price statistics that meets on a regular basis and include all types of users to discuss existing data programs, plans for improvement, and to obtain user feedback on current and planned data programs.

Producer price index

- Update the related methods of imputing missing prices, treating quality changes, and introducing new products into the PPI. Implement appropriate imputation methods into the new PPI software being developed.

- Document and disseminate PPI metadata for both advanced and general users, and include analysis to accompany the PPI data release.

- $\quad$ Ensure that properly timed total turnover, or preferably the total output, covering the whole economy in scope is used for the PPI weights. 
- Allow the data collection to differentiate between certain complex industries where physical and transaction specifications of the sample products change in time. A central price collection dedicated to deal with these would likely improve the quality of the price data in times of sample changes.

- $\quad$ Establish a users' advisory group for price statistics that meets on a regular basis and include all types of users to discuss existing data programs, plans for improvement, and to obtain user feedback on current and planned data programs.

\section{Government finance statistics}

- $\quad$ Review and update the sectorization of Legal Entities of Public Law.

- Value securities at current market prices.

- Introduce a structured and periodic process of consultation with users.

\section{Monetary statistics}

- To improve classification, include into the definition of broad money debit card deposits, check book deposits, credit guarantee deposits, deposits for letters of credit, and deposits for other payment documents. Classify accrued interest together with the outstanding amount of assets or liabilities for loans to nonresidents, deposits and loans to central and local government, deposits and loans to OFCs and NPIs. Separate positions on financial instruments with OFC's and NPI's from positions with the ONFC.

- To improve accuracy of source data, provide a clear statistical definition of residency in the report forms for financial institutions to ensure that all institutional units are sectorized as residents and nonresidents consistent with the MFSM.

- $\quad$ Record transactions with financial derivatives on balance sheets of the NBG and ODCs consistent with the MFSM and the MFSCG.

Balance of payments statistics

- Conduct training activities with data reporters, to improve the quality of the ITRS. The private nonfinancial external debt compilation program needs strengthening.

- $\quad$ Base the calculation of the adjustment for c.i.f./f.o.b. prices on imports on a sound method, such as a survey among major importers to estimate transportation and insurance costs.

- $\quad$ For transactions that fall below the reporting threshold, conduct a sample survey of banks and nonbanking institutions with accounts abroad to obtain information to classify the low-value transactions across the balance of payments components.

- $\quad$ Document revision studies and enhance communication with users about revisions. 


\section{Appendix I. Practices Compared to the SDDS Coverage, Periodicity, and Timeliness of Data}

\begin{tabular}{|c|c|c|c|c|c|c|}
\hline \multirow{2}{*}{ SDDS Data Category } & \multirow{2}{*}{\begin{tabular}{|c|} 
Coverage \\
(meets SDDS \\
requirement)
\end{tabular}} & \multicolumn{2}{|c|}{ Periodicity } & \multicolumn{2}{|l|}{ Timeliness } & \multirow{2}{*}{ Comments } \\
\hline & & SDDS & Georgia & SDDS & Georgia & \\
\hline \multicolumn{7}{|l|}{ Real Sector } \\
\hline National accounts & Yes & $\mathrm{Q}$ & $\mathrm{Q}$ & 1Q & $85 \mathrm{D}$ & \\
\hline Production index & Yes & M & Q & $\begin{array}{c}6 \mathrm{~W} \\
\text { (1M encouraged) }\end{array}$ & $85 \mathrm{D}$ & $\begin{array}{l}\text { Periodicity flexes. } \\
\text { Timeliness flex. }\end{array}$ \\
\hline Employment & & Q & $\mathrm{A}$ & $1 \mathrm{Q}$ & $150 \mathrm{D}$ & $\begin{array}{l}\text { Periodicity flexes. } \\
\text { Timeliness flex. }\end{array}$ \\
\hline Unemployment & Yes & Q & $\mathrm{A}$ & $1 \mathrm{Q}$ & $150 \mathrm{D}$ & $\begin{array}{l}\text { Periodicity flexes. } \\
\text { Timeliness flex. }\end{array}$ \\
\hline Wages/Earnings & Yes & $\mathrm{Q}$ & $\mathrm{Q}$ & $1 \mathrm{Q}$ & $80 \mathrm{D}$ & \\
\hline Consumer price index & Yes & $\mathrm{M}$ & $\mathrm{M}$ & $1 \mathrm{M}$ & $5 \mathrm{D}$ & \\
\hline Producer price index & Yes & $\mathrm{M}$ & $\mathrm{M}$ & $1 \mathrm{M}$ & $15 \mathrm{D}$ & \\
\hline \multicolumn{7}{|l|}{ Fiscal Sector } \\
\hline General government & Yes & $\mathrm{A}$ & $\mathrm{Q}$ & $2 \mathrm{Q}$ & NLT 2M & \\
\hline $\begin{array}{l}\text { Central government } \\
\text { operations }\end{array}$ & Yes & M & M & $1 \mathrm{M}$ & NLT 1M & \\
\hline $\begin{array}{l}\text { Central government } \\
\text { Debt }\end{array}$ & Yes & $\mathrm{Q}$ & Q & $1 \mathrm{Q}$ & NLT 1M & \\
\hline \multicolumn{7}{|l|}{ Financial Sector } \\
\hline $\begin{array}{l}\text { Analytical accounts } \\
\text { of the banking sector }\end{array}$ & Yes & $\mathrm{M}$ & M & $1 \mathrm{M}$ & 20D & \\
\hline $\begin{array}{l}\text { Analytical accounts } \\
\text { of the central bank }\end{array}$ & Yes & $\begin{array}{c}\mathrm{M} \\
\text { (W } \\
\text { encouraged ) }\end{array}$ & $\mathrm{M}$ & $\begin{array}{c}2 \mathrm{~W} \\
(1 \mathrm{~W} \text { encouraged })\end{array}$ & $7 \mathrm{D}$ & \\
\hline Interest rates & Yes & $\mathrm{D}$ & $\mathrm{D}$ & 1 & 1D & \\
\hline $\begin{array}{l}\text { Stock market: Share } \\
\text { price index }\end{array}$ & & $\mathrm{D}$ & & 1 & & \\
\hline \multicolumn{7}{|l|}{ External Sector } \\
\hline Balance of payments & Yes & $\mathrm{Q}$ & $\mathrm{Q}$ & $1 \mathrm{Q}$ & $90 \mathrm{D}$ & \\
\hline Official reserve assets & & $\begin{array}{c}\mathrm{M} \\
(\mathrm{W} \\
\text { encouraged ) }\end{array}$ & M & $1 \mathrm{~W}$ & $7 \mathrm{D}$ & \\
\hline Reserves template & & $\mathrm{M}$ & M & $\begin{array}{c}1 \mathrm{M} \\
\text { (1W encouraged) }\end{array}$ & 7D & \\
\hline Merchandise trade & Yes & $\mathrm{M}$ & $\mathrm{M}$ & $\begin{array}{c}8 W \\
\text { (4-6W encouraged) }\end{array}$ & 24D & \\
\hline $\begin{array}{l}\text { International } \\
\text { investment position }\end{array}$ & Yes & $\begin{array}{c}\text { A } \\
(\mathrm{Q} \\
\text { encouraged ) }\end{array}$ & $\mathrm{Q}$ & $\begin{array}{c}3 \mathrm{Q}(1 \mathrm{Q} \\
\text { encouraged })\end{array}$ & 90D & \\
\hline External debt & Yes & $\mathrm{Q}$ & Q & $1 \mathrm{Q}$ & 90D & \\
\hline Exchange rates & Yes & $\mathrm{D}$ & $\mathrm{D}$ & 1 & $1 \mathrm{D}$ & \\
\hline \begin{tabular}{|l|} 
Addendum: \\
Population \\
\end{tabular} & Yes & $\mathrm{A}$ & $\mathrm{A}$ & $\ldots$ & $6 \mathrm{M}$ & \\
\hline
\end{tabular}

Note: Periodicity and timeliness: (D) daily; (W) weekly or with a lag of \#\# week(s) from the reference date; (WD) working days, or business days; (M) monthly or with a lag of \#\# month(s); (NLT) not later than; (Q) quarterly or with a lag of \#\# quarter(s); (A) annually; (SA) semiannual; and (...) not applicable.

${ }^{1}$ Given that the data are broadly disseminated by private means, the timeliness with which official data are disseminated is not time critical. 
This page intentionally left blank

(C)International Monetary Fund. Not for Redistribution 


\section{INTERNATIONAL MONETARY FUND}

\section{GEORGIA}

\section{Report on the Observance of Standards and Codes (ROSC)—Data Module Volume II}

\section{Response by the Authorities}

March 7, 2012

This document contains the authorities' response to the IMF's data quality assessment (Volumes I and III).

\section{CONTENTS}

RESPONSE OF NATIONAL STATISTICS OFFICE OF GEORGIA (GEOSTAT) .......... $\underline{2}$

I. National Accounts ……………………...................................................

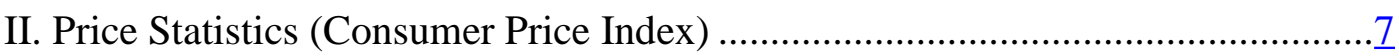

III. Price Statistics (Producer Price Index) ..........................................................11

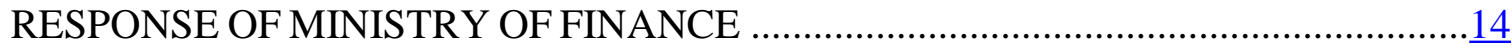

IV. Government Finance Statistics.....................................................................

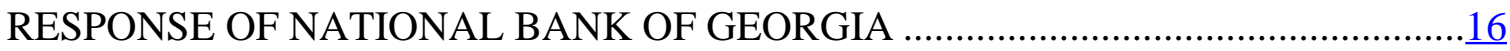

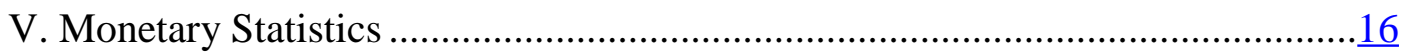

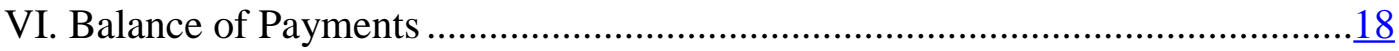




\section{RESPONSE OF NATIONAL STATISTICS OFFICE OF GEORGIA (GEOSTAT)}

\section{National Accounts}

\subsubsection{Data sharing and coordination among data-producing agencies are adequate.}

\section{Recommendation:}

Conduct pre-established, regular meetings, such as one per year, to improve communication among data compilers at NBG, GEOSTAT, and MOF, by discussing issues of common interest, avoid duplication of efforts, and ensure the consistency of macroeconomic statistics (national accounts, monetary, fiscal, and external sector).

\section{The authorities' comment on the recommendation:}

Such meetings between the three agencies are already conducted. The recommendation of introducing a pre-established time schedule for the meetings is acceptable and will be implemented from 2012. Besides, there are representatives from NBG and MOF in the GEOSTAT Board. Main responsibilities of the Board are to review and to approve methodology, statistical activity program, annual progress report, budget etc. This obviously plays an essential role in the communication and ensures coordination of entire statistical system as a whole.

0.1.4 Statistical reporting is ensured through legal mandate and/or measures to encourage response.

\section{Recommendation:}

Enact appropriate amendments to the Law of Georgia on Official Statistics to reinforce mandatory reporting of statistical data and ensure application of sanctions for nonreporting. The authorities' comment on the recommendation:

The issue of mandatory reporting by businesses is currently under consideration.

0.2.1 Staff, facilities, computing resources, and financing are commensurate with statistical programs.

\section{Recommendation:}

Augment staff and IT resources in the GEOSTAT. Ensure proper training for the staff and implement measures to retain experienced staff.

\section{The authorities' comment on the recommendation:}

Starting from 2012 there was a 30 percent increase in average salaries at the Geostat. Trainings are conducted on a regular basis, with a large training component included in the cooperation agreement with the Statistics Sweden. IT needs are prioritized and a number of important activities (such as new IT software for business register, data collection from administrative sources, online questionnaires for business, etc.) will be completed throughout 2012. 
2.2.1 The scope is broadly consistent with internationally accepted standards, guidelines, or good practices.

\section{Recommendation:}

Set up the compilation system for GDP by expenditure approach in real terms.

The authorities' comment on the recommendation:

The work for deflation of exports and imports will start in 2012. Deflation of investments and final consumption expenditure is planned for 2013. The production of GDP at constant prices by expenditure approach will be implemented by the end of 2013. The action plan for this activity is also outlined in the cooperation agreement with the Statistics Sweden.

2.3.1 Classification/sectorization systems used are broadly consistent with internationally accepted standards, guidelines, or good practices.

\section{Recommendation:}

Make efforts to compile data at establishments' level.

The authorities' comment on the recommendation:

Data compilation at establishments' level is likely to take about two years. At the first stage the business register will be updated at establishments' level and questionnaires will be changed accordingly.

\section{Recommendation:}

Resolve classification issues for transactions of LEPLs.

\section{The authorities' comments on the recommendation:}

The cooperation with the Ministry of Finance with respect to classification of LEPLs will be started from 2012. The compilation of Government Account is planned for 2012.

\section{Recommendation:}

Reclassify vouchers to students for education from subsidies on product to social transfers in kind.

\section{The authorities' comment on the recommendation:}

The recommendation is acceptable. The time series of subsidies on products will be adjusted during 5-year strategic revisions in 2012. The strategic revisions will also affect time series of gross fixed capital formation, imputed rent of own occupied dwellings, depreciation of fixed capital, and final consumption expenditure of households and NPISH.

\subsubsection{Source data are obtained from comprehensive data collection programs that take into account country-specific conditions.}

\section{Recommendation:}

To improve coverage of business survey, conduct economic census of nonfinancial corporations and update the register.

\section{The authorities' comment on the recommendation:}

Cooperation with the Ministry of Finance has started to improve business register. The government decree ensures exchange of information (data on VAT tax-payers, enterprise turnover, etc.) between the two agencies at least on a quarterly basis. In addition, in 2012 a 
number of activities will be implemented by the Geostat to improve coverage and quality of the business register data.

\section{Recommendation:}

Refine the register maintenance procedures, especially with regard to removing the defunct businesses from the register.

\section{The authorities' comment on the recommendation:}

Defunct businesses will be removed from business register after the update of business register in the first quarter of 2012. The identification of "active" and "idle" enterprises will be largely based on monthly data received from the MoF.

\section{Recommendation:}

Ensure more detail in business survey for other community, social, and personal activities.

The authorities' comment on the recommendation:

The 2012 sampling design for quarterly and annual business surveys has already been set up to address the issue. Other community, social and personal services are sampled now at 5digit level of NACE rev 1.1.

\section{Recommendation:}

Cooperate with MOF to obtain consolidated budget data by organization and based on COFOG at the level of detail that would allow for better estimates of intermediate consumption.

\section{The authorities' comment on the recommendation:}

Discussions with the MoF have been started with respect to content and timing of budget data provision by organization.

\section{Recommendation:}

Conduct ad hoc investment survey to be able to derive better estimates for consumption of fixed capital.

\section{The authorities' comment on the recommendation:}

The detailed survey on investment in fixed capital was conducted in 2011. The survey results are now available and the data will be used for compilation of the capital account in 2012.

\section{Recommendation:}

Set up the compilation of export/import price indices.

The authorities' comment on the recommendation:

Unit value indices will be calculated for homogeneous products, while price indices of main exporter countries will be used for the more complex products. Some experimental estimates of imports and exports of goods in constant prices will be available in 2012. Also in 2012 the work on inclusion of export/import price questions into the PPI questionnaires will be started. The use of export/import indices in official statistical data is planned for 2013. 


\section{Recommendation:}

Update the sample frame for the quarterly agriculture sample survey.

The authorities' comment on the recommendation:

Sample frame for the quarterly agricultural survey was partially updated in cooperation with the Ministry of Regional Development and Infrastructure (the list of large agricultural farms was provided). Further improvement is expected after completion of the World Bank grant on Tbilisi preliminary census in 2012. The overall update of the frame will be available as a result of the next population and agricultural census.

\subsubsection{Other statistical procedures (e.g., data adjustments and transformations, and} statistical analysis) employ sound statistical techniques.

\section{Recommendation:}

Refine estimates of the volume measures of the trade margin and taxes by applying base-year tax rates to the volume of the transactions taxed or subsidized.

The authorities' comment on the recommendation:

The recommendation is acceptable. The implementation of base-year tax rates method will take approximately two years. At first stage more detailed information on VAT turnover by economic activities will be obtained from statistical survey. The next step will represent accounting of taxes on products on accrual basis. Finally, base-year tax rates will be used for deflation of taxes on products.

\section{Recommendation:}

Use the Denton method to adjust quarterly original estimates to agree with annual benchmark estimates.

The authorities' comment on the recommendation:

The benchmarking of quarterly and annual data will be improved in the scope of cooperation with the Statistics Sweden in 2012. Swedish experts also recommend to use one of the Denton family of least-square-based methods, which is actually used in the Statistics Sweden.

\section{Recommendation:}

Update the coefficients used for the quarterly allocation of work in progress in agriculture. The authorities' comment on the recommendation:

The recommendation is completely acceptable. Use of data from the quarterly agricultural survey for calculation of the intermediate consumption in agriculture will be started in 2012 . 
3.5.1 Studies and analyses of revisions are carried out routinely and used internally to inform statistical processes (see also 4.3.3).

\section{Recommendation:}

Repeat from time to time comprehensive analyses of revisions to the data to inform statistical processes.

The authorities' comment on the recommendation:

More detailed and comprehensive analysis of annual adjustments started in November 2011. Revisions of preliminary data and sources of errors will be explained in more detail and placed on the Geostat's website from 2012.

4.3.1 Revisions follow a regular and transparent schedule.

\section{Recommendation:}

Enhance communication with users about revision policy.

The authorities' comment on the recommendation:

Information about revisions is published on the Geostat's website. More detailed explanations will be prepared in the metadata format within the next two years.

\subsubsection{Preliminary and/or revised data are clearly identified.}

\section{Recommendation:}

Enhance communication with users regarding revision studies and analysis of revisions.

The authorities' comment on the recommendation:

Information about revision studies and analysis will be given in the annual statistical publication "National Accounts of Georgia," with detailed explanations published on the Geostat's website from 2012.

5.2.1 Documentation on concepts, scope, classifications, basis of recording, data sources, and statistical techniques is available, and differences from internationally accepted standards, guidelines, or good practices are annotated.

\section{Recommendation:}

Develop and disseminate detailed documentation on data sources and methods for compilation of national accounts in Georgia.

The authorities' comment on the recommendation:

The work on preparation of metadata has been already started in cooperation with the Statistics Sweden. In the next two years detailed metadata will be available on the Geostat's website. The model of Swedish National Accounts metadata will be used as an example for that purpose. 


\section{Price Statistics (Consumer Price Index)}

\section{Methodological soundness}

\subsection{Scope}

2.2.1 The scope is broadly consistent with internationally accepted standards, guidelines, or good practices.

\section{Recommendations:}

Extend the coverage to include the expenditure pattern of the whole population in the CPI weights and evaluate the need for including additional outlets for price collection to cover the rural areas.

Clarify the treatment of owner-occupied housing in the weights. The common international approach is to include the weights based on imputed rents for similar housing units and covering the price survey with an appropriate rental survey also used for the actual rental expenditure.

\section{The authorities' comments on the recommendation:}

The recommendations are already taken into account during the consumer basket update by January 2012.

The updated CPI weight coverage is significantly increased and covers urban and rural area consumption. Currently the CPI weights are based mainly on the NA data of 2010, and the HBS is used as an additional source. The CPI weights for 2012 cover monetary consumption of urban and rural areas for 5 regions of the country. Since the cities where the prices are collected represent main economic centers of the regions, price collection is mainly conducted in urban areas, but there are specific products for which prices are collected in rural areas as well e.g. solid fuel (firewood).

Owner-occupied housing is excluded from the weight calculation of the consumer basket 2012 as well as from the price survey. Sound sources for the weights of OOH will be identified during the 3-year cooperation with the Statistics Sweden, if included in the basket again.

\section{Accuracy and reliability}

\subsection{Source data}

3.1.1 Source data are obtained from comprehensive data collection programs that take into account country-specific conditions.

\section{Recommendations:}

Adjust the HBS result to account for known and suspect shortcomings and compare the result against alternative data sources at all aggregation levels. 
If the $\mathrm{OOH}$ is to be included in the CPI, as most countries do with imputed rents as weights and rental equivalence as the pricing approach, evaluate how weights and pricing methodology are determined and improve the coverage of corresponding price collection.

Review all detailed item specifications for completeness and augment as needed. Special attention should be paid to the more complex items (insurance, housing, wireless communication services, computers, etc.) to capture all relevant changes in the item specifications.

\section{The authorities' comments on the recommendation:}

Recommendations are already taken into account during the 2012 consumer basket update. Since the National Accounts data is used as a main source for CPI weights, suspected bias in household consumption, which may exist in the HBS e.g. alcohol, is minimized. $\mathrm{OOH}$ is removed from the 2012 consumer basket.

During the preparatory process of the consumer basket update, outlets were sampled according to the turnover volume, and the list of sampled outlets was given to enumerators. For the completeness of item specifications the selected outlets were surveyed. Special attention was paid to complex goods/services such as computers, communication services, etc.

3.1.2 Source data reasonably approximate the definitions, scope, classifications, valuation, and time of recording required.

\section{Recommendation:}

For some complex goods and service, such as cellular phone services, seek alternative data sources, virtual outlets, outside the normal regional price survey to reflect consumer behavior.

\section{The authorities' comment on the recommendation:}

The recommendations are already taken into account during the 2012 consumer basket update.

A survey of virtual outlets was conducted. The latter will be included in the sample by next update of weights, if appropriate.

\subsection{Statistical techniques}

3.3.1 Data compilation employs sound statistical techniques to deal with data sources.

\section{Recommendations:}

Consider estimating the December base prices for seasonal products based on an average over a longer time period that would include actual prices for each transaction. Make sure that the actual price levels from end of previous season to the beginning of the new season 
reflect similar changes in the chained sub-indices.

Introduce quality adjustment methods to implicitly or explicitly account for the quality changes.

\section{The authorities' comments on the recommendation:}

The recommendations are already taken into account during the 2012 consumer basket update.

Base prices in December 2011 for seasonal goods/services in the updated consumer basket were registered based on imputed prices from the previous consumer basket. In special cases outlets were surveyed for actual average prices of surveyed items.

Experimental work on quality adjustment methods is planned for 2012.

3.3.2 Other statistical procedures (e.g., data adjustments and transformations, and statistical analysis) employ sound statistical techniques.

\section{Recommendations:}

Change the Dutot formula to a Jevons index (geometric average) to partially account for substitution effect and to lessen the impact of large price variation within the elementary aggregates.

Price-update the expenditure weights to align the weight and index reference periods.

\section{The authorities' comment on the recommendation:}

The recommendations are already taken into account during the 2012 consumer basket update.

The Jevons index (ratio of geometric averages) is used for elementary aggregates instead of the Dutot index (ratio of arithmetic means).

The expenditure weights were not price updated, as we find substitution effects to be significant.

\section{Accessibility}

\subsection{Metadata accessibility}

5.2.1 Documentation on concepts, scope, classifications, basis of recording, data sources, and statistical techniques is available, and differences from internationally accepted standards, guidelines, or good practices are annotated.

\section{Recommendation:}

Produce and disseminate detailed metadata describing the methodology practiced in compilation of Georgian CPI. 
The authorities' comment on the recommendation:

Recommendations are already taken into account during the 2012 consumer basket update. Indices with long term base period were published, which make easier to analyze the data for an average user.

Detailed metadata describing the methodology practiced in compilation of the CPI is planned to be accomplished during 2012.

5.2.2 Levels of detail are adapted to the needs of the intended audience.

\section{Recommendation:}

Develop further and disseminate the different metadata publications.

The authorities' comment on the recommendation:

The recommendation is acceptable. A number of metadata publications are planned to be released during 2012. 


\section{Price Statistics (Producer Price Index)}

\section{Methodological soundness}

\subsection{Concepts and definitions}

2.1.1 The overall structure in terms of concepts and definitions follows internationally accepted standards, guidelines, or good practices.

\section{Recommendation:}

Apply the output concept for the PPI weights at higher aggregation levels instead of turnover. Include also the products from significant secondary activities into the PPI sample.

The authorities' comment on the recommendation:

Recommendation is already taken into account during weight update by 2012 . PPI weights are based on output values instead of turnover. Enterprises are selected according to the volume of products produced, notwithstanding the primary activity.

\subsection{Scope}

2.2.1 The scope is broadly consistent with internationally accepted standards, guidelines, or good practices.

\section{Recommendation:}

Consider compiling the PPIs also by product classification. This will also serve in improving imputation method within the PPI and make it more valuable for some key users.

\section{The authorities' comment on the recommendation:}

Recommendation is already taken into account during weight update by 2012. Compiling the PPIs by product classification will be started from 2012.

\section{Accuracy and reliability}

\subsection{Source data}

3.1.1 Source data are obtained from comprehensive data collection programs that take into account country-specific conditions.

\section{Recommendations:}

Ensure that total turnover or preferably the total output covering the whole economy in scope is used for the PPI weights. Include weights also for secondary products since the PPI weights should reflect the total value of turnover for each sampled industry.

Seek ways to minimize the sources of nonsampling errors in the Business Survey. Updating the Business Register (by conducting an economic census), varying the establishment size stratification variable by sectors, and investigating the existence of potential systematic factors in nonresponse could help improve the quality of both the Business Register and Business Survey results. 
Review all detailed transaction specifications and include description on the transaction specifications that detail the nonphysical characteristics of the sale. Introduce central price collection dedicated to deal with certain industries where pricing practices are complex since this would likely improve the quality of the price data in times of sample and quality changes.

\section{The authorities' comments on the recommendation:}

The recommendations are already taken into account during weight update by 2012 . PPI weights are based on the total output of the whole economy. All the products from the main or secondary activities are included in the weights.

\subsection{Statistical techniques}

3.3.1 Data compilation employs sound statistical techniques to deal with data sources.

\section{Recommendations:}

Update the related methods of imputing missing prices, treating of quality changes, and introduction of new products into the PPI. All missing prices should be imputed; quality changes should be accounted for using either implicit or explicit quality methods; or permanently unavailable items should be replaced. Implement appropriate imputation methods into the new PPI software being developed.

Consider estimating the December base price for seasonal products based on an average over a longer time period that would include actual prices for each transaction.

\section{The authorities' comments on the recommendation:}

The recommendation on price imputations will be implemented after experimental work and the corresponding software update, no later than from the beginning of 2013.

The December base price for seasonal products are used already in the $2012 \mathrm{PPI}$.

\subsubsection{Other statistical procedures (e.g., data adjustments and transformations, and statistical analysis) employ sound statistical techniques.}

\section{Recommendation:}

In order to implement sample changes consider changing the long-term elementary aggregate formula with either a weighted geometric average or the modified Laspeyres formula based on short-term price changes. Price-update the weights to align with the index reference period.

\section{The authorities' comments on the recommendation:}

The recommendation on changing the long-term elementary aggregate formula is acceptable and will be implemented while updating the software in the first half of 2012.

The weights are not price updated, as we find substitution effects to be significant. 


\section{Accessibility}

\subsection{Data accessibility}

5.1.1 Statistics are presented in a way that facilitates proper interpretation and meaningful comparisons (layout and clarity of text, tables, and charts).

\section{Recommendation:}

Release the PPI with a monthly press release explaining both recent changes in the index as well as showing longer-term trends.

The authorities' comment on the recommendation:

The recommendation is acceptable and will be implemented in 2012.

\subsection{Metadata accessibility}

5.2.1 Documentation on concepts, scope, classifications, basis of recording, data sources, and statistical techniques is available, and differences from internationally accepted standards, guidelines, or good practices are annotated.

\section{Recommendation:}

Develop and disseminate metadata describing the concepts and methods to compile the PPI. The authorities' comment on the recommendation:

The recommendation is acceptable and will be implemented in 2012.

5.2.2 Levels of detail are adapted to the needs of the intended audience.

\section{Recommendation:}

Produce and disseminate both detailed (for internal use and advanced users) and more general information about the use, compilation practices and methodology of the PPI.

The authorities' comment on the recommendation:

The recommendation is acceptable and will be implemented in 2012 . 


\section{RESPONSE OF MINISTRY OF FINANCE}

\section{Government Finance Statistics}

0.1.2 Data sharing and coordination among data-producing agencies are adequate.

\section{Recommendation:}

Establish periodic, regular meetings with the technical data compilers of macroeconomic statistics at the NBG and GEOSTAT.

The authorities' comment on the recommendation:

There exists an effective exchange of information between data producing agencies. Meetings between MOF, NBG, and GEOSTAT are organized immediately, when needed. Staff of data producing agencies know each other well and communicate directly on a regular basis.

0.3.1 The relevance and practical utility of existing statistics in meeting users' needs are monitored.

\section{Recommendation:}

Introduce a structured and periodic process of consultation with users.

The authorities' comment on the recommendation:

There are email addresses and telephones of the contact persons on the webpage of the MOF of Georgia and the IMF's SDDS page. Every user can call or send questions and receive answers. Meetings can also be organized with users, if necessary.

\subsubsection{Internal governmental access to statistics prior to their release is publicly identified.}

\section{Recommendation:}

Publicly identify the arrangements with the NBG and GEOSTAT for internal government access to GFS prior to their release.

The authorities' comment on the recommendation:

The GFS data satisfies the SDDS standard. Every interested party has equal access to the data. The NBG and the GEOSTAT have prior access to the GFS data only for internal use by data compilers and not for internal government use, which is stipulated in bilateral memorandums of understanding. 


\subsection{Classification/sectorization}

\section{Recommendation:}

Review and update the sectorization of the LEPLs.

The authorities' comment on the recommendation:

The cooperation with the GEOSTAT with respect to classification of LEPLs will be started from 2012.

2.4.1 Market prices are used to value flows and stocks.

\section{Recommendation:}

Value securities at current market prices.

The authorities' comment on the recommendation:

Government securities are sold at the market-based auctions which are open for every interested party. Therefore, we think that securities are valued at current market prices.

\subsubsection{Contact points for each subject field are publicized.}

\section{Recommendation:}

Provide users with contact points and material to raise awareness on the use of GFS.

The authorities' comment on the recommendation:

The emails of contact persons are available on the MOF and the IMF's SDDS webpages. The MOF webpage contains budget classification and explanatory notes. In case users have additional questions, they can forward them to GFS contact persons. 


\section{RESPONSE OF NATIONAL BANK OF GEORGIA}

\section{Monetary Statistics}

\subsubsection{Data sharing and coordination among data-producing agencies are adequate.}

\section{Recommendation:}

Conduct pre-established, regular meetings, such as one per year, to improve communication among data compilers at NBG, GEOSTAT, and MOF, by discussing issues of common interest, avoid duplication of efforts, and ensure the consistency of macroeconomic statistics (national accounts, monetary, fiscal, and external sector). The authorities' comment on the recommendation:

The recommendation is acceptable. The National Bank of Georgia puts its best efforts to improve communication among data compilers at NBG, GEOSTAT, and MOF by discussing set of statistical issues. Some discussions also was initiated by the NBG, however most of the discussions take place by phone. In the future meetings between data compliers will be formalized.

1.2.4 Advance notice is given of major changes in methodology, source data, and statistical techniques.

\section{Recommendation:}

Provide advance notice of major changes in methodology, source data, and statistical techniques, for example, within the press release of the previous period.

The authorities' comment on the recommendation:

The recommendation is implemented. In particular, in line with the ROSC mission's recommendations (October 2011), Monetary Surveys of CB, ODC and DC were reviewed and before providing to users by the web-site we has already published advance notice about methodological reasons of the changes. The NBG will definitely implement this practice in its statistical activity. Moreover, further revisions of time series will be accompanied with detailed explanations of changes in methods used.

2.3.1 Classification/sectorization systems used are broadly consistent with internationally accepted standards, guidelines, or good practices.

\section{Recommendations:}

Include into the definition of broad money debit card deposits, check book deposits, credit guarantee deposits, deposits for letters of credit, and deposits for other payment documents. 
Separate positions on financial instruments with OFC's and NPI's from positions with ONFC. Depending on governance structure and financing sources classify NPI's either as part of the government or as 'Other Resident Sectors'.

Classify accrued interest for deposits and loans to nonresidents, deposits and loans to central

and local government, deposits and loans to OFCs and NPIs together with the outstanding amount of respective deposits or loans.

Include in monetary statistics data on positions on financial derivatives consistent with recommendations of the MFSM and the MFSMCG.

The authorities' comment on the recommendation:

The NBG has already updated the Monetary Survey data as suggested by the ROSC mission. The appropriate time series and methodological notes will be available on the NBG's website from February 29, 2012.

\subsubsection{Sources data reasonably approximate the definitions, scope, classifications,} valuation, and time of recording required.

\section{Recommendation:}

Introduce a clear statistical definition of residency to ensure that all institutional units are sectorized on residents and nonresidents consistent with the MFSM. Conduct regular trainings/consultations with data compilers to improve the quality of source data.

The authorities' comment on the recommendation:

The definition of residency is provided in the NBG's Guidelines for Filling the Monthly Statistical Data Reporting Forms F4 on Loans. However, under the implementation of new statistical software, NBG's Monetary Statistics Division, conducts regular meetings, trainings, and consultations with data compilers from commercial banks to improve the data quality. One of the major topics discussing with data providers is sectorization of institutional units and residency criteria. 


\section{Balance of Payments}

0.1.2 Data sharing and coordination among data-producing agencies are adequate.

\section{Recommendation:}

Conduct pre-established, regular meetings, such as one per year, to improve communication among data compilers at NBG, GEOSTAT, and MOF, by discussing issues of common interest, avoid duplication of efforts, and ensure the consistency of macroeconomic statistics (national accounts, monetary, fiscal, and external sector).

The authorities' comment on the recommendation:

See Monetary Statistics comment.

\subsection{Advance notice is given of major changes in methodology, source data, and statistical \\ techniques.}

\section{Recommendation:}

Provide advance notice of major changes in methodology, source data, and statistical techniques, for example, within the press release of the previous quarter.

The authorities' comment on the recommendation:

See Monetary Statistics comment.

3.1.1 Source data are obtained from comprehensive data collection programs that take into account country-specific conditions.

\section{Recommendations:}

The quality of the ITRS data can be improved by conducting training activities with data reporters. The private nonfinancial external debt compilation system needs strengthening.

For transactions that fall below the reporting threshold, a sample survey of banks and nonbanking institutions with accounts abroad should be conducted to obtain information to classify the low-value transactions across the balance of payments components.

The quality of the private nonfinancial external debt compilation system should be improved by increasing the coverage of data.

\section{The authorities' comments on the recommendation:}

To improve the quality of the ITRS data NBG plans to conduct training for representatives of commercial banks. 
With regard to the data processing, the NBG works on creation of a database for private nonfinancial external debt. As for data collection, the NBG and the GEOSTAT consider measures for improving the quality of primary data.

For the ITRS transactions below the threshold the NBG plans to conduct sample surveys of banks with accounts abroad to classify the low-value transactions across the balance of payments components.

The NBG and the GEOSTAT consider possibilities of increasing coverage of data on private nonfinancial external debt.

\subsubsection{Data compilation employs sound statistical techniques to deal with data sources.}

\section{Recommendation:}

The calculation of the adjustment for C.I.F./F.O.B. prices on imports should be based on a sound method, such as a survey among major importers to estimate transportation and insurance costs.

\section{The authorities' comment on the recommendation:}

The NBG is working on a methodology for converting valuations from C.I.F. into F.O.B. basis. The new methodology will be completed in 2012. It will take into consideration geographical location, volumes and means of transportation for imports.

\subsubsection{Studies and analyses of revisions are carried out routinely and used internally to} inform statistical processes (see also 4.3.3).

\section{Recommendation:}

Document analyses and studies of revisions and make them known to users if findings impact the analysis, such as significant differences between preliminary and final data.

The authorities' comment on the recommendation:

The recommendation is acceptable. The NBG intends to document analyses and studies of revisions during 2012 which will be published in our publications and updated periodically.

\subsubsection{Preliminary and/or revised data are clearly identified.}

\section{Recommendation:}

Inform users whenever data are revised, providing detailed explanation of the revisions, when significant.

\section{The authorities' comment on the recommendation:}

The recommendation is acceptable. The NBG will follow the recommendation and inform users about any major revisions. 
This page intentionally left blank

(C)International Monetary Fund. Not for Redistribution 


\title{
INTERNATIONAL MONETARY FUND
}

GEORGIA

\section{Report on the Observance of Standards and Codes (ROSC)—Data Module Volume III}

\section{Detailed Assessments Using the Data Quality Assessment Framework (DQAF)}

\author{
Prepared by the Statistics Department
}

Approved by Adelheid Burgi-Schmelz and Ahmed Masood

March 7, 2012

This document contains a detailed assessment by dataset of the elements and indicators that underlie the data quality dimensions discussed in Georgia's Report on the Observance of Standards and Codes (ROSC)—Data Module. It also includes as appendices the DQAF generic framework and the results of the users' survey. 


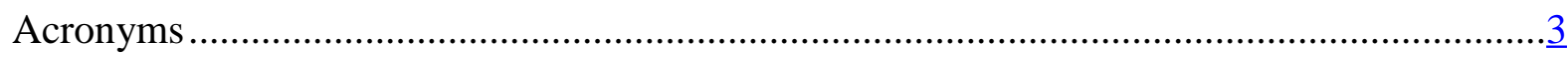

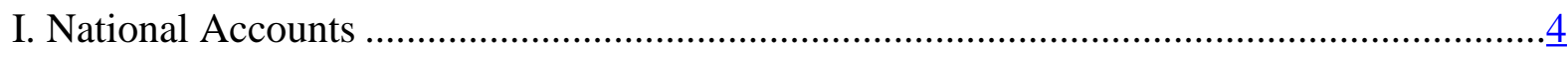

II. Price Statistics (Consumer Price Index) ……………..................................................

III. Price Statistics (Producer Price Index) ……………...................................................

IV. Government Finance Statistics ...............................................................................

V. Monetary Statistics...................................................................................................

VI. Balance of Payments Statistics ...........................................................................118

Tables

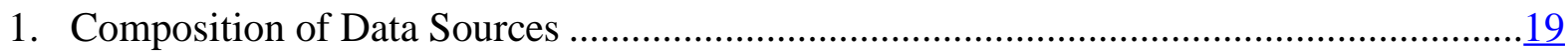

2. Data Quality Assessment Framework (July 2003): Summary of Results for

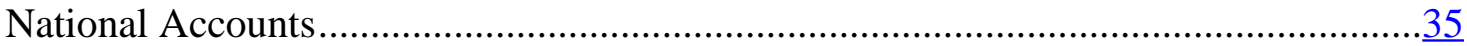

3. Data Quality Assessment Framework (July 2003): Summary of Results for

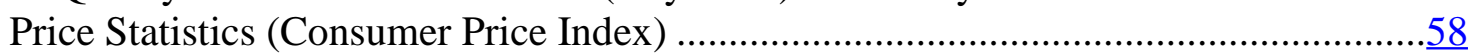

4. Data Quality Assessment Framework (July 2003): Summary of Results for Price Statistics (Producer Price Index) ........................................................................79

5. Data Quality Assessment Framework (July 2003): Summary of Results for Government Finance Statistics ..........................................................................96

6. Valuation Methods in the National Bank of Georgia and Commerical Banks................109

7. Data Quality Assessment Framework: Summary of Results for Monetary Statistics...........................................................................................

8. Data Quality Assessment Framework: Summary of Results for Balance of Payments Statistics ..... 


\section{ACRONYMS}

1993 SNA

2008 SNA

BoPD

BPM5

BPM6

COFOG

COICOP

$\mathrm{CPA}$

CPI

FFD

GEOSTAT

GFS

GFSM 2001

HBS

IFS

IPI

JVI

LEPL

MFS

MFSM

MOE

MOF

MPD

MSD

NA

NACE

NAD

NBG

NOE

NSDS

OECD

$\mathrm{OOH}$

PPI

ROSC

SDDS

SUT

UNECE
System of National Accounts 1993

System of National Accounts 2008

Balance of Payments Division

Balance of Payments Manual, fifth edition

Balance of Payments and International Investment Position Manual, sixth edition

Classification of the Functions of Government

Classification of Individual Consumption According to Purpose

Classification of Products by Activity

Consumer Price Index

Fiscal Forecasting Department

National Statistics Office of Georgia

Government Finance Statistics

Government Finance Statistics Manual 2001

Household Budget Survey

International Financial Statistics

Industrial Production Index

Joint Vienna Institute

Legal Entity of Public Law

Monetary and Financial Statistics

Monetary and Financial Statistics Manual

Ministry of Economy and Sustainable Development of Georgia

Ministry of Finance of Georgia

Monetary Policy Division

Monetary Statistics Division

National Accounts

Standard Classification of Economic Activities within the European

Communities

National Accounts Division of GEOSTAT

National Bank of Georgia

Nonobserved Economy

National Strategy of Development of Statistics

Organization for Economic Co-operation and Development

Owner-Occupied Housing

Producer Price Index

Report on the Observance of Standards and Codes

Special Data Dissemination Standard

Supply and Use Table

United Nations Economic Commission for Europe 


\section{National AcCounts}

\section{Prerequisites of quality}

\subsection{Legal and institutional environment}

0.1.1 The responsibility for collecting, processing, and disseminating the statistics is clearly specified.

The National Statistics Office of Georgia (GEOSTAT) was established as an independent legal entity under the Law on Statistics of December 11, 2009, N 2291-rs to be responsible for compiling and disseminating official statistics. Article 9 of the Charter of GEOSTAT (approved by the Presidential Decree No. 72 on February 1, 2010) mandated GEOSTAT to be in charge of all collection and dissemination of official statistics as well as the improvement in the coverage and quality of official data responsible by GEOSTAT as well as by other government agencies. Article 7 of the Law authorizes the GEOSTAT to work out a statistical activities program; and carry out statistical activities, which sets the central position of the GEOSTAT in the Georgian statistical system.

Accordingly, maintaining the national accounts system and compiling the satellite accounts is defined as one of the main functions of the Macroeconomic Statistics Division (as of now, National Accounts Division (NAD)). No other institution compiles alternative estimates of national accounts.

Article 25 of the Law on Statistics authorizes GEOSTAT to request from the administrative bodies and other physical and legal entities and receive all the statistical and other information (including confidential information) from them necessary for carrying out its functions.

Arrangements to promote consistency of methods and results are set up by the Board of the GEOSTAT, which has representatives from other data producing agencies, namely the National Bank of Georgia (NBG), the Ministry of Economy and Sustainable Development of Georgia (MOE), and Ministry of Finance of Georgia (MOF).

In addition to that, the President of Georgia approves annual State Program for Development of Statistics. The compilation and dissemination of national accounts statistics are stated in the State Program. (e.g., for current year there is an updates in survey of domestic investments). 


\subsubsection{Data sharing and coordination among data-producing agencies are adequate.}

Article 5 of the Law on Statistics requires that GEOSTAT cooperate and coordinate with the local organizations producing the statistics in order to achieve efficiency. The GEOSTAT compiles many source statistics for the national accounts itself, and also use data from other data producing agencies, such as the NBG, which compiles balance of payments and monetary and financial statistics, some other related data from other financial corporations; MOF, which is responsible for compiling government finance statistics; and Revenue Service (under MOF) for value-added tax data and as an input for updating survey frames, as well as the Revenue Service. Article 16 of the Law on Statistics stipulates that GEOSTAT coordinates exchange of information among the administrative bodies in order to produce the statistics and facilitates effective implementation of the statistical standards and methodology approved. In addition, there are memorandums of understanding between the GEOSTAT and the MOF, GEOSTAT and Education Quality Development Center, and GEOSTAT and the NBG covering the sharing of macroeconomic data.

Within the GEOSTAT, the internal procedures are in place to ensure coordination between various divisions, namely Business Statistics Division, Agriculture and Environmental Statistics Division, Social Statistics Division, Population Census and Demographic Statistics D Division), Price Statistics Division. All proposed changes in questionnaire should be adopted by GEOSTAT Board. According to working procedures all divisions consult with NAD on methodology issues.

The central role of GEOSTAT in the field of statistics is further reiterated in Article 2 of the Charter of GEOSTAT, which states that the GEOSTAT should work out a unified policy for the field of statistics, prepare and introduce statistical standards and methodology, create and realize statistical classification system, create and improve statistical databases, information banks and networks; and create and approve statistical observance forms for producing official statistics. Such centralized statistical system in principle guards against duplication of efforts and unnecessary burden on respondents. However, there is no arrangement for regular meetings of all technical staff responsible for macroeconomic statistics. Such meetings provide a comprehensive arena for exchanging information on current and forthcoming projects for statistical development, promoting cross-sectoral data consistency crucial for macro-economic policy making, and coordinating work programs to avoid duplication of effort, ensure coherent application of methodology at all stages of data collection, and enhance effectiveness. Nevertheless, these agencies have several bi-lateral meetings and arrangements for collaboration on data issues, e.g., GEOSTAT with MOF and NBG on GDP estimates, GEOSTAT and NBG on data sources for BOP.

There are regular informal contacts with the staff of other data-producing agencies. Changes in the production of statistics are preceded by consultations and should be approved by the Board of the GEOSTAT. 


\section{Recommendation:}

Conduct pre-established, regular meetings, such as one per year, to improve communication among data compilers at NBG, GEOSTAT, and MOF, by discussing issues of common interest, avoid duplication of efforts, and ensure the consistency of macroeconomic statistics (national accounts, monetary, fiscal, and external sector.

\subsubsection{Individual reporters' data are to be kept confidential and used for statistical purposes only.}

GEOSTAT has sound legal and institutional provisions to ensure confidentiality of individual data. Article 26 of the Law on Statistics states that statistical data shall be public except for the data which allows for identification of an observation unit. Article 28 states that the confidential statistical data shall not be issued or disseminated or used for a nonstatistical purpose with exceptions envisaged by the Georgian legislation. When producing the official statistics it is obligatory to destroy or store separately the identity data including the questionnaires containing such data. According to Article 29 of the Law, the employees of the GEOSTAT should not use or disseminate confidential statistical data either for the personal, academic, research or any other activities. Violation of these provisions will lead to imposing a disciplinary responsibility against employee, notably in view of the guilt or/and the damage inflicted the Executive Director shall impose the following disciplinary penalties: warning, withholding a salary, and/or dismissal.

GEOSTAT staffs are required to keep individual data confidential by Law and the staff is well informed by the requirement. Access to individual data both to the actual forms and to the computer records is restricted to the appropriate staff. The procedures are adopted that prevent residual disclosure. There are special aggregation rules that ensure that unintended disclosure does not occur. Respondents to surveys are informed about the confidentiality of their responses (relevant statement is included in each survey form). Archive procedures ensure appropriate storage of information with clearly articulated rules.

\subsubsection{Statistical reporting is ensured through legal mandate and/or measures to encourage response.}

Article 25 of the Law on Statistics sets the obligation to provide statistical and other information to GEOSTAT, notably upon the request and according to the legislation of Georgia the administrative bodies shall be obliged to provide the GEOSTAT with the information on physical and private entities (including confidential information) available to them. However, no sanctions for nonreporting or misreporting are stipulated by the Law and, due to lack of legal and administrative support, very senior staff is required to intervene in order to get the respondents to collaborate. 
Despite GEOSTAT's increased efforts during last years to raise awareness and improve direct contacts with respondents, there has been the tendency of increasing of nonresponse rate for business survey (around 7 percent in 2011).

\section{Recommendation:}

Enact appropriate amendments to the Law of Georgia on Official Statistics to reinforce mandatory reporting of statistical data and ensure application of sanctions for nonreporting.

\section{$0.2 \quad$ Resources}

\subsubsection{Staff, facilities, computing resources, and financing are commensurate with statistical} programs.

Staff resources are not adequate for performing the current and upcoming tasks. The NAD includes six employees (head, one senior specialist, and four chief specialists), responsible for compiling annual and quarterly gross domestic product (GDP) in current and constant prices, supply and use tables (SUT), sequence of accounts up to capital account, annual and quarterly regional accounts, compilation of industrial production index (IPI), publication of other relevant statistics (Government Finance Statistics (GFS), Monetary statistics) in annual publications, national account (NA) section for quarterly bulletin of GEOSTAT, and prepare various reports for international organizations (Eurostat, United Nations Economic Commission for Europe (UNECE), etc.). The projects are under way on development of regional accounts and public-private partnerships GDP data. There is no spare capacity to develop sectoral accounts.

The salaries of the staff are lower compared to similar job positions in other data producing agencies in Georgia, which triggers staff turnover. Out of six staffs in NAD, two have more than five years of experience in national accounts.

The qualifications of the staff are generally adequate. The GEOSTAT takes every opportunity to send staff on international training courses, seminars, and workshops. Over past years, GEOSTAT staff attended various training activities in real sectors statistics including NA training courses at the IMF Institute (2006 and 2009), quarterly NA course at the Joint Vienna Institute (JVI) (two staff, in 2008), and price statistics course at the JVI in 2006. The GEOSTAT encourages staff to attend and present papers at domestic and international conferences (e.g., in 2009, UNECE, workshop on System of National Accounts 2008 (2008 SNA) challenges and exchange experiences with other countries). GEOSTAT staff participated in selected Organization for Economic Co-operation and 
Development (OECD) meetings. There is also informal on-the-job training in national accounts for new staff.

The IT resources in NAD are considered to be broadly commensurate with the needs of the current program of NAD, but not adequate for further development of national accounts statistics. The NAD is equipped with six personal computers, one laptop, two printers, and one all-in-one printer. The computers are connected by a network within the division. However, inter-divisional exchange of information is undertaken via e-mails that affect efficiency of the process. Hardware and software facilities are not quite up to date. IT resources are not adequate for the development of business statistics, which are based on the quarterly census of big companies and a sample of small and medium enterprises. Thus, there is no room for additional commitments.

After moving GEOSTAT to two separate buildings, communication problem arises and hampers the efficiency of the processes.

Article 9 of the Law on Statistics authorize the Executive Director to develop the list of staff and the salary funds of GEOSTAT and submit them for approval to the Board of the GEOSTAT, as well as to work out the draft budget of the GEOSTAT according to the statistical activity program. Budget limitations create some problems, for instance in the number of publications that can be produced.

\section{Recommendation:}

Augment staff and IT resources in the GEOSTAT. Ensure proper training for the staff and implement measures to retain experienced staff.

\subsubsection{Measures to ensure efficient use of resources are implemented.}

The GEOSTAT Board provides overall supervision of the organization of statistical work and oversees strategic plans for statistical development. In order to ensure the efficient use of resources the following measures are undertaken: (i) the thorough planning of statistical works (on multi-annual, annual and quarterly basis); (ii) the permanent monitoring of the appropriate use of resources according their destination. Special attention is granted to the improvement of the staff performances, especially its qualification and abilities. Time to time, staff receive differentiated bonuses based on the assessment results. The outside consultants are widely used to evaluate statistical methodologies and compilation systems. 


\section{$0.3 \quad$ Relevance}

\subsubsection{The relevance and practical utility of existing statistics in meeting users' needs are monitored.}

The relevance of statistical program is ensured by the Board of the GEOSTAT, which consists of seven members and a Chairman, with the following composition: one representative of NBG, one representative of the Ministry of Economy and Sustainable Development of Georgia, one representative of MOF, and other five members, which represent private sector. The Parliament of Georgia should give consent to appoint the members of the Board (Law on Statistics, Article 11). The Board also serves as an advisory group to inform statistical processes. In addition, Article 5 of the Law on Statistics encourage cooperation with the international organizations in order to introduce the international practice and methodology and share relevant experience based on the agreements and treaties concluded with the international organizations engaged in this field.

Article 7 of the Law on Statistics stipulates that GEOSTAT should produce the statistics that are approved and/or recognized by the Board of the GEOSTAT, and also should need arises, the GEOSTAT is authorized to produce the statistics which is not envisaged by the statistical activity program. Executive Director submits the statistical activity program for approval to the President of Georgia (Article 9 of the Law on Statistics).

In addition, Eurostat (as one of users) performs regular quality checks of reported data. Their requirements are monitored and addressed in consistent manner. The broader group of users are approached directly on an ad hoc basis (e.g., during celebration of International Statistics Day). There is a GEOSTAT website on the social networks (e.g., Face book). Users are also encouraged to provide feedback via GEOSTAT official website. The feedback for commentary on national accounts releases are provided in timely manner. The GEOSTAT has an intensive reaching out activity, with meetings and seminars held with major groups of users including private sector. The users' feedback is encouraged via GEOSTAT website.

\subsection{Other quality management}

\subsubsection{Processes are in place to focus on quality.}

The GEOSTAT commitment to quality is stipulated by law and well publicized. Article 1 of the Law on Statistics states that its goal is to ensure producing independent, objective and reliable statistics in the country based on the internationally recognized basic principles of statistics. Reflecting the spirit of this law, the GEOSTAT's mission statement emphasizes the improvement and harmonization of statistical activities and the maintenance of independence, accuracy, relevance, integrity, timeliness, and professional standard of 
statistical information produced in Georgia. GEOSTAT is finalizing the National Strategy of Development of Statistics (NSDS) that includes special chapter on quality.

Quality policy is based on the provisions of national and EU legislation, Strategy of GEOSTAT, European Statistics Code of Practice, user needs and expectations. It defines overall intentions and directions of institution related to quality. The new management of the institution is giving priority to building trust and increasing the credibility of the statistics produced by GEOSTAT.

Conscious of value of independent quality assessment, GEOSTAT regularly participates in international evaluations, such as the IMF Report on the Observance of Standards and Codes (ROSC) Data module and the World Bank's statistical capacity indicators. It also conducts regular communications with Eurostat on data quality issues. A global assessment mission from Eurostat is expected in 2012.

\subsubsection{Processes are in place to monitor the quality of the statistical program.}

The GEOSTAT regularly reviews and plans improvements to their internal processes. More formal annual Statistical Program is produced annual and approved by the President of Georgia. The newly created Monitoring Department is responsible for operating the monitoring, control and internal audit. To obtain a prompt feedback from users, a hot line phone number has been introduced on the website.

The expert guidance on the quality of their statistics is also ensured vie peer reviews within the framework of cooperation with other statistics agencies. GEOSTAT has established longterm cooperation with Statistics Sweden. Strategy of cooperation in national accounts is based on three year plan of Developing Georgian National Accounts. There is also established Cooperation with the Central Statistical Office of Poland. Main task of the project is to improve methodology of Regional Accounts compilation.

\subsubsection{Processes are in place to deal with quality considerations in planning the statistical program.}

The Board of GEOSTAT coordinates the economic statistics work program, including explicit decisions about quality and trade-offs among the dimensions of quality (e.g., resource availability, timeliness, and accuracy/reliability). The quality dimensions are also recognized explicitly in the NSDS. 


\section{Assurances of integrity}

\subsection{Professionalism}

\subsubsection{Statistics are produced on an impartial basis.}

Article 6 of the Law on Statistics stipulates that GEOSTAT independently carries out its activities based on the Georgian legislation. Article 1 of the Charter of GEOSTAT, 2010 further elaborate that the GEOSTAT carries out its activities based on the Georgian legislation, internationally accepted statistical principles, Law on Statistics, Law of Georgia on Legal Entity of Public Law, this Charter, GEOSTAT Board's regulations and other normative acts. The GEOSTAT acquires rights and obligations to implement the goals established and functions assigned to it. There is no external pressure on the GEOSTAT with respect to the content or release of the statistics.

On the above premise, all official statistics including national accounts (and price) statistics are compiled on an impartial basis. The basic principles governing the collection, processing, and dissemination of statistics in Georgia includes professional independence, objectivity, reliability, confidentiality of statistical data, and efficiency (Law on Statistics, Article 4).

The Executive Director of GEOSTAT is appointed by Board of the GEOSTAT for the term of 4 years and may be dismissed by the President of Georgia under special conditions (Article 8 of the Law on Statistics). The Executive Director is authorized to invite foreign or local experts on the contractual basis in accordance with the recommendations of the members of Board of the GEOSTAT in order to ensure effective operation of the GEOSTAT (Article 9.2).

Professional competency plays a key role in the promotion practices in the GEOSTAT and professional enhancement is encouraged. The general performance assessment of GEOSTAT staff is planned (including regional offices).

\subsubsection{Choices of sources and statistical techniques, as well as decisions about dissemination, are informed solely by statistical considerations.}

The choices of sources, statistical techniques, and dissemination of national accounts are made solely by the GOSTAT based entirely on statistical considerations. There has been no instance of ministerial interference in the choice of the statistical sources and methods. 


\subsubsection{The appropriate statistical entity is entitled to comment on erroneous interpretation and misuse of statistics.}

The GEOSTAT provides explanatory materials when releasing the national accounts statistics. The GEOSTAT monitors media coverage of its statistical products and has the authority to comment on erroneous interpretation and misuse of the statistics that it produces.

\subsection{Transparency}

\subsubsection{The terms and conditions under which statistics are collected, processed, and disseminated are available to the public.}

The terms and conditions governing the collection of statistics are published in the Law on Statistics and in Charter of GEOSTAT, which are widely available to the public, including from the GEOSTAT website:

http://www.geostat.ge/index.php?action=page\&p_id=29\&lang=eng. In addition to legal provisions, the GEOSTAT website contains other relevant documents, such as the National Strategy of Development of Statistics, annual report of the GEOSTAT, information about the special data dissemination standard (SDDS), and information about individual statistical products.

\subsubsection{Internal governmental access to statistics prior to their release is publicly identified.}

The GEOSTAT disseminates the national accounts statistics to all users simultaneously. There is no governmental access to statistics prior to release. This practice is clearly made known to the public.

\subsubsection{Products of statistical agencies/units are clearly identified as such.}

Products of the GEOSTAT are clearly identified as such by its name and logo. The national accounts tables disseminated in the NBG's publications identify the GEOSTAT as the source. However, in the GEOSTAT publications, there are cases, in which that attribution is not made to the source, when statistics from other data-producing agencies is reproduced.

\subsubsection{Advance notice is given of major changes in methodology, source data, and statistical techniques.}

It is the GEOSTAT policy to provide advance notice to users about major changes in methodology, source data, and statistical techniques. This usually is done in the Statistics Program, Strategy for the Development of National Accounts, and via regular publications for periods before the changes take effect. Examples where advance notice was provided in 
advance of such changes include the introduction of seasonally adjusted estimates; changes in business survey questionnaire, etc. Advanced notice is given for major changes in methodology (e.g., users are notified that 2012 data will accommodated new 2008 SNA classification of GFCF as a result of 2011 investment survey).

\subsection{Ethical standards}

\subsubsection{Guidelines for staff behavior are in place and are well known to the staff.}

On its website, the GEOSTAT states that the Fundamental Principles of Official Statistics developed by United Nations Statistical Commission were at core in drafting the Law on Statistics and consequently establishing the GEOSTAT

(http://www.geostat.ge/index.php?action=page\&p id=32\&lang=eng). The Fundamental Principles stipulate that for retaining trust in official statistics, the statistical agencies need to act according to strictly professional considerations, including professional ethics. New staffs are made aware of the ethical standards when they join the GEOSTAT.

\section{Methodological soundness}

\subsection{Concepts and definitions}

\subsubsection{The overall structure in terms of concepts and definitions follows internationally} accepted standards, guidelines, or good practices.

Quarterly and annual GDP estimates are produced based on the concepts and definitions recommended by the System of National Accounts 1993 (1993 SNA) under both the production and expenditure approaches.

\subsection{Scope}

2.2.1 The scope is broadly consistent with internationally accepted standards, guidelines, or good practices.

GEOSTAT has recently made improvements and implemented some recommended requirements, but more is to be done to meet the minimum scope requirements established by Inter-Secretariat Working Group on National Accounts (ISWGNA). The GEOSTAT compiles and disseminates the following core national accounts and aggregates: (i) annual and quarterly value added (VA) and GDP at current and constant (previous year) prices by activity; (ii) annual GDP by expenditure at current prices; (iii) annual rest-of-the-world accounts (up to net lending); (iv) annual sequence of accounts, except for the financial account, for the total economy. However, there is no GDP by expenditure approach at 
constant prices due to the absence of the export/import price indexes and problems in deflation of consumption.

Consumption of fixed capital has now been estimated with the historical time series back to 1996. A set of SUTs has now been prepared in more detail than the one compiled annually for the years since 1998. The latest SUT is available for 2009 with a breakdown of 67 products and 45 activities. In addition, the GEOSTAT compiles and disseminates quarterly and annual regional estimates of GDP. Regional estimates of Quarterly GDP are currently compiled using regionalization based on employment data from Household Budget Survey (HBS). HBS covers the whole territory and all types of households. Starting from 2006, annual regional accounts are complied following, in principle, ESA 95 methodology (combined methods). From 2007, the seasonally adjusted time-series were introduced. Work has started on compiling tourism satellite accounts. There are plans to establish sectoral accounts, starting from financial corporations and government sector in 2012 and households sector in 2013, subject to resource availability.

The definition of the economy and concept of residence are consistent with the 1993 SNA and the Balance of Payments Manual, fifth edition (BPM5). The whole territory of the country under control of the government is covered, including free zones (e.g., Poti). Parttime workers abroad (less than one year) are considered residents.

The definition of institutional unit is in accordance with the 1993 SNA, although data are collected at the enterprise level. The production boundary is in accordance with the 1993 SNA and includes in principle all of the following activities:

- Own-account production of goods for own-final consumption.

- $\quad$ Output of goods for own-account fixed-capital formation (separate data are available from business survey but not from other economic surveys).

- $\quad$ Research and development on own account is, in principle, is included but quality is hampered by the quality of source data that are (i) not of sufficient detail, (ii) are not compiled at the level of establishment. Data on the research activity of Academy of Science and other research institutions financed by the government are received from MOF with limited distinction between capital and current expenditures and limited detail.

- Mineral exploration.

- $\quad$ Production of computer software, entertainment, literary and artistic originals.

Although, the split between software and databases is difficult to make. The data collection is not done in sufficient level of detail to record separately entertainment, literary, and artistic originals.

Illegal output sold to willing buyers is not in the scope of output measurement. 
The assets boundary is generally in accordance with the 1993 SNA. Among tangible assets, agricultural work-in-progress is included in the scope of the assets boundary, including agriculture (breeding and for perennial crops). Land improvement in agriculture is included. The defense related assets that could be used for civilian purposes are included in the scope but not presented separately in the accounts. Historical monuments are not at present in the scope of capital formation. However, newly built churches are correctly included at cost of production. No estimates are made for valuables.

The following intangible assets are included based on information from annual business survey questionnaire (quarterly data are extrapolated using previous year structure): (i) mineral exploration, whether successful or not; (ii) systems and standard applications computer software and databases used for more than one year; (iii) entertainment, literary, or artistic originals; (iv) patented entities; and (v) leases and other transferable contracts.

\section{Recommendation:}

Set up the compilation system for GDP by expenditure approach in real terms.

\subsection{Classification/sectorization}

\subsubsection{Classification/sectorization systems used are broadly consistent with internationally accepted standards, guidelines, or good practices.}

The classification and sectorization used in the compilation of the national accounts are in conformity with internationally recommended standards. The national classification of economic activities (GNC 001-2004) is based on Standard Classification of Economic Activities within the European Communities (NACE Rev. 1.1) at five-digit level for declared output an intermediate consumption. For nonobserved economy (NOE) output -45 activities bridged to 5-digit level NACE. The national classification of products (CPA 002-99) based on Classification of Products by Activities (CPA) is used for classifying products (in some cases at section level and up to three-digit level). Government expenditures are classified according to the Classification of the Functions of Government (COFOG) at three-digit level. Household consumption, which was published earlier as a total figure, is now broken down according to the Classification of Individual Consumption according to Purpose (COICOP). Foreign trade is classified according to the International Harmonized Commodity Description and Coding System (HS) at six-digit level. The bridge table between product and activity classifications is obtained from the UNSD website and customised. No sectoral data are compiled.

NBG output is treated as nonmarket services that are consumed by government. The ancillary units are not treated as separate establishments. There are a large number of entities set up by central and local governments as legal entity of public law (LEPL) whose institutional sector 
status and coverage in GFS is uncertain. Some 3,000 of 5,000 plus LEPLs are schools. A detailed sectorization of LEPLs has not been done by MOF, so it is not known to which sector these units belong. Many LEPLs report to a line ministry, or to a local government. Many receive funding from the central budget, some have own-source revenue, and others are completely self financing. Some LEPLs also have the power to borrow. In the majority of cases the only data captured in the budget reporting system on LEPLs are the transfers to them from the State Budget or local government budgets. A minority of LEPLs are accounted for inside the State Budget, like a budgetary organization. Vouchers to students for education are treated as subsidies on product and not as social transfers in kind.

\section{Recommendations:}

Make efforts to compile data at establishments' level.

Resolve classification issues for transactions of LEPLs.

Reclassify vouchers to students for education from subsidies on product to social transfers in kind.

\section{$2.4 \quad$ Basis for recording}

\subsubsection{Market prices are used to value flows and stocks.}

The valuation rules used for recording flows and stocks are in accordance with the 1993 SNA. Market output is valued at basic prices. For households, output for own use is valued at equivalent market prices using average prices for analogous goods or services of the closest region. Nonmarket output is valued at cost.

Expenditure aggregates are valued at purchasers' prices, that is, including levied taxes on products and value added taxes (VAT) with the deductible (refunded) part excluded, as well as trade and transportation margins. Total exports and imports are recorded on a free on board basis. Imports and exports of goods in US dollars are converted into Georgian Lari using arithmetic quarterly average, rather than using the rate prevailing in the market at the time of transaction. General government consumption expenditure is recorded at cost including an estimate of the consumption of fixed assets (based on accumulated fixed assets of the government during 10 years period). Nonprofit institutions consumption expenditure is recorded at factor cost, but consumption of fixed capital is not included. Gross fixed capital formation (GFCF) is recorded at purchaser's prices, when the capital goods are purchased and estimated by cost for own-produced GFCF. The investment survey that is currently in progress will provide data on the stocks of fixed assets for all institutional sectors and by type of assets.

National Accounts 
The imputations are made when market prices are not observable. Imputed rent on owneroccupied dwellings is calculated using data from HBS together with data on the comparable rental values for similar dwellings from consumer price index collection. Starting form the first quarter of 2012, it is planned to implement the cost approach using the methodology recommended by the OECD. The transfer prices have been detected in the country mainly for Foreign Direct Investment enterprises (e.g., transportation of oil) and adjustments to market prices is done by external sector statistics.

\subsubsection{Recording is done on an accrual basis.}

In principle, enterprises are asked to provide data on an accrual basis in accordance with the recommendations of the 1993 SNA. Work-in-progress, including output in agriculture is recorded in the period that it is produced, based on business survey data. General government data on taxes and subsidies on products, and expenditure and revenue data, which are recorded on a cash basis, are not currently adjusted to an accrual basis. However, the plans are to adjust government data to accrual based on monthly data from Revenue Services on taxable turnover. Rest of the world data are recorded on an accrual basis.

\section{Recommendation:}

Implement adjustments procedure for accrual recording of general government data on taxes and subsidies on products, and expenditure and revenue data.

\subsubsection{Grossing/netting procedures are broadly consistent with internationally accepted standards, guidelines, or good practices.}

Since the compilation system is set up at the enterprise level, transactions between establishments within the same enterprise (which may be materially significant in Georgia for communication and trade enterprises) are not recorded on a gross basis. However, business survey data contains separate data on output for each kind of economic activity undertaken by an enterprise. Moreover, for the compilation of regional GDP estimates, when establishments of the same enterprise are located in different regions, the transactions between them are estimated on a gross basis using annual information on turnover and using wages as an indicator.

\section{Recommendation:}

Make adjustments to business survey questionnaire to be able to make adjustments for gross recording of transactions between establishments, starting from communication and trade activities. 


\section{Accuracy and reliability}

\subsection{Source data}

3.1.1 Source data are obtained from comprehensive data collection programs that take into account country-specific conditions.

The design of data collection program employed for national accounts compilation is adequate for annual and quarterly compilation of GDP by production and expenditure approaches. The following table presents the composition of data sources with the discrete data for both, annual and quarterly GDP compilation. 
Table 1. Composition of Data Sources

\begin{tabular}{|c|c|}
\hline NACE & Main Sources \\
\hline \multicolumn{2}{|l|}{ Production approach } \\
\hline $\begin{array}{l}\text { Agriculture, forestry, hunting } \\
\text { and fishing }\end{array}$ & $\begin{array}{l}\text { Annual and quarterly agricultural survey (production quantities, no prices). } \\
\text { Annual value of sales by product. } \\
\text { Data from business survey on farms (for verification only). } \\
\text { Data on fishing are based on quarterly HBS). }\end{array}$ \\
\hline Mining and quarrying & $\begin{array}{l}\text { Business survey - quarterly and annual output, and annual intermediate } \\
\text { consumption. } \\
\text { Number of employed people from HBS (source for calculation of } \\
\text { nonobserved economy (NOE)). }\end{array}$ \\
\hline Manufacturing & $\begin{array}{l}\text { Business survey - quarterly and annual output, and annual intermediate } \\
\text { consumption. } \\
\text { Number of employed people from HBS (source of calculation of NOE). }\end{array}$ \\
\hline $\begin{array}{l}\text { Electricity, gas, and water } \\
\text { supply }\end{array}$ & $\begin{array}{l}\text { Business survey - quarterly and annual output, and annual intermediate } \\
\text { consumption. }\end{array}$ \\
\hline Construction & $\begin{array}{l}\text { Business survey - quarterly and annual output, and annual intermediate } \\
\text { consumption. } \\
\text { For construction activity outside the coverage of business survey, the labor } \\
\text { input method is not considered effective. Therefore, the specialized survey } \\
\text { on construction was conducted in } 2007 \text { based on business survey frame (for } \\
\text { individual entrepreneurs) augmented by data from HBS. } \\
\text { Administrative data for public infrastructure (from GFS). }\end{array}$ \\
\hline $\begin{array}{l}\text { Trade, repair of motor } \\
\text { vehicles, and personal and } \\
\text { household goods }\end{array}$ & $\begin{array}{l}\text { Business survey - quarterly and annual output, and annual intermediate } \\
\text { consumption. } \\
\text { HBS data for informal trade (bazaars). } \\
\text { Trade margins from SUT. } \\
\text { The Retail Trade Survey conducted in } 2007 . \\
\text { Financial Statement Analysis. } \\
\text { External trade for NOE. }\end{array}$ \\
\hline $\begin{array}{l}\text { Restaurants and hotels } \\
\text { accommodation, and food } \\
\text { Services }\end{array}$ & $\begin{array}{l}\text { Business survey - quarterly and annual output, and annual intermediate } \\
\text { consumption. No labor input method is used. } \\
2007 \text { specialized survey of restaurants for } 2006 \text { data. } \\
\text { There are plans to use data from tourism survey. }\end{array}$ \\
\hline $\begin{array}{l}\text { Transport, storage, } \\
\text { postal, and } \\
\text { warehousing }\end{array}$ & $\begin{array}{l}\text { Business survey - quarterly and annual output, and annual intermediate } \\
\text { consumption. HBS data for NOE component of transport. }\end{array}$ \\
\hline Communication & $\begin{array}{l}\text { Business survey - quarterly and annual output, and annual intermediate } \\
\text { consumption. } \\
\text { Social statistics, survey on employment. }\end{array}$ \\
\hline Financial intermediation & $\begin{array}{l}\text { Monthly NBG data on depository corporations, suitable also for estimating } \\
\text { FISIM. } \\
\text { Quarterly NBG data on premiums and claims of insurance companies. }\end{array}$ \\
\hline $\begin{array}{l}\text { Real estate, renting and } \\
\text { business services }\end{array}$ & $\begin{array}{l}\text { Business survey - quarterly and annual output, annual intermediate } \\
\text { consumption. } \\
\text { HBS for rent for owner occupied dwelling, different weights are used for } \\
\text { sampling separately for Tbilisi, other urban areas, and other rural areas. }\end{array}$ \\
\hline Public administration & Consolidated Budget of Georgia from MOF based on COFOG. \\
\hline Education & $\begin{array}{l}\text { Business survey - quarterly and annual output, and annual intermediate } \\
\text { consumption. }\end{array}$ \\
\hline
\end{tabular}




\begin{tabular}{|c|c|}
\hline NACE & Main Sources \\
\hline & $\begin{array}{l}\text { Subsidies and vouchers for education from the government are used for } \\
\text { validation of output data. }\end{array}$ \\
\hline Health and social work & $\begin{array}{l}\text { Business survey - quarterly and annual output, and annual intermediate } \\
\text { consumption. } \\
\text { Health subsidies from the government are used for validation of output } \\
\text { data. }\end{array}$ \\
\hline $\begin{array}{l}\text { Other community, social and } \\
\text { personal services }\end{array}$ & $\begin{array}{l}\text { Business survey - quarterly and annual output, and annual intermediate } \\
\text { consumption. } \\
\text { Annual survey of nonprofit institutions serving households (NPISH) } \\
\text { (starting from 2007). } \\
\text { This section accounts for around } 4 \text { percent of GDP, with several activities } \\
\text { blended together. }\end{array}$ \\
\hline Expenditure approach & Main Sources \\
\hline $\begin{array}{l}\text { Household final consumption } \\
\text { expenditure }\end{array}$ & $\begin{array}{l}\text { Quarterly HBS following COICOP classification. } \\
\text { Own account nonmarket production is covered. } \\
\text { The data are compared with SUT (the latest is of 2009). Housing rents } \\
\text { (HBS, questionnaire 01). } \\
\text { Health expenditure from HBS. } \\
\text { NBG data on financial services (including FISIM). } \\
\text { Education, entertainment and miscellaneous services - data from HBS are } \\
\text { verified via various source data. } \\
\text { BOP Data on tourism, health, and education. } \\
\text { Household Expenditure Survey - (questionnaires } 03 \text {-04). }\end{array}$ \\
\hline $\begin{array}{l}\text { Government final consumption } \\
\text { expenditure }\end{array}$ & $\begin{array}{l}\text { Monthly government data on government expenditures by COFOG, with } \\
\text { the split into individual and collective consumption expenditure (education, } \\
\text { health care and cultural). }\end{array}$ \\
\hline Gross Fixed Capital Formation & $\begin{array}{l}\text { Business survey for corporations (including own-produced capitalized } \\
\text { goods) } \\
\text { General Government - data from GFS. }\end{array}$ \\
\hline Changes in inventories & $\begin{array}{l}\text { Business survey questionnaire request information on four types of } \\
\text { inventories. } \\
\text { SUT goods are balanced by changes in inventories. }\end{array}$ \\
\hline Exports of goods and services & BOP data form NBG. \\
\hline Imports of goods and services & BOP data from NBG. \\
\hline
\end{tabular}




\section{Business Register}

A centralized State Business Register is established in GEOSTAT based on registrations of legal entities and contains around 360,000 private companies and individuals. The maintenance of register is to be improved. It is believed that some enterprises do not register, but the situation is gradually improving. The register distinguishes between legal entities and individual entrepreneurs (physical persons registered as entrepreneurs) and contains active as well as nonactive entities. For statistical surveys, the updated register is maintained based on the following procedures:

- $\quad$ Every month Public Registry from Ministry of Justice provides information on newly registered enterprises.

- Every quarter the survey on actualization of register is conducted for new enterprises, but not for individual entrepreneurship activity (economic activity; status (active or nonactive), contact information, number of employees.

- $\quad$ Following the relevant government Resolution, the Revenue Service of Georgia on the quarterly basis provides GEOSTAT with the list of active business entities by type of activity. The intention is to provide activities by NACE sections, however NACE codes are not always attributed (only 60 percent include clear activity attribution) and contact information is not included in the database).

- $\quad$ The updates are done using quarterly (8,500 enterprises in the sample) and annual (12,500 enterprises in the sample) business surveys.

- Occasionally, the ad hoc surveys of individual economic activity are conducted (up to 7,000 entities). It is planned to conduct microeconomic census of NACE Section G activity (excluding individual entrepreneurs) in 2012.

These procedures ensure that the new units are added on a timely basis, but not necessarily that defunct businesses are removed from the register. The GEOSTAT Business Statistics Division employs seven staff to work on the register, which is considered to be sufficient.

\section{Business Survey}

In principle, business survey data are sufficiently detailed to derive all key GDP components. Quarterly and annual output and fixed capital formation, intermediate consumption, and four types of changes in inventories are compiled for around 360 NACE activities at customized aggregation level for each NACE section. NAD GEOSTAT has recently conducted the Detailed Survey on Investments in Fixed Capital. The survey results will allow compiling the capital account data following the 2008 SNA methodology.

The coverage of the business survey is not considered to be comprehensive as there have been no economic censuses in observable past. The business survey is conducted with quarterly and annual periodicity. The survey covers all economic activities, except agriculture, which is covered by survey conducted by Agricultural and Environment Statistics Division, and activities of the financial sector, which are covered by a National 
Bank of Georgia data collection. The survey frame is based on the operational updated statistics register, which contains 40000 entities, covering nonfinancial enterprises and the Non Profit Institutions Serving Households (NPISH). In 2009, the GEOSTAT carried out the actualization of survey population, the whole base is normally updated every 5 years. The producing unit in the register is enterprise which may consist of one or more local units within a territory of Georgia.

The survey entails full coverage of registered large enterprises (around 2000 with either more than 1.5 Million GEL of turnover or more than 100 employees) and sampling of the small and medium enterprises stratified by size, kind of activity, and using random sample techniques. The quarterly regular sample size is 8,500 enterprises and annual $-12,500$ enterprises. Three types of survey questionnaires (annual, quarterly, and for small enterprises) are constructed according to sound design principles and underwent through field testing.

The coverage of the total activities in terms of value added is considered incomplete. The coverage of industry (in terms of value added) is considered to be good; the coverage for transport and communications is satisfactory; while the coverage of retail trade, construction, catering, and services is considered to be poor. The business survey does not survey routinely the activity of individual entrepreneurs (unincorporated enterprises), which for some activities, e.g., trade, comprises more than 50 percent. To overcome the coverage problem, the ad hoc specialized surveys are carried out (e.g., the Retail Trade Survey was conducted in 2007 with the objective to repeat it every five years; 2007 survey on NOE in construction, restaurant and repair services). Other community, social and personal activities (NACE, Section O), which accounts for around four percent of GDP, are stratified in one group, which may result in sample errors. In addition, starting from 2007, annual sample survey of NPISH has been established with target population of around 2500 entities and sample size of 400 entities.

\section{Agriculture Survey}

The sample frame of the survey of agriculture is based on the 2004 Census of Agriculture. There are about 815 thousand household farms that are included in the survey frame, which is considered to be a sound sample size. An annual rotating sample technique is applied, where five thousand household farms are surveyed five times per year (annual survey and four quarterly surveys). The two stage sample design is applied. The first stage is a stratified random sample of villages within a region and the second stage - of households within a village. Each region had its own unique village strata and holding strata criteria, based on targeted commodities of importance in each region. Grossing-up factors are derived scientifically, based on sample design. Data for 45 types of agricultural products contain cultivation area by crop, changes in quantity of livestock, sales, and selected types of expenditures. 


\section{Household surveys}

The survey has started in 1996 with Statistics Canada's and World Bank's financial and technical assistance. The survey methodology seems to be relatively sound even though the estimates of sampling errors and potential nonsampling errors and biases are likely not effectively used to inform and update the survey cluster. The questionnaire and the sample designs have been kept largely unchanged since then. The HBS is part of the Integrated Household Survey that consists of 7 separate annual, quarterly or monthly questionnaires. The survey is based on the 2002 population census, covers all types of households from all regions, and has a regular sample size of 3500 households. For 2008-09 the sample size was doubled to 7000 households with funding from Millennium Challenge Georgia. A two-stage scientific stratified sample is drawn and selected households rotated on monthly basis. Grossing-up factors are derived scientifically, based on sample design. The expenditure items are based on the COICOP groups. Data collected are sufficiently detailed and cover purchases of consumption goods and services, purchases of durable goods, production (including for own-consumption), and own-account fixed capital formation. In addition, data on employment in the informal sector are collected for the needs of the national accounts compilation. The major issue is underreporting.

\section{Other sources}

Comprehensive GFS on cash basis are available from MOF on a monthly basis for central government and local government. Data include all defense related expenditures.

Consolidated budget data by organization and based on COFOG are not considered detailed enough to properly estimate intermediate consumption. Data on change in nonfinancial assets are not considered to be sufficient to properly derive consumption of fixed capital. It is also difficult to reconcile data derived from business survey with related data from the MOF, for instance for health and education.

Monthly data for the depository corporations on an accrual basis and quarterly data for other financial corporations are received from the NBG and considered to be sufficiently detailed for the compilation of the national accounts aggregates on financial services. Data on the balance of payments statistics are received on a quarterly basis from the NBG and contain all the necessary detail for the compilation of the national accounts.

Main price indices available monthly are the consumer price index (CPI) for all basket items and the producer price index (PPI) at three level NACE (Sections C, D, and E). Price indices for transport at two digit level of NACE, and for construction - prices for two types of activities are available. Price indices for 45 types of agricultural products are available. No exports and imports price indices are compiled.

Administrative data on value-added tax taxes from Revenue Services are provided following government Resolution and contain quarterly list of active business entities by NACE sections. Also, data from line ministries (e.g., data from Ministry of Health on number of employees in health sector, and data from Ministry of Education on number of lecturers and number of students) support the main data collection. 


\section{Recommendations:}

To improve coverage of business survey, conduct economic census of nonfinancial corporations and update the register.

Refine the register maintenance procedures, especially with regard to removing the defunct businesses from the register.

Ensure more detail in business survey for other community, social, and personal activities.

Cooperate with MOF to obtain consolidated budget data by organization and based on COFOG at the level of detail that would allow for better estimates of intermediate consumption.

Conduct ad hoc investment survey to be able to derive better estimates for consumption of fixed capital.

Set up the compilation of export/import price indices.

Update the sample frame for the quarterly agriculture sample survey.

3.1.2 Source data reasonably approximate the definitions, scope, classifications, valuation, and time of recording required.

GEOSTAT relies on various source data and makes adjustments to improve accuracy of source data to produce GDP estimate, but some gaps remain. GEOSTAT business surveys (including agriculture survey), monetary, government finance, and balance of payments statistics are designed to collect data consistent with the SNA definitions. The NAD staff cooperates with other GEOSTAT divisions in designing the surveys that would meet SNA requirements. Despite these procedures, some coverage and valuation issues remain. Quarterly IC data from business survey seem to be prone to under coverage; therefore, the growth rate is used to extrapolate data from previous year.

In 2010, NOE for all activities combined comprised around 20 percent and varied up to more than 50 percent for selected activities (trade, and other community, social, and personal services). The labor input data from business survey are compared with labor data from HBS to determine part that is not covered by business survey. For education, following the results from specialized household survey on education, it is believed that up to 20 percent of total education output is produced by private tutors. The relevant coverage adjustments are made in national accounts data. The GEOSTAT plans to conduct specialized survey on education in 2012.

Administrative data from other government agencies, which use different definitions, level of detail, or time of recording, are also adjusted to meet to national accounts requirements. Only around 60 percent of value-added tax data from Revenue service include clear activity attribution. 


\subsubsection{Source data are timely.}

All source data are available on a timely basis. Balance of payments statistics is available with 85 days timeliness, monetary statistics -30 days after the reference month, monthly state budget data are available with 30 days timelines and monthly consolidated budget - 70 days after the reference quarter. There may be some delays with quarterly data on premiums and claims for insurance companies, related to accounting procedures. Data from other GEOSTAT divisions are provided on timely basis following timeliness established in the GEOSTAT Program.

\subsection{Assessment of source data}

\subsubsection{Source data-including censuses, sample surveys, and administrative records-are} routinely assessed, e.g., for coverage, sample error, response error, and nonsampling error; the results of the assessments are monitored and made available to guide statistical processes.

For business survey, data entry is done by the GEOSTAT central office. The reported data go through initial plausibility and consistency checks. High-value transactions are confirmed with respondents. Survey errors are routinely assessed. If sample error is high, the stratum is collapsed to an upper digit level. Confidence intervals are calculated for all variables to assess the accuracy. Nonresponses are sorted by seven reasons and analyzed ( 88 percent of nonresponse rate pertain to small enterprises), but results of this analysis is yet to be used to improve the data collection process. No consistency checks are performed with other data sources (e.g., administrative) and no adjustments are made to the survey results. The nonresponse rate has noticeably increased over last year.

The HBS has recently introduced additional validation. This has reportedly improved the data accuracy but uncertainty about under and misreporting remains. Sampling errors are available and adjusted for nonresponse but they are not used to improve the data collection process. In addition to several plausibility and consistency checks, data are subject to checks for data entry errors with double entry bookkeeping. Data of all 200 interviewers are verified and randomly checked by field supervisors, who in turn are monitored and randomly checked by central office expert. Logical controls within each questionnaire are computerized and erroneous or misreported data are removed from the database. No consistency checks are performed with other data sources (e.g., administrative) and no adjustments are made to the survey results. There's roughly a 15 percent quarterly nonresponse. GEOSTAT is considering cooperation with Statistics Netherlands on improving the quality of HBS.

The accuracy of source data, such as government finance statistics, balance of payments data, and the price data is routinely assessed. 


\subsection{Statistical techniques}

\subsubsection{Data compilation employs sound statistical techniques to deal with data sources.}

Surveys conducted by GEOSTAT employ sound statistical techniques, based on experts' advice relating to the survey design and compilation. The computer software (based on SQL and Access) used to process survey results helps to minimize processing errors through the embedded checking procedures. Adjustments for outliers and nonresponse are made using sound statistical techniques. The special procedures are applied to improve consistency between the sum of the sample weights and the targeted population. Small-scale special collections are used to validate major source data.

\subsubsection{Other statistical procedures (e.g., data adjustments and transformations, and statistical analysis) employ sound statistical techniques.}

The GEOSTAT makes significant efforts to ensure the exhaustiveness of the GDP estimates. Activities of NOE are separately identified in the accounts. In addition to specialized surveys, the SUT data, data from the HBS, and administrative data are scrutinized to ensure coverage of all NOE components. Estimates for the NOE are made for both the production and the expenditure approach for compiling GDP. For agriculture, the output and intermediate consumption is estimated on the basis of the commodity flows for agricultural goods as well as data on area planted, livestock numbers, and productivity. Adjustments to the foreign trade data for nonrecorded exports and imports are made by the balance of payments compilers.

\section{Production approach procedures}

The annual and quarterly accounts are compiled at a sufficient breakdown by economic activities (360, NACE section level in the publication). There is no use of outdated fixed input - output ratios; however, in some cases the ratios based on annual data of previous year are used. The final national accounts estimates for value added by industry are validated using the annual SUT tables. For health and education, quarterly data coverage for both Output and intermediate consumption (IC) is considered to be insufficient - the quarterly gross rates from previous year are used to extrapolate data.

The output of owner-occupied dwellings is shown separately in publication and valued at the estimated rentals that tenants would pay for similar accommodation. Data collected by HBS (self-assessment of such rentals) contain weight from sampling separately for Tbilisi, other urban areas, and other rural areas. The HBS data are also cross-checked with information on rent is available from the consumer price index collection. More detail for input-output ratio is needed. It is planned to implement user cost method (total cost of maintenance, consumption of fixed capital, and return to capital) using Polish experience.

Work in progress is estimated for growing crops, livestock reared for food, large construction projects and output of large equipment. For data from agriculture, the annual output is 
allocated proportionally using the allocation coefficients by type of product. There were no benchmark estimates in observable past, so the coefficients need update and revision.

Inventory valuation adjustments are made in the calculations of output and in the calculations of intermediate consumption, in accordance with the internationally recommended practices. The questionnaires request information on changes in inventories by type. However, there is no information on the inventory valuation method prevailing in the country's bookkeeping practice so the quality of adjustment for holding gains/losses is difficult to assess.

Contrary to the recommendation of $S N A$ and best practices, the perpetual inventory method is not used as the basis for estimating consumption of fixed capital. The estimates are based on the book-keeping values. Government expenditure and revenue data, as well as taxes and subsidies on products, are valued on a cash basis.

Overall, the compilation methods for the volume measures have been improved, but yet to be completely adhering to best practices. The double indicator method is used to obtain real value added in most activities. Output is deflated by PPI at three digit level of NACE, C, D, E sections, transport, and construction. For renting activity output deflated using CPI, for agriculture - using implicit price indicators. Intermediate consumption is deflated by CPI by forty-five activities from sixty seven products, derived using bridge tables based on SUT structure of IC. Public administration, health, and education activities in real term are calculated based on number of employed from HBS (for estimating real growth rate) and implicit price indices.

Volume measures of taxes and subsidies on products are estimated by deflation of the current values using the total CPI (except for CPI element for renting activities) to deflate rather than by applying base-year tax rates to the volume of the transactions taxed or subsidized. The volume of trade margins is estimated by deflating the current values using sub-groups of the $\mathrm{CPI}$, rather than by applying base-year trade margins as a percentage of sales to the volume of sales in the current year.

GDP volume measures are compiled using the successive multiplication of chain links each derived using a Laspeyres-type formula with the reference period of 2003. For quarterly GDP estimation, two methods are used, namely quarterly to the same quarter of previous quarter and the annual overlap method, which uses average price data from the previous year.

\section{Expenditure approach procedures}

The GDP estimates by expenditure approach in current prices are derived independently. In particular, independent estimates are compiled for household final consumption expenditure (at five digit level of COICOP); government final consumption expenditure (at two digit level of COFOG); gross fixed capital formation and changes in inventories (by activities at section level of NACE and 67 products). Expenditures of residents abroad are included in household final consumption expenditure and in imports of services. Expenditures of nonresidents in the economy are excluded from household final consumption expenditure 
and included in exports of services. Discrepancies between GDP by production and GDP by expenditure are shown explicitly in the publication (See 3.4.3).

\section{Other specific quarterly compilation techniques}

A technique used to align annual and quarterly data is proportional distribution of the difference between annual estimate and the sum of the four quarters to the unadjusted quarterly data. This technique is not appropriate as it introduces a step problem - a distortion of the growth rate between the last quarter of every year and the first quarter of the following year. An appropriate technique, as the Denton method should be used for benchmarking the quarterly estimates to the respective annual data.

Estimates of quarterly GDP are derived from unadjusted source data and subsequently seasonally adjusted. Both time series are published. The seasonally adjusted time series are derived using software application Demetra + , using X-12 ARIMA method for national accounts time-series and TRAMO\&SEATS method (Time series Regression with ARIMA noise, Missing values and Outliers \& Signal Extraction in ARIMA Time Series) for IPI timeseries.

\section{Recommendations:}

Refine estimates of the volume measures of the trade margin and taxes by applying base-year tax rates to the volume of the transactions taxed or subsidized.

Use the Denton method to adjust quarterly original estimates to agree with annual benchmark estimates.

Update the coefficients used for the quarterly allocation of work in progress in agriculture.

\subsection{Assessment and validation of intermediate data and statistical outputs}

\subsubsection{Intermediate results are validated against other information, where applicable.}

Intermediate data are validated using time-series analysis combined with the cross checking with independent data sources such as employment statistics and tax data from Revenue Service.

\subsubsection{Statistical discrepancies in intermediate data are assessed and investigated.}

Assessments of potential discrepancies of major intermediate data are undertaken, and adjustments are made to remove the discrepancies. In particular, the following ratios are checked thoroughly: intermediate consumption/gross output, gross value added/gross output, consumption of fixed capital/gross output. In addition, the value added structure by industries is also checked for temporal consistency. Proper adjustments are made to remove the discrepancies. 


\subsubsection{Statistical discrepancies and other potential indicators of problems in statistical outputs are investigated.}

The statistical discrepancy for 2010 annual GDP by production and expenditure approach is about 1 percent, but volatile and reach up to 3 percent in size for quarterly data.

Discrepancies are shown explicitly in publication. Recently improved SUT are used to make the estimates more consistent. No studies about the bias in the GDP estimates are performed.

\subsection{Revision studies}

3.5.1 Studies and analyses of revisions are carried out routinely and used internally to inform statistical processes ( see also 4.3.3).

The GEOSTAT does not conduct systematic revision studies. The NAD analyses direction and magnitude of revisions between preliminary and final data, but there is no documentation of the sources of errors, omissions, and fluctuations in the data. The results of investigations and adjustments made in the statistical processes are taken into account in compiling the data for the subsequent periods.

\section{Recommendation:}

Repeat from time to time comprehensive analyses of revisions to the data to inform statistical processes.

\section{Serviceability}

\subsection{Periodicity and timeliness}

\subsubsection{Periodicity follows dissemination standards.}

Georgia meets the SDDS with respect to the periodicity of the GDP estimates. Quarterly GDP estimates are compiled and disseminated.

\subsubsection{Timeliness follows dissemination standards.}

The timeliness of quarterly GDP estimates exceeds SDDS requirements. It has been recently improved to 80 days after the reference period.

Monthly flash estimate of GDP in growth rates are available approximately 30 days after the end of the reference month. 


\subsection{Consistency}

\subsubsection{Statistics are consistent within the dataset.}

The official estimates of GDP for Georgia are derived using the production approach. The estimates for GDP by production and expenditure approaches in current prices have an explicit statistical discrepancy, which is around one percent of GDP but volatile over time. Also, an explicit statistical discrepancy shown in the accounts pertains to a discrepancy between the sum of saving and capital transfers and the sum of gross capital formation and net lending/net borrowing.

The GDP by production at constant prices are consistent with those in current prices, and the implicit deflators are consistent within the "value $=$ volume $\times$ price" framework. Users are notified about nonadditivity of the chain-linked volume measures.

In the supply and use tables, supply of goods and services adjusted by NOE is balanced with the use through the changes in inventories (for goods) and through final consumption expenditures of the households (for services). Aggregates published in the input-output tables are consistent with the annual accounts estimates for the relevant year.

The quarterly and the annual GDP estimates are consistent. The conceptual framework and, in most cases, sources and methods (including index formula and base year) used for the quarterly and annual GDP compilation are the same. Quarterly accounts are benchmarked to annual accounts by prorating the difference over the quarters, but not making an appropriate use of Denton technique.

\subsubsection{Statistics are consistent or reconcilable over a reasonable period of time.}

Consistent annual and quarterly time series are published from 2003 (reference year). The quarterly estimates are consistent over time. Consistent historical time-series were reconstructed for 1996 - 2003 and offered to users upon special request. In explanatory notes within the national accounts publications, the GEOSTAT informs users about unusual changes in the economic trends. For instance, users were notified about the impact on the result of 2006 business survey on the estimates of output and the trends in NOE estimates with this regard. Chain-linked quarterly time series are published from 2003.

Advanced notice is given for major changes in methodology (e.g., users are notified that 2012 data will accommodate new 2008 SNA classification of GFCF as a result of 2011 investment survey).

\subsubsection{Statistics are consistent or reconcilable with those obtained through other data sources and/or statistical frameworks.}

National accounts data for the rest of world are consistent with BOP data. The BOP data are used directly in the national accounts after being converted to the national currency using average exchange rate for the respective quarter. Net lending/net borrowing is not entirely 
consistent with the BOP financial account. Data on capital transfers receivable and payable are consistent with the relevant BOP capital account data. Data on current transfers in secondary distribution of income account are consistent with the relevant BOP component. Data on import and export of goods and services for the GDP by the expenditure approach are consistent with the BOP current account data. Government finance statistics are used directly in the national accounts after making appropriate adjustments for consumption of fixed capital.

NBG provide monthly monetary and financial statistics data on depository corporations and quarterly data on insurance companies, which are used for compilation of the production accounts for financial corporations' sector including for calculation of FISIM.

Implicit price deflators are comparable with published producer price indices.

\subsection{Revision policy and practice}

\subsubsection{Revisions follow a regular and transparent schedule.}

The revision cycle of the national accounts follows a regular schedule, determined on the basis of the availability of source data and the timing of revisions to related datasets. Revisions to quarterly data can be made with each quarterly release, although most revisions are made following annual estimates. Upon completion of annual estimates, the quarterly data for four quarters of reference period and two available quarters of the current period are revised. At the end of March (80 days timeliness) each year preliminary annual production estimates are released for the reference period, followed by final estimates in 11 months after the reference period (November) after completion of the SUT tables (published at the end of December). In most cases revisions do not affect the trends in the time series in real terms. Special revisions, due to the introduction of new data sources (e.g., results of 2007 survey of NOE survey) are not explained to public.

Public is not well informed about the revision policy.

\section{Recommendation:}

Enhance communication with users about revision policy.

\subsubsection{Preliminary and/or revised data are clearly identified.}

Users are made aware that data are subject to revision. The preliminary estimates are clearly identified in the databases that are available to users, with expected date of revision. The revised data are disseminated with the same level of detail as those previously published. The hard copy publications with final data have no indication whether the data have been revised.

\subsubsection{Studies and analyses of revisions are made public (see also 3.5.1).}

Differences between the preliminary and final data are not explained to users.

National Accounts 


\section{Recommendation:}

Enhance communication with users regarding revision studies and analysis of revisions.

\section{Accessibility}

\subsection{Data accessibility}

\subsubsection{Statistics are presented in a way that facilitates proper interpretation and meaningful} comparisons (layout and clarity of text, tables, and charts).

In recent years there have been a lot of improvements in data dissemination practice. The level of detail is sufficient for analysis. The GEOSTAT website was developed with elaborated annual and quarterly national account time series. In 2004, the new annual publication on national accounts was issued with more detail. The following national accounts estimates are disseminated: (i) gross output by type of economic activities one digit level of NACE, at current prices; (ii) intermediate consumption by types of economic activities, at current prices; (iii) GDP by types of economic activities, at current prices;(iv) GDP at constant (2003) prices; (v) GDP growth indices (real growth, chain-linked, cumulative), to the same period of the previous year; (vi) GDP by categories of use, at current prices; (vii) generation of income account; (viii) gross national income and other aggregates of national accounts up to financial account; (ix) gross value added by regions, at current prices; (x) supply and use tables (by type of economic activities and products 15/15, 19/27 and 45/67); (xi) share of NOE output to total output by type of economic activities; (xii) labor productivity at current and constant (2003) prices; (xiii) production indices; and (xiv) seasonal adjustments. The deflators of GDP are published, including the chain-linked time series. A limited number of charts are included and accompanied by brief analysis of recent trends.

\subsubsection{Dissemination media and format are adequate.}

The dissemination format is adequate. The annual and quarterly preliminary estimates are disseminated first by a press release. Selected time series can be downloaded from the GEOSTAT website in Excel format. Following Article 27 of the Law on Statistics, the GEOSTAT disseminates statistical data in electronic form free of charge; and charges all the users except the administrative bodies for the printed statistical publications.

\subsubsection{Statistics are released on a preannounced schedule.}

Schedule of statistical release is backed by legislation. Article 7 of the Law on Statistics obliges GEOSTAT to produce the schedule for promulgation of the statistical data and ensure its publicity; as well as disseminate the statistical data in observance of this schedule. The GEOSTAT disseminates an advance release calendar, which includes the national accounts statistics, for the forthcoming year on a month by month basis. 


\subsubsection{Statistics are made available to all users at the same time.}

Article 7 of the Law on Statistics explicitly stipulates that GEOSTAT secures the equal access to the statistical data for all the users. This principle is strictly followed.

\subsubsection{Statistics not routinely disseminated are made available upon request.}

Unpublished but nonconfidential customized data are made available to users upon request, which is publicized on the GEOSTAT website. The users' survey indicates that GEOSTAT is responsive to their requests.

\subsection{Metadata accessibility}

5.2.1 Documentation on concepts, scope, classifications, basis of recording, data sources, and statistical techniques is available, and differences from internationally accepted standards, guidelines, or good practices are annotated.

There is no detailed information on data sources and methods for compilation of national accounts in Georgia. The short summary of general methodology is available in the annual publication of national accounts and on the website. Also, the list of data sources is available on the web under the GDP General Methodology heading. The National Summary Data Pages with the SDDS data categories is disseminated in accordance with the electronic procedures established by the IMF to facilitate quarterly certification of the national metadata for national accounts and IPI. The GEOSTAT website contains references to the elaborated list of documents related to internationally accepted standards.

\section{Recommendation:}

Develop and disseminate detailed documentation on data sources and methods for compilation of national accounts in Georgia.

\subsubsection{Levels of detail are adapted to the needs of the intended audience.}

Metadata are not made available at different levels of detail.

\subsection{Assistance to users}

\subsubsection{Contact points for each subject field are publicized.}

The GEOSTAT website and all statistical publications contain the mailing address, telephone and fax numbers, and e-mail address of the GEOSTAT. The proper procedures are in place to redirect queries to the specific division. National accounts staff promptly and knowledgeably handle all inquiries. Recently, a lot of work has been done by GEOSTAT management to raise awareness of the use of statistics (e.g., for other government agencies, businesses, etc.). 
5.3.2 Catalogs of publications, documents, and other services, including information on any charges, are widely available.

A catalog of publications is provided on the GEOSTAT website. Users can download annual, quarterly, and monthly publications, as well as archived publications and specialized releases from the GEOSTAT website free of charge. 
Table 2. Data Quality Assessment Framework (July 2003): Summary of Results for National Accounts

(Compiling Agency: National Statistics Office)

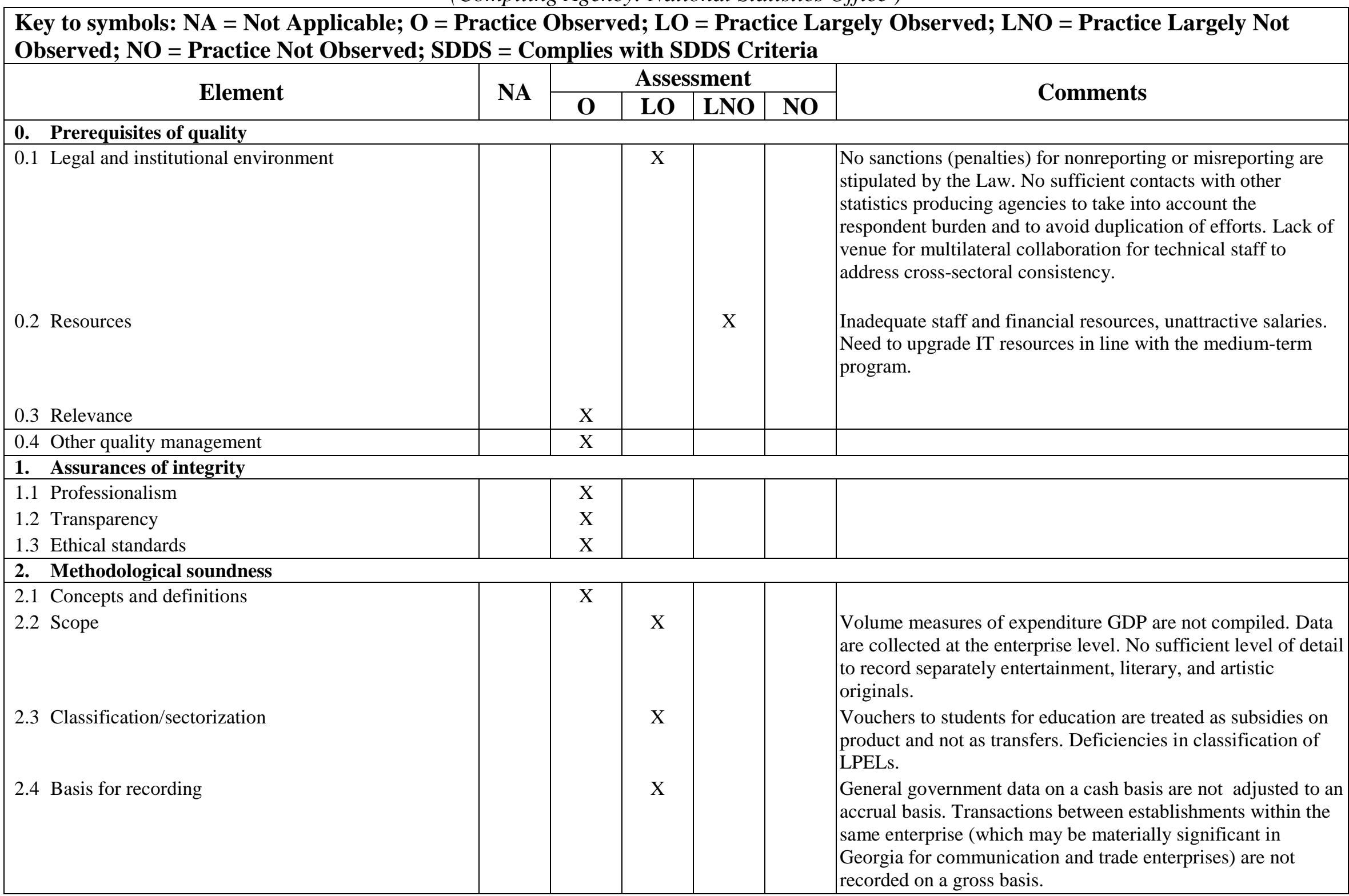


Table 2. Data Quality Assessment Framework (July 2003): Summary of Results for National Accounts

(Compiling Agency: National Statistics Office)

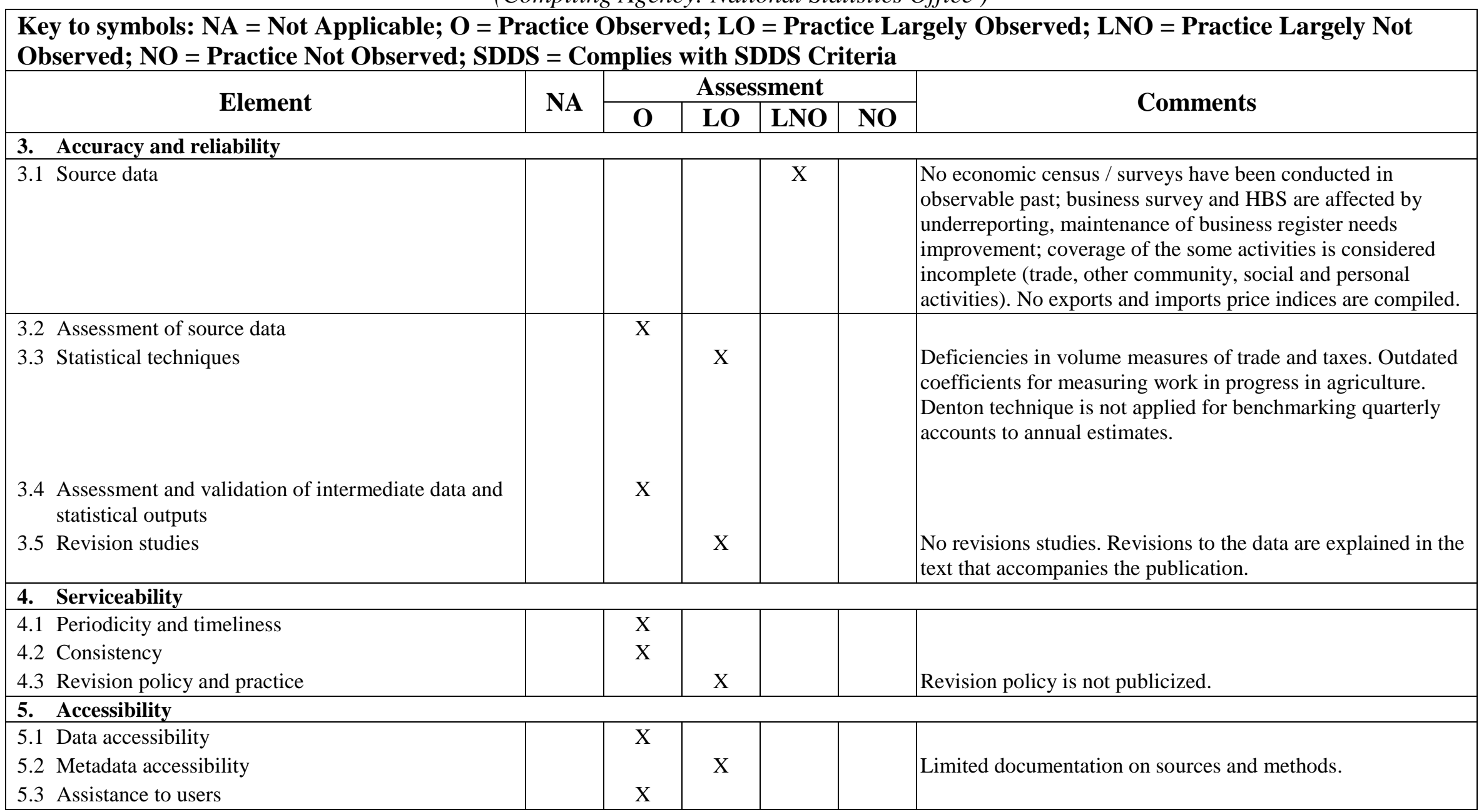




\section{Price Statistics (Consumer Price Index)}

\section{Prerequisites of quality}

\subsection{Legal and institutional environment}

\subsubsection{The responsibility for collecting, processing, and disseminating the statistics is clearly specified.}

The GEOSTAT was established as an independent legal entity under the Law on Statistics of December 11, 2009, N 2291-rs to be responsible for compiling and disseminating official statistics. Article 9 of the Charter of GEOSTAT (approved by the Presidential Decree no.72 on February 1, 2010) mandated GEOSTAT to be in charge of all collection and dissemination of official statistics as well as the improvement in the coverage and quality of official data responsible by GEOSTAT as well as by other government agencies. Article 7 of the Law authorizes the GEOSTAT to work out a statistical activities program; and carry out statistical activities, which sets the central position of the GEOSTAT in the Georgian statistical system.

Accordingly, collecting, compiling and disseminating CPI and PPI and analyzing the inflation dynamics are defined as the main functions of the Price Statistics Division of GEOSTAT. No other institution compiles alternative inflation estimates.

Article 25 of the Law on Statistics authorizes GEOSTAT to request from the administrative bodies and other physical and legal entities and receive all the statistical and other information (including confidential information) from them necessary for carrying out its functions.

Arrangements to promote consistency of methods and results are set up by the Board of the GEOSTAT, which has representatives from other data producing agencies, namely the NBG, the MOE, and the MOF.

In addition to that, the President of Georgia approves annual State Program for Development of Statistics. The compilation and dissemination of price statistics are stated in the State Program (e.g., for current year there is an updates on CPI weights).

\subsubsection{Data sharing and coordination among data-producing agencies are adequate.}

Article 5 of the Law on Statistics requires that GEOSTAT cooperate and coordinate with the local organizations producing the statistics in order to achieve efficiency. Article 16 of the Law on Statistics stipulates that GEOSTAT coordinates exchange of information among the administrative bodies in order to produce the statistics and facilitates effective 
implementation of the statistical standards and methodology approved. In addition, there are memorandums of understanding between the GEOSTAT and the MOF, GEOSTAT and Education Quality Development Center, and GEOSTAT and the NBG covering the sharing of macroeconomic data. GEOSTAT is the sole compiler of price statistics.

Within the GEOSTAT, the internal procedures are in place to ensure coordination between various divisions, namely Business Statistics Division, Agriculture and Environmental Statistics Division, Social Statistics Division, Population Census and Demographic Statistics Division, Price Statistics Division. All proposed changes in questionnaires as well as other changes in the production of statistics is preceded by consultations and need to be approved by the Board of the GEOSTAT.

The central role of GEOSTAT in the field of statistics is further reiterated in Article 2 of the Charter of GEOSTAT, which states that the GEOSTAT should work out a unified policy for the field of statistics, prepare and introduce statistical standards and methodology, create and realize statistical classification system, create and improve statistical databases, information banks and networks; and create and approve statistical observance forms for producing official statistics. Such centralized statistical system in principle guards against duplication of efforts and unnecessary burden on respondents. There is no arrangement for regular meetings of all technical staff responsible for macroeconomic statistics. Such meetings provide a comprehensive arena for exchanging information on current and forthcoming projects for statistical development, promoting cross-sectoral data consistency crucial for macroeconomic policy making, and coordinating work programs to avoid duplication of effort, ensure coherent application of methodology at all stages of data collection, and enhance effectiveness. Nevertheless, these agencies have several bi-lateral meetings and arrangements for collaboration on data issues e.g., the GEOSTAT has a memorandum of cooperation with the NBG as well as a working group with NBG dealing with CPI. In addition, Vice-President of NBG is GEOSTAT board member, ensuring cooperation at the higher level and there are regular informal contacts with the staff of other data-producing agencies.

\section{Recommendation:}

Conduct pre-established, regular meetings, such as one per year, to improve communication among data compilers at NBG, GEOSTAT, and MOF, by discussing issues of common interest, avoid duplication of efforts, and ensure the consistency of macroeconomic statistics (national accounts, monetary, fiscal, and external sector.)

\subsubsection{Individual reporters' data are to be kept confidential and used for statistical purposes only.}

GEOSTAT has adequate legal and procedural provisions to ensure confidentiality of individual reporters, and in satisfactorily follow these in practice. Article 26 of the Law on 
Statistics states that statistical data shall be public except for the data which allows for identification of observation unit. Article 28 states that the confidential statistical data shall not be issued or disseminated or used for a nonstatistical purpose with exceptions envisaged by the Georgian legislation. When producing the official statistics it is obligatory to destroy or store separately the identity data including the questionnaires containing such data. According to Article 29 of the Law, the employees of the GEOSTAT should not use or disseminate confidential statistical data either for the personal, academic, research or any other activities. Violation of these provisions will lead to imposing a disciplinary responsibility against employee, notably in view of the guilt or/and the damage inflicted the Executive Director shall impose the following disciplinary penalties: warning, withholding a salary, and/or dismissal.

GEOSTAT staffs are required to keep individual data confidential by Law and the staff is well informed by the requirement. Access to individual data both to the actual forms and to the computer records is restricted to the appropriate staff. The procedures are adopted that prevent residual disclosure. There are special aggregation rules that ensure that unintended disclosure does not occur. Respondents to surveys are informed about the confidentiality of their responses (relevant statement is included in each survey form). Archive procedures ensure appropriate storage of information with clearly articulated rules.

\subsubsection{Statistical reporting is ensured through legal mandate and/or measures to encourage response.}

Article 25 of the Law on Statistics sets the obligation to provide statistical and other information to GEOSTAT, notably upon the request and according to the legislation of Georgia the administrative bodies shall be obliged to provide the GEOSTAT with the information on physical and private entities (including confidential information) available to them. However, no sanctions for nonreporting or misreporting are stipulated by the Law and, due to lack of legal and administrative support, very senior staff at times is required to intervene in order to get the respondents to collaborate.

With its price statistics surveys, nonreporting has not been an issue and no deterioration in response rates has been observed in practice.

\section{Recommendations:}

Enact appropriate amendments to the Law of Georgia on Official Statistics to reinforce mandatory reporting of statistical data and ensure application of sanctions for nonreporting. If reporting is mandatory, penalties for noncompliance (including misreporting) act as effective deterrent, even if such provision rarely needs to be employed.

Establish mechanisms in place to promote the voluntary reporting of data. 


\subsection{Resources}

\subsubsection{Staff, facilities, computing resources, and financing are commensurate with statistical} programs.

Staff resources at the Price Statistics Division (PSD) are barely sufficient for carrying out the day-to-day compilation work for both CPI and PPI, but not further improvement to better adhere to international standards. To further improve the quality of its statistics and undertake tasks, like establishing central price collection for complex products for CPI and PPI, and participating in the International Comparison Program (ICP), additional staff resources are needed. The current staff level is fully occupied with the routine monthly cycle and tasks related to issues like identifying alternative data sources, evaluating and adjusting the weight data against additional information, improving the quality adjustment methodology. The Price division employs 7 central staff, all with university education with economics as the main subject. All staff members divide their time between the CPI and the PPI, roughly in a 70 to 30 proportion, respectively. In addition, there are 20 field collectors in the regions who work with the data collection and receive direct guidance and training from the PSD staff. This is, by international comparison, a small organisation for compiling price statistics. Staff turnover has been very slow in recent years regardless of the significantly below-average remuneration within the public sector.

All employees have their personal computers, and the network services within GEOSTAT and between the regional offices seem sufficient. While new statistical software licences have been acquired with donor assistance, there are issues with maintaining other IT infrastructure up-to-date. The data processing resources have recently improved significantly with the implementation of hand held computers (USAID funded) and accompanied software for CPI data collection and transfer, as well as a Delphi based index compilation system. However, the PPI compilation process still relies on out-dated technology that ties the scarce staff resources at the central office. Current 3-year bilateral cooperation with Statistics Sweden is expected to address these issues shortly.

The GEOSTAT makes good use of its existing resources but, overall, GEOSTAT suffers from inadequate resources, as acknowledged by the data users. There is a great disparity in average salaries between other government agencies; NDSD indicates GEOSTAT staff receiving around $60 \%$ for similar government positions. To supplement its limited resources, GEOSTAT participates in various statistical programmes with the financial supports from donors. While these partnerships provide significant benefits to the GEOSTAT, the financial dependency on donors increases the risk on sustainability of these data programs. The new GEOSTAT central office facilities are appropriate but the long distance from other government offices and the GEOSTAT Tbilisi office may, to a degree, hamper day-to-day communication within the organization and with its key users.

Price Statistics (Consumer Price Index) 


\section{Recommendation:}

Increase the overall staff, IT, and financial resources for the GEOSTAT.

\subsubsection{Measures to ensure efficient use of resources are implemented.}

The GEOSTAT Board provides overall supervision of the organization of statistical work and oversees strategic plans for statistical development. In order to ensure the efficient use of resources the following measures are undertaken: (i) the thorough planning of statistical works (on multi-annual, annual and quarterly basis); (ii) the permanent monitoring of the appropriate use of resources according their destination. The Internal Audit Division carries out inspections of the staff of regional staff and monitors the resource use within the budgeting and execution of the Annual and Mid Term Actions Plans.

Special attention is granted to the improvement of the staff performance, especially its qualifications and abilities. Time to time, staff receive differentiated bonuses based on the assessment of the heads of divisions.

Outside consultants are widely used to evaluate statistical methodologies and compilation systems.

\section{$0.3 \quad$ Relevance}

0.3.1 The relevance and practical utility of existing statistics in meeting users' needs are monitored.

The relevance of statistical program is ensured by the Board of the GEOSTAT, which consists of seven members and a Chairman, with the following composition: one representative of the NBG, one representative of the Ministry of Economy and Sustainable Development, one representative of the MOF, and other five members, which represent private sector. The Parliament of Georgia should give consent to appoint the members of the Board (Law on Statistics, Article 11). The Board also serves as an advisory group to inform statistical processes. In addition, Article 5 of the Law on Statistics encourage cooperation with the international organizations in order to introduce the international practice and methodology and share relevant experience based on the agreements and treaties concluded with the international organizations engaged in this field.

Article 7 of the Law on Statistics stipulates that GEOSTAT should produce the statistics that are approved/recognized by the Board of the GEOSTAT, and also should need arises; the GEOSTAT is authorized to produce the statistics which is not envisaged by the statistical 
activity program. Executive Director submits the statistical activity program for approval to the President of Georgia (Article 9 of the Law on Statistics).

There is no user's advisory group that would meet on a regular basis to provide feedback on the relevance of the current price statistics and new data requirements. Nevertheless, GEOSTAT consults various broader user groups on an ad hoc basis (e.g., during celebration of International Statistics Day). Users are also encouraged to provide feedback via GEOSTAT official website and its social networks (e.g., Facebook.) In addition, Eurostat (as one of users) performs regular quality checks of reported data. Their requirements are monitored and addressed in consistent manner.

\section{Recommendation:}

Establish a users' advisory group for price statistics that meets on a regular basis (e.g., annually) and include all types of users to discuss existing data programs, plans for improvement, and to obtain user feedback on current and planned data programs.

\subsection{Other quality management}

\subsubsection{Processes are in place to focus on quality.}

The GEOSTAT commitment to quality is stipulated by law and well publicized. Article 1 of the Law on Statistics states that its goal is to ensure producing independent, objective and reliable statistics in the country based on the internationally recognized basic principles of statistics. Reflecting the spirit of this law, the GEOSTAT's mission statement emphasizes the improvement and harmonization of statistical activities and the maintenance of independence, accuracy, relevance, integrity, timeliness, and professional standard of statistical information produced in Georgia. GEOSTAT is finalizing the NSDS that includes special chapter on quality.

Quality policy is based on the provisions of national and EU legislation, Strategy of GEOSTAT, European Statistics Code of Practice, user needs and expectations. It defines overall intentions and directions of institution related to quality. The management of the institution is giving priority to building trust and increasing the credibility of the statistics produced by GEOSTAT. From the ROSC Users' survey, users indicated that in the last few years GEOSTAT disseminates more statistics, survey results, and information on methodology as well as becomes more responsive to their queries.

Conscious of value of independent quality assessment, GEOSTAT regularly participates in international evaluations, such as the IMF ROSC Data module and the World Bank's statistical capacity indicators. It also conducts regular communications with Eurostat on data quality issues.

Price Statistics (Consumer Price Index) 


\subsubsection{Processes are in place to monitor the quality of the statistical program.}

The GEOSTAT regularly reviews and plans improvements to their internal processes. More formal annual Statistical Program is produced annual and approved by the President of Georgia. The newly created Monitoring Department is responsible for operating the monitoring, control and internal audit. The Internal Audit Division is established in GEOSTAT for systematic internal reviews of GEOSTAT processing including data collection and processing.

The expert guidance on the quality of their statistics is also ensured vie peer reviews within the framework of cooperation with other statistics agencies. GEOSTAT has established longterm cooperation with Statistics Sweden. Strategy of cooperation in price statistics is based on three-year plan of Developing Georgian CPI and PPI. There is also established Cooperation with the Central Statistical Office of Latvia.

\subsubsection{Processes are in place to deal with quality considerations in planning the statistical program.}

The Board of GEOSTAT coordinates the economic statistics work program, including explicit decisions about quality and trade-offs among the dimensions of quality (e.g., resource availability, timeliness, and accuracy/reliability.) The quality dimensions are also recognized explicitly in the NSDS.

\section{Assurances of integrity}

\subsection{Professionalism}

\subsubsection{Statistics are produced on an impartial basis.}

Article 6 of the Law on Statistics stipulates that GEOSTAT independently carries out its activities based on the Georgian legislation. Article 1 of the Charter of GEOSTAT, 2010 further elaborate that the GEOSTAT carries out its activities based on the Georgian legislation, internationally accepted statistical principles, Law on Statistics, Law of Georgia on Legal Entity of Public Law, this Charter, GEOSTAT Board's regulations and other normative acts. The GEOSTAT acquires rights and obligations to implement the goals established and functions assigned to it. There is no external pressure on the GEOSTAT with respect to the content or release of the statistics.

On the above premise, all official statistics including price statistics are compiled on an impartial basis. The basic principles governing the collection, processing, and dissemination 
of statistics in Georgia includes professional independence, objectivity, reliability, confidentiality of statistical data, and efficiency (Law on Statistics, Article 4).

The Executive Director of GEOSTAT is appointed by Board of the GEOSTAT for the term of 4 years and may be dismissed by the President of Georgia only under special circumstances (Article 8 of the Law on Statistics). The Executive Director is authorized to invite foreign or local experts on the contractual basis in accordance with the recommendations of the members of Board of the GEOSTAT in order to ensure effective operation of the GEOSTAT (Article 9.2).

Professional competency plays a key role in the promotion practices in the GEOSTAT and professional enhancement is encouraged.

\subsubsection{Choices of sources and statistical techniques, as well as decisions about dissemination, are informed solely by statistical considerations.}

The choices of sources, statistical techniques, and dissemination of price statistics are made solely by the GEOSTAT based entirely on statistical considerations. There has been no instance of ministerial interference in the choice of the statistical sources and methods.

\subsubsection{The appropriate statistical entity is entitled to comment on erroneous interpretation and misuse of statistics.}

The GEOSTAT provides explanatory materials in the price statistics press releases and on its website. The GEOSTAT monitors media coverage of its statistical products and has the authority to comment on erroneous interpretation and misuse of the statistics that it produces. At times, senior staff of GEOSTAT corrected the misinterpretation of statistics by media.

\subsection{Transparency}

\subsubsection{The terms and conditions under which statistics are collected, processed, and disseminated are available to the public.}

The terms and conditions governing the collection of statistics are published in the Law on Official Statistics and in Charter of GEOSTAT, which are widely available to the public, including from the GEOSTAT website

http://www.geostat.ge/index.php?action=page\&p_id=29\&lang=eng. In addition to legal provisions, the GEOSTAT website contains other relevant documents, such as the National Strategy of Development of Statistics, annual report of the GEOSTAT, information about the SDDS, and information about individual statistical products. 


\subsubsection{Internal governmental access to statistics prior to their release is publicly identified.}

The GEOSTAT disseminates the price statistics to all users simultaneously. There is no governmental access to statistics prior to release.

\subsubsection{Products of statistical agencies/units are clearly identified as such.}

Products of the GEOSTAT are clearly identified as such by its name and logo. The price statistics in the NBG's publications and website identify the GEOSTAT as the source. However, in the GEOSTAT publications, there are cases, in which that attribution is not made to the source, when statistics from other data-producing agencies is reproduced but does not concern the dissemination of price statistics.

\subsubsection{Advance notice is given of major changes in methodology, source data, and statistical techniques.}

The GEOSTAT provides advance notice about major methodology changes in price statistics in the Annual and Mid-Term Action Plans as well as in the National Strategy for the Development of Statistics in Georgia (2011-2014), available on the GEOSTAT website http://www.geostat.ge/index.php?action=page\&p_id=794\&lang=eng.

Advance notice was provided for major changes such as the introduction of the three-year cycle in CPI weight revisions, seasonally adjusted estimates, changes in business survey questionnaire, etc. For the upcoming CPI revision a note will be added on the GEOSTAT website and CPI press release.

\subsection{Ethical standards}

\subsubsection{Guidelines for staff behavior are in place and are well known to the staff.}

On its website, the GEOSTAT states that the Fundamental Principles of Official Statistics developed by United Nations Statistical Commission were at core in drafting the Law on Statistics and consequently establishing the GEOSTAT: http://www.geostat.ge/index.php?action=page\&p_id=32\&lang=eng. The Fundamental Principles stipulate that for retaining trust in official statistics, the statistical agencies need to act according to strictly professional considerations, including professional ethics. New staffs are made aware of the ethical standards when they join the GEOSTAT.

Guidelines for Effective Communication, a code of conduct -document last updated in August 2011 and approved by the Executive Director, gives further guidance for the GEOSTAT staff on how to interact with other staff and external stakeholders.

Price Statistics (Consumer Price Index) 


\section{Methodological soundness}

\subsection{Concepts and definitions}

\subsubsection{The overall structure in terms of concepts and definitions follows internationally accepted standards, guidelines, or good practices.}

The CPI concepts and definitions largely follow the Consumer Price Index Manual (CPI Manual) and the household monetary consumption expenditure of the 1993 SNA. The CPI estimates the price changes of goods and services urban households purchase for their own consumption. The expenditure estimates according to the COICOP are provided at high level of detail.

The concepts and definitions of the HBS, the basis for CPI weights and basket, broadly follow international recommendations.

During the next CPI revision in January 2012 GEOSTAT is planning to introduce expenditure weights based on the National Accounts monetary household consumption expenditure. This would bring the CPI conceptually closer to National Accounts and improve internal data coherence. It would also improve the accuracy of the consumer expenditure pattern. As a result, the change would also affect the way headline inflation is determined due to large changes in relative weights of key expenditure categories.

\section{$2.2 \quad$ Scope}

2.2.1 The scope is broadly consistent with internationally accepted standards, guidelines, or good practices.

The scope is largely consistent with internationally accepted standards, except the CPI weights currently cover the expenditure of only the households of the five largest cities (covering some $40 \%$ of the population), even though the HBS data for the urban and rural areas is available. In addition, treatment of owner-occupied housing is inconsistent. While the limited coverage is well known and clearly communicated with the users, the international standard recommends that population coverage includes all households and not be restricted to urban-only households. Otherwise the CPI population coverage relates to urban families of all sizes and income levels. The index covers marketed goods and services for final consumption purchase including purchases by unincorporated businesses.

The CPI relies exclusively on the HBS of 2008-09 for the CPI weight structure, which implicitly determines the difference in the scope of coverage between the CPI and the consumption expenditure of the household sector as defined in the 1993 SNA. No adjustments are made for the HBS weights. The treatment of services of owner-occupied 
housing in the CPI is unclear. On one hand the owner-occupied housing is excluded from the weight estimates, which rely on cash consumption expenditure. On the other hand, a small expenditure share from actual rental expenditure is diverted to 'purchase of housing'. This is represented in the price survey with an item measuring 'Apartment price', measuring the actual or estimated acquisition prices of apartments. The resulting practice of excluding the owner-occupied housing in the weights but including it in the price survey is clearly not soundly based.

Other common and acceptable exclusions in the CPI scope with respect to consumption expenditure are own-account and illegal market goods and services. These exclusions are described in the metadata. In terms of geographical coverage, the CPI weights cover the expenditure of all urban households in the five main cities. Abkhazian Autonomous Republic and Tskhinvali Region (former South Ossetian Autonomous Region), a part of Georgian territory not controlled by the central authorities are excluded.

\section{Recommendations:}

Extend the coverage to include the expenditure pattern of the whole population in the CPI weights and evaluate the need for including additional outlets for price collection to cover the rural areas.

Clarify the treatment of owner-occupied housing in the weights. The common international approach is to include the weights based on imputed rents for similar housing units and covering the price survey with an appropriate rental survey also used for the actual rental expenditure.

\subsection{Classification/sectorization}

\subsubsection{Classification/sectorization systems used are broadly consistent with internationally accepted standards, guidelines, or good practices.}

International classification standard COICOP is used throughout in both the HBS and CPI. In addition, for a few certain typical national and regional items, Georgia has adapted COICOP by expanding classification to the 8-digit level to account for country-specific needs and better facilitate the price collection. 


\subsection{Basis for recording}

\subsubsection{Market prices are used to value flows and stocks.}

Market prices, including trade and transportation margins, taxes less subsidies are used to value the consumption expenditure weights. Product specifications also largely include pricedetermining characteristics related to the terms of transactions. See also 3.1.1.

\subsubsection{Recording is done on an accrual basis.}

Prices for goods and services are recorded on an accrual basis. Most are collected each month over the period between the $10^{\text {th }}$ and the $20^{\text {th }}$ of the month. Infrequently changing prices such as public transport fees and nationally set prices are reviewed at the time of changes are applied.

\subsubsection{Grossing/netting procedures are broadly consistent with internationally accepted standards, guidelines, or good practices.}

The CPI compilation does not include any grossing/netting. The main area where netting could play a significant role is with treatment of personal vehicle markets. Used cars purchases are included in the CPI with gross weights, as available from the HBS. The weighting practice will be reviewed during the next CPI revision in 2012.

\section{Accuracy and reliability}

\subsection{Source data}

\subsubsection{Source data are obtained from comprehensive data collection programs that take into account country-specific conditions.}

The source data for the CPI are (i) the HBS which provides expenditure data by commodity for the whole country except the conflict territory for the CPI weighting pattern, and (ii) the monthly regional survey of retail prices. Broadly, they provide a sound but not sufficient basis for the CPI. However, relying solely on the HBS for the weights structure does not provide sufficiently accurate structure of true expenditures. Similarly, the monthly price survey carried out by the regional price collectors may not alone capture the relevant price changes for all items. 


\section{Household Budget Survey}

The HBS covering all urban and rural households (the latest is for 2008-09) is the sole source for the CPI weight structure and basket selection. The CPI staff does not make any adjustments for these data and only utilizes the expenditure data for the five urban centers. To a large part due to resource constrains, the HBS weights are not adjusted to reflect known or suspect biases e.g., in alcohol consumption. The HBS does not currently collect information on sales of used goods, such as personal vehicles. The survey started in 1996 with Statistics Canada's and World Bank's financial and technical assistance. The questionnaire and the sample designs have been kept largely the same since then. The HBS is part of the Integrated Household Survey that consists of 7 separate annual, quarterly or monthly questionnaires. The survey is based on the 2002 population census with a sample size of 3500. For 2008-09 the sample size was doubled to 7000 households with funding from Millennium Challenge Georgia. A two-stage scientific stratified sample is drawn and selected households rotated on monthly basis, using detailed location and household size as stratification factors. The survey methodology seems sound even though the estimates of sampling errors and potential nonsampling errors and biases are likely not effectively used to inform and update the survey cluster.

The weights for owner-occupied housing $(\mathrm{OOH})$ are currently excluded since they are not part of monetary consumption expenditure. However, a partial weight from HBS rental expenditure is attached to the $\mathrm{OOH}$ in the CPI. See also 2.2.1.

\section{Price Survey}

A regular field price survey in the five largest cities is the basis for the estimation of the CPI. The current basket includes 266 items, which are collected from over 1300 outlets. The monthly CPI is compiled from some 8000 individual price quotes.

The sample of outlets is based on a combination of a random sample from a register of outlets and price collectors' local knowledge of popular markets. The item selection takes place by judgmental sample within well-defined product specifications resulting in generally well-defined outlet-specific item specifications. The item specifications are largely sufficient to capture the price determining characteristics of each and the DSP staff considers them not to be a significant issue. However, additional detailed specifications for select items such as insurance, housing, telephony services, computers, etc., lack sufficient detail and may account some quality change as price change. Similarly, the description of some complex goods and services that experience changes may not allow for proper treatment for example for quality change. Alternative price sources like the Internet, magazines, catalogues, etc. are currently not used since centralized data collection is very limited. 
Housing price data, for rents and 'selling of houses,' is also very thin. Combined with ambiguous methodology regarding their weights, the national level estimates of property prices and rents from the CPI price survey alone are likely not to be sufficiently accurate to describe the property markets well.

\section{Recommendations:}

Adjust the HBS result to account for known and suspect shortcomings and compare the result against alternative data sources at all aggregation levels.

If the $\mathrm{OOH}$ is to be included in the CPI, as most countries do with imputed rents as weights and rental equivalence as the pricing approach, evaluate how weights and pricing methodology are determined and improve the coverage of corresponding price collection.

Review all detailed item specifications for completeness and augment as needed. Special attention should be paid to the more complex items (insurance, housing, wireless communication services, computers, etc.) to capture all relevant changes in the item specifications

3.1.2 Source data reasonably approximate the definitions, scope, classifications, valuation, and time of recording required.

The CPI price survey provides a good approximation for the definitions, scope, classifications, valuation and time of recording required. However, for some goods the current price collection may not provide a complete picture, in a sense that alternative markets outside typical physical outlets currently excluded from the regional surveys may be or may soon become relevant. Travel ticket purchases though the Internet is an example.

\section{Recommendation:}

For some complex goods and service, such as cellular phone services, seek alternative data sources, virtual outlets, outside the normal regional price survey to reflect consumer behavior.

\subsubsection{Source data are timely.}

Both the HBS and CPI price survey have good periodicity and timeliness and enable GEOSTAT to disseminate the CPI estimates only 3 days after the end of the reference month. The quarterly HBS results are obtainable some 8 weeks after the survey and detailed annual estimates are available two months after the end of year. The price survey, conducted between the $10^{\text {th }}$ and $20^{\text {th }}$ of the month, is validated daily during the survey and transferred to 
the central office already on the $21^{\text {st }}$ of the month for further data validation and CPI compilation.

\subsection{Assessment of source data}

3.2.1 Source data-including censuses, sample surveys, and administrative records-are routinely assessed, e.g., for coverage, sample error, response error, and nonsampling error; the results of the assessments are monitored and made available to guide statistical processes.

Accuracy of the CPI source data is routinely assessed, both with respect to the HBS and the Price Survey.

\section{Household Budget Survey}

The HBS is routinely assessed to monitor its accuracy. Recently GOESTAT introduced additional validation procedures to the data collection and compilation. This has reportedly improved the data accuracy while uncertainty about under and misreporting remain. Sampling errors are available and adjusted for nonresponse. The primary data goes through several plausibility and consistency checks as well as checks for data entry errors with double entry bookkeeping. Data of all 200 interviewers are verified and randomly checked by field supervisors, whom in turn are monitored and randomly checked by central office expert. Logical controls within each questionnaire are computerized and erroneous or misreported questionnaires are removed from the database. There's roughly a $15 \%$ quarterly nonresponse and extreme changes within individual stratum are accounted for in the population estimates at a higher aggregate level.

The assessment of HBS is also made against National Accounts expenditure estimates. The discrepancy is sometimes significant but, as a practice, the HBS does not adjust the survey results without verification from an accurate alternative data source.

\section{Price Survey}

The Surveybe is software used for the price collection includes internal validation procedures, which require the price collector to comment and approve for suspect price movements at the time of recording. This minimizes data entry errors and also provides the central office information on the reasons for price changes. Supervisors go through all price data to identify erroneous and influential price observations for further review. During the CPI compilation, large sub-index changes are routinely diagnosed and reasons sought. 


\subsection{Statistical techniques}

\subsubsection{Data compilation employs sound statistical techniques to deal with data sources.}

The CPI compilation techniques have improved in 2010 by enhancing the previous imputation method for seasonal products. Previously the method relied on imputing only elementary or higher level aggregate indices instead of individual prices. However, few issues still remain in order to implement international best practices.

In the case of quality change, efforts are made to identify changes and some changes, like package size adjustments are carried out. However, the practice is to treat the changed product as a new item and splice out the associated price change, rather than directly estimate the value of the quality change. If there are overlapping prices available, this implicitly assumes that the whole price difference is due to quality change. With rapidly changing goods like mobile phones and computers some of the quality change is potentially missed with the current method.

Missing prices are also imputed based on a default group relative method. Although a good basic method, an additional imputation strategy would likely decrease sudden corrections at the time the item reappears in the basket. The imputation could be based on either the same items' price movements in other regions, which provide sufficiently similar price movements given that Georgia is a relatively small country, or similar individual items' price changes in the within the region. This can have significant impact when combined with the Dutot formula and relatively high price variation within some elementary aggregates.

However, the current practice in treating seasonal product may significantly miss the price changes at the beginning of each annual index. If a seasonal item is not available in December that is used as the base price period, the elementary index for this item is imputed in January based on the next higher level in the classification structure. Hence, base prices are in some cases not imputed. Within an annual index everything is fine but the problem appears with chaining these annual indices to form longer time-series. Historically, before the 2010 methodology improvement, this has led to situations where the long-term indices for some seasonal items have significantly deviated from the actual price levels. There is still a potential problem if the price change of a seasonal item (between first introductory price in the new index and the last observed price in the previous index) differs from the corresponding group relative used for the imputation.

Number of improvement in the statistical methods recommended in the assessment is already being planned for the next revision in January 2012. 


\section{Recommendations:}

Consider estimating the December base prices for seasonal products based on an average over a longer time period that would include actual prices for each transaction. Make sure that the actual price levels from end of previous season to the beginning of the new season reflect similar changes in the chained sub-indices.

Introduce quality adjustment methods to implicitly or explicitly account for the quality changes.

\subsubsection{Other statistical procedures (e.g., data adjustments and transformations, and statistical analysis) employ sound statistical techniques.}

Generally, the household consumption expenditure is used to establish the CPI weights. However, the treatment of expenditure on $\mathrm{OOH}$ is unclear, as explained above. To calculate the elementary aggregate, the Dutot formula (relative of arithmetic average prices) is calculated for each item by region. The HBS expenditure weights are used to aggregate the elementary aggregates progressively first within each region. The modified Laspeyres formula is used, updating series of short-term price changes to compile the annual index series. Corresponding regional expenditure weights from the HBS finally aggregates regions for an all-Georgian CPI. However, the Dutot formula used at the elementary aggregate level can lead to significant index changes due to large price variance within some elementary aggregates.

The weight reference period is updated every three years, based on the availability of the most recent HBS. However, the weights are not adjusted to coincide the price and index reference period of month of December. Long consistent time series are compiled by chaining annual index series together.

\section{Recommendations:}

Change the Dutot formula to a Jevons index (geometric average) to partially account for substitution effect and to lessen the impact of large price variation within the elementary aggregates.

Price-update the expenditure weights to align the weight and index reference periods. 


\subsection{Assessment and validation of intermediate data and statistical outputs}

\subsubsection{Intermediate results are validated against other information, where applicable.}

The regional CPIs and sub-series are compared with each other to identify inconsistencies. Large differences are check with the field supervisors and, if needed, individual price data are confirmed.

\subsubsection{Statistical discrepancies in intermediate data are assessed and investigated.}

Unusual movements in the index arising from large movements in particular sectors are investigated and corresponding price date reviewed. The procedures concentrate on the monthly movement of the index series.

\subsubsection{Statistical discrepancies and other potential indicators of problems in statistical} outputs are investigated.

Reasons for short-term changes in both the price and index data are generally rigorously investigated and their impact to the overall index explained.

\subsection{Revision studies}

3.5.1 Studies and analyses of revisions are carried out routinely and used internally to inform statistical processes (see also 4.3.3).

The CPI estimates are released final as a policy. Some internal analysis on the impact of weight structure changes is carried out.

\section{Serviceability}

\subsection{Periodicity and timeliness}

\subsubsection{Periodicity follows dissemination standards.}

The CPI is compiled and released monthly and therefore conforms to the SDDS standard.

\subsubsection{Timeliness follows dissemination standards.}

The timeliness of the price indices meets SDDS dissemination standards. The CPI is released only three days after the end of the reference month. 


\subsection{Consistency}

\subsubsection{Statistics are consistent within the dataset.}

The aggregation structure and practice ensures internal consistency of the regional and subgroup CPI estimates.

\subsubsection{Statistics are consistent or reconcilable over a reasonable period of time.}

Consistent long time-series is available from year 2000, even though they are not published together with the monthly index publication. They are however, available on the GEOSTAT website in other publications. There is a policy of not revising the historical series, which is in line with international best practice.

\subsubsection{Statistics are consistent or reconcilable with those obtained through other data sources and/or statistical frameworks.}

The CPI estimates are routinely compared with the corresponding PPI estimates and are largely consistent with them. Similarly, since detailed CPI series are used in the deflation of household goods consumption, consistency is largely ensured in that part. For a large part of consumer services expenditure CPI series are used in conjunction with direct volume measures that may deviate from each other.

\subsection{Revision policy and practice}

\subsubsection{Revisions follow a regular and transparent schedule.}

As a policy and is a common practice, there are no revisions to the CPI series once disseminated. The weight revision schedule of every three years has been in use since 2000 and explained to the users. The revisions of weights use information from HBS, which is scheduled to take place every three years even though there have been deviations due to partial dependency on donors' financial support.

\subsubsection{Preliminary and/or revised data are clearly identified.}

Following internationally accepted practice, the CPI data are final upon release.

\subsubsection{Studies and analyses of revisions are made public (see also 3.5.1).}

Not applicable since data are final. 


\section{Accessibility}

\subsection{Data accessibility}

5.1.1 Statistics are presented in a way that facilitates proper interpretation and meaningful comparisons (layout and clarity of text, tables, and charts).

The main CPI press release is disseminated in a format that helps interpreting the results: it explains the main sources of price change in writing and in charts. The data are provided in a set of Microsoft Excel-files at regional and COICOP division level from year 2000 onward. To analyze long-term trends users need to either construct the series themselves or search for the quarterly bulletin that includes longer consistent time-series.

Monthly short (month-on-month) and long-term (12-month change) inflation estimates are accompanied with period average and annual inflation estimates.

\subsubsection{Dissemination media and format are adequate.}

The CPI press release has been recently improved and currently provides a basis for good understanding of recent inflationary trends. More detailed CPI series are available on the GEOSTAT website.

\subsubsection{Statistics are released on a preannounced schedule.}

An annual Statistical Calendar for all GEOSTAT publications is published in advance in the Publication calendar on the GEOSTAT website.

\subsubsection{Statistics are made available to all users at the same time.}

The CPI press release is made available for all interested users receive simultaneously.

\subsubsection{Statistics not routinely disseminated are made available upon request.}

As a policy, all nonconfidential data are available from GEOSTAT upon request and special compilations can be provided to users. A list of available additional products and their fees is published on the GEOSTAT website.

\subsection{Metadata accessibility}

5.2.1 Documentation on concepts, scope, classifications, basis of recording, data sources, and statistical techniques is available, and differences from internationally accepted standards, guidelines, or good practices are annotated.

GEOSTAT website provides a short description in English and Georgian of the CPI use, methodology, and the list of CPI basket items. It also provides a link for the SDDS metadata, 
which is the main detailed description of the CPI. However, it does not reflect the latest methodology changes and lacks of detail. ${ }^{1}$ The website also has a placeholder for a whole section of metadata but still needs to be populated.

\section{Recommendation:}

Produce and disseminate detailed metadata describing the methodology practiced in compilation of Georgian CPI.

\subsubsection{Levels of detail are adapted to the needs of the intended audience.}

The current limited metadata is not adapted for different audiences. The short methodology description is intended for the general public and a planned CPI handbook and SDDS metadata for more advanced users.

\section{Recommendation:}

Develop further and disseminate the different metadata publications.

\subsection{Assistance to users}

\subsubsection{Contact points for each subject field are publicized.}

A general email and telephone contacts are available on the GEOSTAT website and main publications. Main users are directly in contact with specific technical staff or the head of the Price Division. The CPI press release refers to the GEOSTAT website.

\subsubsection{Catalogs of publications, documents, and other services, including information on any charges, are widely available.}

The GEOSTAT website provides list of all available publications and calendar or publication dates. In addition, a document "Prices for dissemination of statistical data generated beyond the statistical activity program of National Statistics Office of Georgia," (Decree \#14, 2011, of Board of GEOSTAT) which sets the fees for disseminating additional statistical data.

\footnotetext{
${ }^{1}$ The CPI weight structure at COICOP division level was made available during the mission.
} 
Table 3. Data Quality Assessment Framework (July 2003): Summary of Results for Price Statistics (Consumer Price Index)

(Compiling Agency: National Statistics Office of Georgia)

\begin{tabular}{|c|c|c|c|c|c|c|}
\hline \multicolumn{7}{|c|}{$\begin{array}{l}\text { Key to symbols: NA = Not Applicable; } \mathbf{O}=\text { Practice OI } \\
\text { Observed; NO = Practice Not Observed; SDDS = Com }\end{array}$} \\
\hline \multirow{2}{*}{ Element } & \multirow{2}{*}{$\mathbf{N A}$} & \multicolumn{4}{|c|}{ Assessment } & \multirow{2}{*}{ Comments } \\
\hline & & $\mathbf{O}$ & $\mathbf{L O}$ & LNO & NO & \\
\hline \multicolumn{7}{|l|}{ 0. $\quad$ Prerequisites of quality } \\
\hline 0.1 Legal and institutional environment & & \multirow[b]{4}{*}{$\mathrm{X}$} & $\mathrm{X}$ & \multirow{4}{*}{$\mathrm{X}$} & & No sanctions for nonreporting are stipulated by law. \\
\hline 0.2 Resources & & & & & & $\begin{array}{l}\text { The staff and financial resources are inadequate to seriously develop } \\
\text { the quality of price statistics. }\end{array}$ \\
\hline 0.3 Relevance & & & $\mathrm{X}$ & & & No user group exists for price statistics. \\
\hline 0.4 Other quality management & & & & & & \\
\hline \multicolumn{7}{|l|}{ 1. Assurances of integrity } \\
\hline 1.1 Professionalism & & $\mathrm{X}$ & & & & \\
\hline 1.2 Transparency & & $\mathrm{X}$ & & & & \\
\hline 1.3 Ethical standards & & $\mathrm{X}$ & & & & \\
\hline \multicolumn{7}{|l|}{ 2. Methodological soundness } \\
\hline 2.1 Concepts and definitions & & $\mathrm{X}$ & & & & \\
\hline 2.2 Scope & & & $\mathrm{X}$ & & & $\begin{array}{l}\text { Coverage restricted to urban-only households. Treatment of owner- } \\
\text { occupied housing not clear. }\end{array}$ \\
\hline 2.3 Classification/sectorization & & $\mathrm{X}$ & & & & \\
\hline 2.4 Basis for recording & & $\mathrm{X}$ & & & & \\
\hline \multicolumn{7}{|l|}{ 3. $\quad$ Accuracy and reliability } \\
\hline 3.1 Source data & & & $\mathrm{X}$ & & & $\begin{array}{l}\text { Housing weights and price survey inadequate, transactions } \\
\text { specifications lack detail. }\end{array}$ \\
\hline 3.2 Assessment of source data & & $\mathrm{X}$ & & & & \\
\hline 3.3 Statistical techniques & & & $\mathrm{X}$ & & & Imputation methods and treatment of quality change do not \\
\hline $\begin{array}{l}\text { 3.4 Assessment and validation of intermediate data and } \\
\text { statistical outputs }\end{array}$ & & $\mathrm{X}$ & & & & Meet international standards. \\
\hline 3.5 Revision studies & & $\mathrm{X}$ & & & & \\
\hline \multicolumn{7}{|l|}{ 4. $\quad$ Serviceability } \\
\hline 4.1 Periodicity and timeliness & & $\mathrm{X}$ & & & & \\
\hline 4.2 Consistency & & $\mathrm{X}$ & & & & \\
\hline 4.3 Revision policy and practice & & $\mathrm{X}$ & & & & \\
\hline \multicolumn{7}{|l|}{ 5. $\quad$ Accessibility } \\
\hline 5.1 Data accessibility & & $\mathrm{X}$ & & & & \\
\hline 5.2 Metadata accessibility & & & $\mathrm{X}$ & & & Develop and release detailed methodology for CPI. \\
\hline 5.3 Assistance to users & & $\mathrm{X}$ & & & & \\
\hline
\end{tabular}




\section{Price Statistics (Producer Price Index)}

\section{Prerequisites of quality}

\subsection{Legal and institutional environment}

\subsubsection{The responsibility for collecting, processing, and disseminating the statistics is clearly specified.}

The GEOSTAT was established as an independent legal entity under the Law on Statistics of December 11, 2009, N 2291-rs to be responsible for compiling and disseminating official statistics. Article 9 of the Charter of GEOSTAT (approved by the Presidential Decree No. 72 on February 1, 2010) mandated GEOSTAT to be in charge of all collection and dissemination of official statistics as well as the improvement in the coverage and quality of official data responsible by GEOSTAT as well as by other government agencies. Article 7 of the Law authorizes the GEOSTAT to work out a statistical activities program; and carry out statistical activities, which sets the central position of the GEOSTAT in the Georgian statistical system.

Accordingly, collecting, compiling and disseminating CPI and PPI and analyzing the inflation dynamics are defined as the main functions of the Price Statistics Division of GEOSTAT. No other institution compiles alternative inflation estimates.

Article 25 of the Law on Statistics authorizes GEOSTAT to request from the administrative bodies and other physical and legal entities and receive all the statistical and other information (including confidential information) from them necessary for carrying out its functions.

Arrangements to promote consistency of methods and results are set up by the Board of the GEOSTAT, which has representatives from other data producing agencies, namely the NBG, the MOE, and the MOF.

In addition to that, the President of Georgia approves annual State Program for Development of Statistics. The compilation and dissemination of price statistics are stated in the State Program (e.g., for current year there is an updates on CPI weights).

\subsubsection{Data sharing and coordination among data-producing agencies are adequate.}

Article 5 of the Law on Statistics requires that GEOSTAT cooperate and coordinate with the local organizations producing the statistics in order to achieve efficiency. Article 16 of the Law on Statistics stipulates that GEOSTAT coordinates exchange of information among the administrative bodies in order to produce the statistics and facilitates effective 
implementation of the statistical standards and methodology approved. In addition, there are memorandums of understanding between the GEOSTAT and the MOF, GEOSTAT and Education Quality Development Center, and GEOSTAT and the NBG covering the sharing of macroeconomic data. GEOSTAT is the sole compiler of price statistics.

Within the GEOSTAT, the internal procedures are in place to ensure coordination between various divisions, namely Business Statistics Division, Agriculture and Environmental Statistics Division, Social Statistics Division, Population Census and Demographic Statistics Division, Price Statistics Division. All proposed changes in questionnaires as well as other changes in the production of statistics is preceded by consultations and need to be approved by the Board of the GEOSTAT.

The central role of GEOSTAT in the field of statistics is further reiterated in Article 2 of the Charter of GEOSTAT, which states that the GEOSTAT should work out a unified policy for the field of statistics, prepare and introduce statistical standards and methodology, create and realize statistical classification system, create and improve statistical databases, information banks and networks; and create and approve statistical observance forms for producing official statistics. Such centralized statistical system in principle guards against duplication of efforts and unnecessary burden on respondents. There is no arrangement for regular meetings of all technical staff responsible for macroeconomic statistics. Such meetings provide a comprehensive arena for exchanging information on current and forthcoming projects for statistical development, promoting cross-sectoral data consistency crucial for macroeconomic policy making, and coordinating work programs to avoid duplication of effort, ensure coherent application of methodology at all stages of data collection, and enhance effectiveness. Nevertheless, these agencies have several bi-lateral meetings and arrangements for collaboration on data issues e.g., the GEOSTAT has a memorandum of cooperation with the NBG as well as a working group with NBG dealing with CPI. In addition, Vice-President of NBG is GEOSTAT board member, ensuring cooperation at the higher level and there are regular informal contacts with the staff of other data-producing agencies.

\section{Recommendation:}

Conduct pre-established, regular meetings, such as one per year, to improve communication among data compilers at NBG, GEOSTAT, and MOF, by discussing issues of common interest, avoid duplication of efforts, and ensure the consistency of macroeconomic statistics (national accounts, monetary, fiscal, and external sector.) 


\subsubsection{Individual reporters' data are to be kept confidential and used for statistical purposes only.}

GEOSTAT has adequate legal and procedural provisions to ensure confidentiality of individual reporters, and in satisfactorily follow these in practice. Article 26 of the Law on Statistics states that statistical data shall be public except for the data which allows for identification of observation unit. Article 28 states that the confidential statistical data shall not be issued or disseminated or used for a nonstatistical purpose with exceptions envisaged by the Georgian legislation. When producing the official statistics it is obligatory to destroy or store separately the identity data including the questionnaires containing such data. According to Article 29 of the Law, the employees of the GEOSTAT should not use or disseminate confidential statistical data either for the personal, academic, research or any other activities. Violation of these provisions will lead to imposing a disciplinary responsibility against employee, notably in view of the guilt or/and the damage inflicted the Executive Director shall impose the following disciplinary penalties: warning, withholding a salary, and/or dismissal.

GEOSTAT staff are required to keep individual data confidential by Law and the staff is well informed by the requirement. Access to individual data both to the actual forms and to the computer records is restricted to the appropriate staff. The procedures are adopted that prevent residual disclosure. There are special aggregation rules that ensure that unintended disclosure does not occur. Respondents to surveys are informed about the confidentiality of their responses (relevant statement is included in each survey form). Archive procedures ensure appropriate storage of information with clearly articulated rules.

\subsubsection{Statistical reporting is ensured through legal mandate and/or measures to encourage response.}

Article 25 of the Law on Statistics sets the obligation to provide statistical and other information to GEOSTAT, notably upon the request and according to the legislation of Georgia the administrative bodies shall be obliged to provide the GEOSTAT with the information on physical and private entities (including confidential information) available to them. However, no sanctions for nonreporting or misreporting are stipulated by the Law and, due to lack of legal and administrative support, very senior staff at times is required to intervene in order to get the respondents to collaborate.

With its price surveys nonreporting has not been an issue for GEOSTAT and no deterioration in response rates has been observed. However, the response rates have declined in the larger annual Business Surveys also used for deriving the PPI weights. 


\section{Recommendations:}

Enact appropriate amendments to the Law of Georgia on Official Statistics to reinforce mandatory reporting of statistical data and ensure application of sanctions for nonreporting. If reporting is mandatory, penalties for noncompliance (including misreporting) act as effective deterrent, even if such provision rarely needs to be employed.

Establish mechanisms in place to promote the voluntary reporting of data.

\section{$0.2 \quad$ Resources}

\subsubsection{Staff, facilities, computing resources, and financing are commensurate with statistical programs.}

Staff resources at the Price Statistics Division (PSD) are barely sufficient for carrying out the day-to-day compilation work for both CPI and PPI. To further improve the quality of its statistics and undertake tasks, like establishing central price collection for complex products for CPI and PPI, and participating in the International Comparison Program (ICP), additional staff resources are needed. The current staff level is fully occupied with the routine monthly cycle and tasks related to issues like identifying alternative data sources, evaluating and adjusting the weight data against additional information, improving the quality adjustment methodology, etc. The Price division employs 7 central staff, all with university education with economics as the main subject. All staff members divide their time between the CPI and the PPI, roughly in a 70 to 30 proportion, respectively. In addition, there are 20 field collectors in the regions who work with the data collection and receive direct guidance and training from the PSD staff. This is, by international comparison, a small organisation for compiling price statistics. Staff turnover has been very slow in recent years regardless of the significantly below-average remuneration within the public sector.

All employees have their personal computers, and the network services within GEOSTAT and between the regional offices seem sufficient. While new statistical software licences have been acquired with donor assistance, there are issues with maintaining other IT infrastructure up-to-date. The data processing resources have recently improved significantly with the implementation of hand held computers (USAID funded) and accompanied software for CPI data collection and transfer, as well as a Delphi based index compilation system. However, the PPI compilation process still relies on out-dated technology that ties the scarce staff resources at the central office. Current 3-year bilateral cooperation with Statistics Sweden is expected to address these issues shortly.

The GEOSTAT makes good use of its existing resources but, overall, GEOSTAT suffers from inadequate resources, as acknowledged by the data users. The limited resources partially explain a great disparity in average salaries between staff of GEOSTAT and other 
government agencies. To supplement its limited resources, GEOSTAT participates in various statistical programmes with the financial supports from donors. While these partnerships provide significant benefits to the GEOSTAT, the financial dependency on donors increases the risk on sustainability of these data programs. The new GEOSTAT central office facilities are appropriate but the long distance from other government offices and the GEOSTAT Tbilisi office may, to a degree, hamper day-to-day communication within the organization and with its key users.

\section{Recommendation:}

Increase the overall staff, IT, and financial resources for the GEOSTAT.

\subsubsection{Measures to ensure efficient use of resources are implemented.}

The GEOSTAT Board provides overall supervision of the organization of statistical work and oversees strategic plans for statistical development. In order to ensure the efficient use of resources the following measures are undertaken: (i) the thorough planning of statistical works (on multi-annual, annual and quarterly basis); (ii) the permanent monitoring of the appropriate use of resources according their destination. The Internal Audit Division carries out inspections of the staff of regional staff and monitors the resource use within the budgeting and execution of the Annual and Mid Term Actions Plans.

Special attention is granted to the improvement of the staff performance, especially its qualifications and abilities. Time to time, staff receive differentiated bonuses based on the assessment of the heads of divisions.

Outside consultants are widely used to evaluate statistical methodologies and compilation systems.

\subsection{Relevance}

0.3.1 The relevance and practical utility of existing statistics in meeting users' needs are monitored.

The relevance of statistical program is ensured by the Board of the GEOSTAT, which consists of seven members and a Chairman, with the following composition: one representative of the NBG, one representative of the Ministry of Economy and Sustainable Development, one representative of the MOF, and other five members, which represent private sector. The Parliament of Georgia should give consent to appoint the members of the Board (Law on Statistics, Article 11). The Board also serves as an advisory group to inform statistical processes. In addition, Article 5 of the Law on Statistics encourage cooperation with the international organizations in order to introduce the international practice and 
methodology and share relevant experience based on the agreements and treaties concluded with the international organizations engaged in this field.

Article 7 of the Law on Statistics stipulates that GEOSTAT should produce the statistics that are approved and or recognized by the Board of the GEOSTAT, and also should need arise; the GEOSTAT is authorized to produce the statistics which is not envisaged by the statistical activity program. Executive Director submits the statistical activity program for approval to the President of Georgia (Article 9 of the Law on Statistics).

In addition, to enhance the relevance of its statistics, GEOSTAT consults various use groups both on a regular and ad hoc basis. Eurostat (as one of users) performs regular quality checks of reported data. Their requirements are monitored and addressed in consistent manner. The broader group of users is approached directly in some statistical events (e.g., during celebration of International Statistics Day). Users are also encouraged to provide feedback via GEOSTAT official website and its social networks (e.g., Facebook). However, there is no regular venue for the users to discuss the issues related to the price statistics and their development.

\section{Recommendation:}

Establish a users' advisory group for price statistics that meets on a regular basis and includes all types of users.

\subsection{Other quality management}

\subsubsection{Processes are in place to focus on quality.}

The GEOSTAT commitment to quality is stipulated by law and well publicized. Article 1 of the Law on Statistics states that its goal is to ensure producing independent, objective and reliable statistics in the country based on the internationally recognized basic principles of statistics. Reflecting the spirit of this law, the GEOSTAT's mission statement emphasizes the improvement and harmonization of statistical activities and the maintenance of independence, accuracy, relevance, integrity, timeliness, and professional standard of statistical information produced in Georgia. GEOSTAT is finalizing the NSDS that includes special chapter on quality.

Quality policy is based on the provisions of national and EU legislation, Strategy of GEOSTAT, European Statistics Code of Practice, user needs and expectations. It defines overall intentions and directions of institution related to quality. The management of the institution is giving priority to building trust and increasing the credibility of the statistics produced by GEOSTAT. From the ROSC Users' survey, users indicated that in the last few 
years GEOSTAT disseminates more statistics, survey results, and information on methodology as well as becomes more responsive to their queries.

Conscious of value of independent quality assessment, GEOSTAT regularly participates in international evaluations, such as the IMF ROSC Data module and the World Bank's statistical capacity indicators. It also conducts regular communications with Eurostat on data quality issues.

\subsubsection{Processes are in place to monitor the quality of the statistical program.}

The GEOSTAT regularly reviews and plans improvements to their internal processes. More formal annual Statistical Program is produced annual and approved by the President of Georgia. The newly created Monitoring Department is responsible for operating the monitoring, control and internal audit. The Internal Audit Division is established in GEOSTAT for systematic internal reviews of GEOSTAT processing including data collection and processing.

The expert guidance on the quality of their statistics is also ensured vie peer reviews within the framework of cooperation with other statistics agencies. GEOSTAT has established longterm cooperation with Statistics Sweden. Strategy of cooperation in price statistics is based on three-year plan of Developing Georgian CPI and PPI. There is also established Cooperation with the Central Statistical Office of Latvia.

\subsubsection{Processes are in place to deal with quality considerations in planning the statistical program.}

The Board of GEOSTAT coordinates the economic statistics work program, including explicit decisions about quality and trade-offs among the dimensions of quality (e.g., resource availability, timeliness, and accuracy/reliability.) The quality dimensions are also recognized explicitly in the NSDS.

\section{Assurances of integrity}

\subsection{Professionalism}

\subsubsection{Statistics are produced on an impartial basis.}

Article 6 of the Law on Statistics stipulates that GEOSTAT independently carries out its activities based on the Georgian legislation. Article 1 of the Charter of GEOSTAT, 2010 further elaborate that the GEOSTAT carries out its activities based on the Georgian legislation, internationally accepted statistical principles, Law on Statistics, Law of Georgia on Legal Entity of Public Law, this Charter, GEOSTAT Board's regulations and other 
normative acts. The GEOSTAT acquires rights and obligations to implement the goals established and functions assigned to it. There is no external pressure on the GEOSTAT with respect to the content or release of the statistics.

On the above premise, all official statistics including price statistics are compiled on an impartial basis. The basic principles governing the collection, processing, and dissemination of statistics in Georgia includes professional independence, objectivity, reliability, confidentiality of statistical data, and efficiency (Law on Statistics, Article 4).

The Executive Director of GEOSTAT is appointed by Board of the GEOSTAT for the term of 4 years and may be dismissed by the President of Georgia only under special circumstances (Article 8 of the Law on Statistics). The Executive Director is authorized to invite foreign or local experts on the contractual basis in accordance with the recommendations of the members of Board of the GEOSTAT in order to ensure effective operation of the GEOSTAT (Article 9.2).

Professional competency plays a key role in the promotion practices in the GEOSTAT and professional enhancement is encouraged.

\subsubsection{Choices of sources and statistical techniques, as well as decisions about dissemination, are informed solely by statistical considerations.}

The choices of sources, statistical techniques, and dissemination of price indices are made solely by the GEOSTAT based entirely on statistical considerations. There has been no instance of ministerial interference in the choice of the statistical sources and methods.

\subsubsection{The appropriate statistical entity is entitled to comment on erroneous interpretation and misuse of statistics.}

The GEOSTAT provides explanatory materials in the price statistics press releases and on its website. The GEOSTAT monitors media coverage of its statistical products and has the authority to comment on erroneous interpretation and misuse of the statistics that it produces. At times, senior staff of GEOSTAT corrected the misinterpretation of statistics by media.

\subsection{Transparency}

\subsubsection{The terms and conditions under which statistics are collected, processed, and disseminated are available to the public.}

The terms and conditions governing the collection of statistics are published in the Law on Official Statistics and in Charter of GEOSTAT, which are widely available to the public, including from the GEOSTAT website 
http://www.geostat.ge/index.php?action=page\&p_id=29\&lang=eng. In addition to legal provisions, the GEOSTAT website contains other relevant documents, such as the National Strategy of Development of Statistics, annual report of the GEOSTAT, information about the SDDS, and information about individual statistical products.

\subsubsection{Internal governmental access to statistics prior to their release is publicly identified.}

The GEOSTAT disseminates the price statistics to all users simultaneously. There is no governmental access to statistics prior to release.

\subsubsection{Products of statistical agencies/units are clearly identified as such.}

Products of the GEOSTAT are clearly identified as such by its name and logo. The price statistics in the NBG's publications and website identify the GEOSTAT as the source. However, in the GEOSTAT publications, there are cases, in which that attribution is not made to the source, when statistics from other data-producing agencies is reproduced but does not concern the dissemination of price statistics.

\subsubsection{Advance notice is given of major changes in methodology, source data, and statistical techniques.}

The GEOSTAT provides advance notice about major methodology changes in price statistics in the Annual and Mid-Term Action Plans as well as in the National Strategy for the Development of Statistics in Georgia (2011-2014), available on the GEOSTAT website (http://www.geostat.ge/index.php?action=page\&p_id=794\&lang=eng). Advance notice was provided for major changes such as the PPI weight revisions, seasonally adjusted estimates, changes in business survey questionnaire, etc. For the upcoming PPI revision a note will be added on the GEOSTAT website and PPI press release.

\subsection{Ethical standards}

\subsubsection{Guidelines for staff behavior are in place and are well known to the staff.}

On its website, the GEOSTAT states that the Fundamental Principles of Official Statistics developed by United Nations Statistical Commission were at core in drafting the Law on Statistics and consequently establishing the GEOSTAT (http://www.geostat.ge/index.php?action=page\&p_id=32\&lang=eng). The Fundamental Principles stipulate that for retaining trust in official statistics, the statistical agencies need to act according to strictly professional considerations, including professional ethics. New staffs are made aware of the ethical standards when they join the GEOSTAT. 
Guidelines for Effective Communication, a code of conduct -document last updated in August 2011 and approved by the Executive Director, gives further guidance for the GEOSTAT staff on how to interact with other staff and external stakeholders.

\section{Methodological soundness}

\subsection{Concepts and definitions}

\subsubsection{The overall structure in terms of concepts and definitions follows internationally} accepted standards, guidelines, or good practices.

With some deficiencies, the concepts and definitions used to compile the PPI follow broadly the guidelines in the 1993 SNA and the PPI Manual. Instead of output, turnover is used at all aggregation levels, and the PPI is not compiled by product detail. Furthermore, only products under the primary activity of the enterprise are included for pricing and assigned weights. Otherwise the industrial and commodity detail for pricing purposes are sufficient and provide reasonable breakdown of the industrial sector, even though the PPI is not compiled and disseminated based on product classification. The separate Construction sector PPI is in effect an input (material only) PPI instead of an output PPI.

\section{Recommendation:}

Apply the output concept for the PPI weights at higher aggregation levels instead of turnover. Include also the products from significant secondary activities into the PPI sample.

\section{$2.2 \quad$ Scope}

2.2.1 The scope is broadly consistent with internationally accepted standards, guidelines, or good practices.

The scope of main PPI includes industrial production activities (mining, manufacturing and electricity, gas and water supply) and is broadly in accordance with international guidelines. However, product based PPIs, useful for internal validation and imputation purposes and for National Account deflation purposes, are not compiled. All resident market enterprises are in scope but only products under their primary activity are included into the PPI within an industry. At higher aggregate level, combining industries together, total turnover is utilized. The international recommendation is to include maximum feasible production, including primary and secondary production. At the headline PPI level this is achieved but within an industry the relevant importance of different products may not be fully representative.

The industrial output is some 20 percent of the total output and significant additional development work has been put to extend the coverage to the agricultural sector, construction 
and select service industries. The construction and freight transport PPIs are currently produced in addition to the industrial core as separate indicators.

\section{Recommendation:}

Consider compiling the PPIs also by product classification. This will also serve in improving imputation method within the PPI and make it more valuable for some key users.

\subsection{Classification/sectorization}

2.3.1 Classification/sectorization systems used are broadly consistent with internationally accepted standards, guidelines, or good practices.

The PPI utilizes standard European industrial classifications (NACE) for classifying the market enterprises in the Business Survey and corresponding CPA for their products. The product classification is only used to derive estimates within the most detailed industrial activities in the PPI.

\section{$2.4 \quad$ Basis for recording}

\subsubsection{Market prices are used to value flows and stocks.}

Internationally acceptably, market turnover at basic prices is used for the weight structure, excluding invoiced VAT, excise taxes, supply-and-sales trade margins, and transportation costs.

\subsubsection{Recording is done on an accrual basis.}

Actual prices from existing invoices are collected and they reflect prices received by the producer 'at the factory gate', excluding sales taxes and separately billed transport costs. More complex products where product sale and delivery may significantly differ in time and by customer type are specified in product descriptions.

\subsubsection{Grossing/netting procedures are broadly consistent with internationally accepted} standards, guidelines, or good practices.

There is no netting procedure in the PPI since it is a gross-weighted index. No stage of processing indices, for which net product weights would need to be determined, is currently produced either. 


\section{Accuracy and reliability}

\subsection{Source data}

\subsubsection{Source data are obtained from comprehensive data collection programs that take into account country-specific conditions.}

The PPI is based on (i) industrial turnover weights from the Business Survey and product weights from turnover breakdown within sampled enterprises' main products, and (ii) the price survey of sampled enterprises' main product transactions. Generally they provide adequate basis for the compilation of the PPI, but the completeness of the Business Register behind the sample, especially for some industries, may not provide an up-to-date source. The reliance of a standard paper questionnaire for all industries makes it possibly difficult to capture different and changing pricing policies across industries. The PPI weighting structure is based solely on the turnover by industry, not the market output. In addition, within the most detailed industry level the total enterprise turnover is distributed to a sample of products under the main activity only, excluding secondary products.

\section{Business Survey}

The sampling design and survey methodology for the Business Survey are adequate to draw industrial turnover estimates for the PPI. GEOSTAT conduct a quarterly business survey with a sample of 8500 enterprises, drawn from a Business Register of some 40000 active enterprises. The register is maintained from various administrative sources but suffers from accuracy and coverage. A full "actualization survey" for the register enterprises to update the information for all existing units was conducted in 2009 but no economic censuses have been carried out, even though sector-specific censuses for medium, small and micro enterprises have been started. For industrial enterprises this census is planned for year 2012 and this is believed to improve the quality of the Business Register and hence surveys relying on it.

All largest enterprises (some 2000 entities with either more than 1.5 Million GEL of turnover or more than 100 employees) are included in the survey whereas small and medium sized companies are sampled in a stratified random design (probability proportional to size), by NACE group and size. While good sample design ensures accuracy at different stratification levels, nonsampling errors such as issues with the business register completeness and accuracy of the reporting and nonresponse are probably more significant issue. Nonresponse among the largest enterprises has also increased after compulsory responding was relaxed.

The PPI weights are derived by first summing the turnover data by 4-digit NACE activity. While the turnover data are believed to be accurate and up-to-date due to the 2009 actualization survey, summing the register data itself still does not provide a fully accurate representation of the total. The weights reflect only the value of turnover of those 
establishments participating in the business survey and are not fully representative of the total value of turnover for a given industry (as is recommended). This may potentially lead to discrepancies and inaccurate representation, although believed to be minor, in the weight structure with respect to the annual total estimates.

\section{Price Survey and product weights}

The price survey is based on a sample of some 600 enterprises, chosen using cut-off sampling within each industrial activity. This sample and weighting structure is revised every other year. The sampled enterprises (rather than establishments recommended by the international standard) are visited and their main products (under their corresponding main activity) asked to be identified on the paper questionnaires delivered to them. GEOSTAT indicated that the number of multi-establishment enterprises in the PPI sample was small. Information on secondary activities is not accounted for. The relative sales volumes are estimated together with the respondents and typical product specifications selected for the price survey. Up to 4 main products are included for detailed specification and monthly pricing. In total, some 2000 detailed products are priced monthly.

Price collectors do all the contact with the companies. The price questionnaires, mostly in paper but also over fax or email, are used to collect invoiced product sales within the reference month. Reports should be submitted to the NSO not later than $8^{\text {th }}$ of the next month and the data are entered to the database up to the $9^{\text {th }}$. The PPI is compiled during the next few days and disseminated on the $15^{\text {th }}$. No special centralized collection for the PPI takes place and the same price collectors who collect data for the CPI are used also for the PPI data collection. The product specifications, specified by the respondent enterprises based on GEOSTAT's instruction, are generally described in terms of their physical characteristics only, leaving room for price differences stemming from transaction changes in specifications, e.g., whether quantity discounts were applied, or the product was exported or sold in the local market. However, the Price Division staff does not report difficulties in re-pricing the specified transactions with respect to the level of specification detail. The industrial production in likely to increase in complexity and relying on a standard paper form to capture different industries pricing and transaction specifications may not be provide sufficient source to deal with changes in specifications.

\section{Recommendations:}

Ensure that total turnover or preferably the total output covering the whole economy in scope is used for the PPI weights. Include weights also for secondary products since the PPI weights should reflect the total value of turnover for each sampled industry.

Seek ways to minimize the sources of nonsampling errors in the Business Survey. Updating the Business Register (by conducting an economic census), varying the establishment size 
stratification variable by sectors, and investigating the existence of potential systematic factors in nonresponse could help improve the quality of both the Business Register and Business Survey results.

Review all detailed transaction specifications and include description on the transaction specifications that detail the nonphysical characteristics of the sale. Introduce central price collection dedicated to deal with certain industries where pricing practices are complex since this would likely improve the quality of the price data in times of sample and quality changes.

3.1.2 Source data reasonably approximate the definitions, scope, classifications, valuation, and time of recording required.

The source data are reasonably consistent with the definitions, scope, and classifications of PPI statistics. The PPI weight data are currently derived from the business register which is updated continuously but more frequently for the larger enterprise than the small. The prices are actual invoiced prices but transaction specifications for some industrial products may leave it unclear when the production, delivery or sales actually take place.

\subsubsection{Source data are timely.}

Price collection finishes on the $8^{\text {th }}$ of the following month corresponding typically 80 90 percent response rate for the price survey. The annual turnover estimates are available and incorporated to the business register within 4-6 months after the survey period.

\subsection{Assessment of source data}

3.2.1 Source data-including censuses, sample surveys, and administrative records-are routinely assessed, e.g., for coverage, sample error, response error, and nonsampling error; the results of the assessments are monitored and made available to guide statistical processes.

The source data validation is generally adequate although there are no adjustments for the PPI weight data that would improve their accuracy relative to the actual turnover and production. Using output estimates is planned for the PPI revision in 2012.

For business survey, data entry is done by the GEOSTAT central office. The reported data go through initial plausibility and consistency checks. High-value transactions are confirmed with respondents. Survey errors are routinely assessed. If sample error is high, the stratum is collapsed to an upper digit level. Confidence intervals are calculated for all variables to assess the accuracy. Nonresponses are sorted by 7 reasons and analyzed ( 88 percent of nonresponse rate pertain to small enterprises). 
For the price survey, the data collectors check and confirm the paper forms for large changes from the previous month's prices before sending to central office supervisors who go through all forms again. At the time of entering the data into the PPI database large changes are evaluated and confirmed directly with the enterprises if necessary.

\subsection{Statistical techniques}

\subsubsection{Data compilation employs sound statistical techniques to deal with data sources.}

Statistical techniques are mostly adequate but certain practices fall behind the international standards. The accuracy of data collection method relies solely on the respondents' correct understanding of the questionnaire and methods to treat quality changes and missing prices do not reflect international recommendations and best practices.

Missing prices are carried forward until the index revision every other year, even in case the products become permanently unavailable. This is not a recommended practice, as missing prices should be imputed and products permanently missing should be replaced. Quality changes are generally not assessed for the degree they represent pure price change. Even though changes happen infrequently, no record of the replacements or specifications changes is kept when changes take place. The current PPI software does not allow for better handling of these changes but GEOSTAT is currently developing a new system for the PPI, expected to be operational already from January 2012 when the next index revision takes place.

For seasonal products the respondent enterprises need to fill in the questionnaire the December base prices even for unavailable products in January when the survey begins. They are instructed to use the last available price from previous year but it leaves a possible issue with year-to-year consistency in the long-term index series. There are a limited number of seasonal products in the PPI but their off-season missing prices, as with other temporary and permanently missing prices, are currently carried forward until they appear the following season.

\section{Recommendations:}

Update the related methods of imputing missing prices, treating of quality changes, and introduction of new products into the PPI. All missing prices should be imputed; quality changes should be accounted for using either implicit or explicit quality methods; or permanently unavailable items should be replaced. Implement appropriate imputation methods into the new PPI software being developed.

Consider estimating the December base price for seasonal products based on an average over a longer time period that would include actual prices for each transaction.

Price Statistics (Producer Price Index) 


\subsubsection{Other statistical procedures (e.g., data adjustments and transformations, and} statistical analysis) employ sound statistical techniques.

The PPI weights are based on gross sales, as is acceptable by international standards. The weights reference period refer to a year while the index and price reference periods to the month of December. The detailed product weights within each industry are derived from the turnover share of sampled enterprises main products, excluding secondary products.

The PPI is compiled using an internationally accepted formula, the weight updates are sufficiently frequent and longer time series are compiled linking annual indices together. Each product specification within an industry gets a weight based on the company weight and the product weight within the company. A standard Laspeyres formula based on longterm price changes is then applied.

\section{Recommendation:}

In order to implement sample changes consider changing the long-term elementary aggregate formula with either a weighted geometric average or the modified Laspeyres formula based on short-term price changes. Price-update the weights to align with the index reference period.

\subsection{Assessment and validation of intermediate data and statistical outputs}

\subsubsection{Intermediate results are validated against other information, where applicable.}

Difference between corresponding CPI and PPI products are compared and differences explained.

\subsubsection{Statistical discrepancies in intermediate data are assessed and investigated.}

Difference between corresponding CPI and PPI products are compared and differences explained.

\subsubsection{Statistical discrepancies and other potential indicators of problems in statistical outputs are investigated.}

Discrepancies with PPI series and global commodity prices and local CPI series are kept under review and reasons for discrepancies sought for.

\subsection{Revision studies}

Price Statistics (Producer Price Index) 
3.5.1 Studies and analyses of revisions are carried out routinely and used internally to inform statistical processes (see also 4.3.3).

The PPI estimates are released final as a policy. Some internal analysis on the impact of weight structure changes is carried out.

\section{Serviceability}

\subsection{Periodicity and timeliness}

\subsubsection{Periodicity follows dissemination standards.}

The PPI is compiled and released monthly, as required in the SDDS.

\subsubsection{Timeliness follows dissemination standards.}

The PPI is released just 15 days after the end of the reference month, meeting the SDDS requirements.

\subsection{Consistency}

\subsubsection{Statistics are consistent within the dataset.}

The aggregation structure follows industrial activity only and hence has no internal consistency issues with respect to aggregation.

\subsubsection{Statistics are consistent or reconcilable over a reasonable period of time.}

Monthly long time-series are available from year 2000 onwards. The data are published on series of quarterly and annual publications, available on the GEOSTAT website. At the time of methodological changes, the series are linked together to form long time-series. There is a policy of not revising the historical series, which is in line with international practice.

\subsubsection{Statistics are consistent or reconcilable with those obtained through other data sources and/or statistical frameworks.}

The PPI estimates are routinely compared with the corresponding sub-group CPI estimates and are largely consistent with them. The PPIs are also increasingly being used in the deflation within the national accounts.

\subsection{Revision policy and practice}




\subsubsection{Revisions follow a regular and transparent schedule.}

There are no revisions to the PPI series once disseminated. The PPI weight revision schedule of every two years has been in use since year 2000 and is explained to the users.

\subsubsection{Preliminary and/or revised data are clearly identified.}

Following internationally accepted practice, the PPI data are final upon release.

\subsubsection{Studies and analyses of revisions are made public (see also 3.5.1).}

Not applicable since data are final.

\section{Accessibility}

\subsection{Data accessibility}

5.1.1 Statistics are presented in a way that facilitates proper interpretation and meaningful comparisons (layout and clarity of text, tables, and charts).

The PPI data are released on the GEOSTAT website without analysis or commentary. The data are published as a set of Microsoft Excel-files that include total and sub-industry level short-term (month-on-month) and long-term (12-month change and period average) changes. The dissemination structure is common with the CPI and may be confusing for average user analyzing PPI trends over time. The Quarterly Bulletin includes longer consistent time-series for sub-industries.

Even though the data are available, some users may find the presentation difficult to interpret, especially since the PPI release does not include any commentary in form of text or graphs.

\section{Recommendation:}

Release the PPI with a monthly press release explains both recent changes in the index as well as showing longer-term trends.

\subsubsection{Dissemination media and format are adequate.}

The monthly PPI data by industry are available on the GEOSTAT website. Longer, consistent time-series are published on the Quarterly Bulletin, also on the website.

\subsubsection{Statistics are released on a preannounced schedule.}


An annual Statistical Calendar for all GEOSTAT publications is published in advance in the Publication calendar on the GEOSTAT website.

\subsubsection{Statistics are made available to all users at the same time.}

The PPI data are first released through the GEOSTAT website and is available for all users at the same time.

\subsubsection{Statistics not routinely disseminated are made available upon request.}

As a policy, all nonconfidential data are available from GEOSTAT upon request and special compilations can be provided to users. A list of available additional products and their fees is published on the GEOSTAT website.

\subsection{Metadata accessibility}

5.2.1 Documentation on concepts, scope, classifications, basis of recording, data sources, and statistical techniques is available, and differences from internationally accepted standards, guidelines, or good practices are annotated.

There are currently no written metadata on the Georgian practices available from the GEOSTAT, even though the website provides the link to the SDDS metadata and international price statistics manuals (CPI and PPI Manuals). Need for improving the accessibility of metadata in general and within the price statistics is acknowledged by the GEOSTAT and requested by users. Improvement in this field is a key area of the ongoing 3year cooperation program with the Statistics Sweden.

\section{Recommendation:}

Develop and disseminate metadata describing the concepts and methods to compile the PPI.

\subsubsection{Levels of detail are adapted to the needs of the intended audience.}

Currently the only PPI metadata available is the SDDS metadata on the dsbb.imf.org. The GEOSTAT is planning to produce a short metadata for the general user and a more detailed PPI Handbook during next year. 


\section{Recommendation:}

Produce and disseminate both detailed (for internal use and advanced users) and more general information about the use, compilation practices and methodology of the PPI.

\subsection{Assistance to users}

\subsubsection{Contact points for each subject field are publicized.}

A general email and telephone contacts are available on the GEOSTAT website and main publications. Main users are directly in contact with specific technical staff or the head of the Price Division.

\subsubsection{Catalogs of publications, documents, and other services, including information on any charges, are widely available.}

The GEOSTAT website provides list of all available publications and calendar or publication dates. In addition, a document "Prices for dissemination of statistical data generated beyond the statistical activity program of National Statistics Office of Georgia," (Degree No. 14, 2011, of Board of GEOSTAT) which sets the fees for disseminating additional statistical data. 
Table 4. Data Quality Assessment Framework (July 2003): Summary of Results for Price Statistics (Producer Price Index)

(Compiling Agency: National Statistics Office of Georgia)

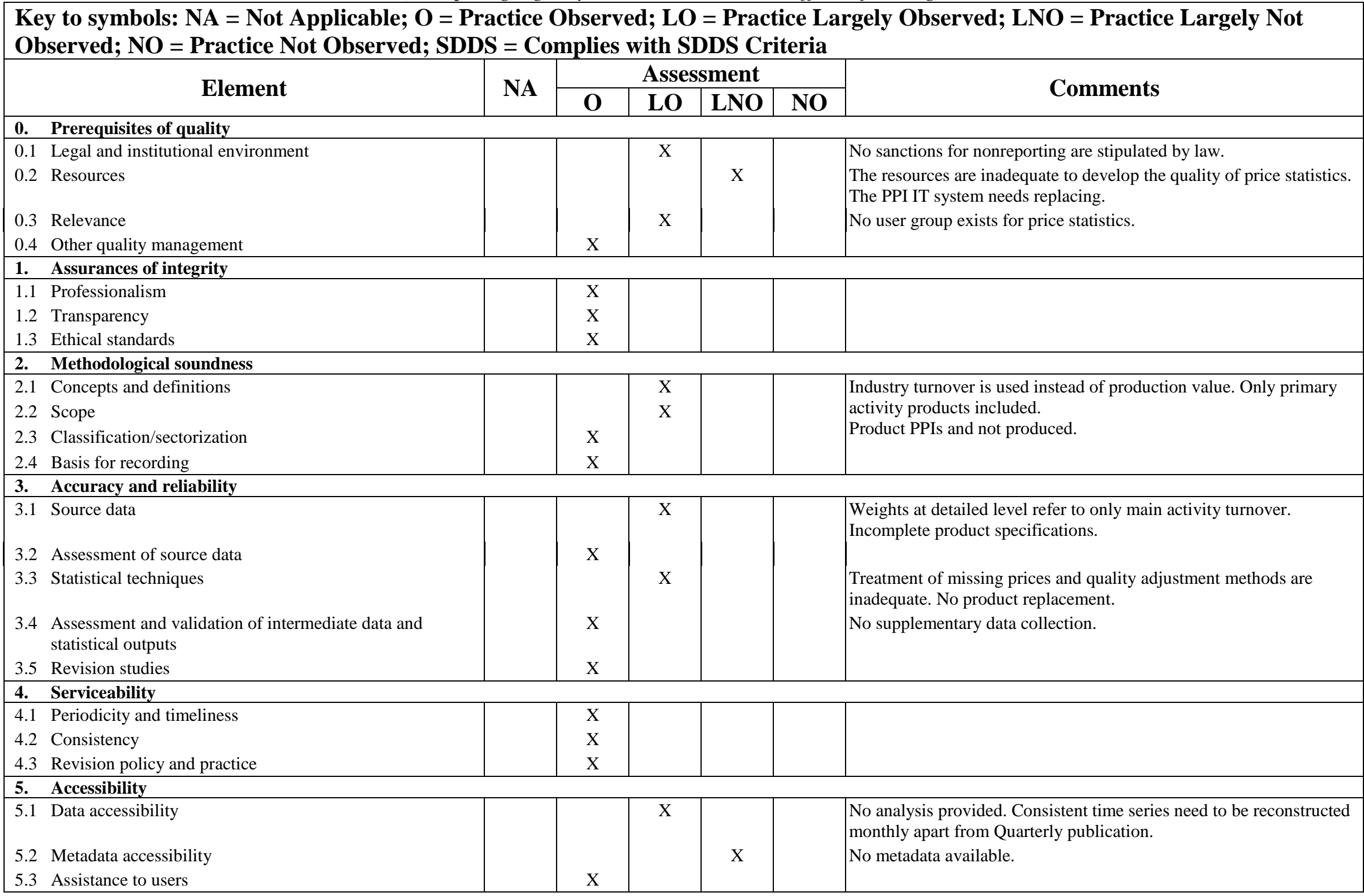




\section{Government Finance Statistics}

\section{Prerequisites of quality}

\subsection{Legal and institutional environment}

\subsubsection{The responsibility for collecting, processing, and disseminating the statistics is clearly specified.}

For budget monitoring and management purposes, the MOF collects and compiles data covering the operations of the consolidated central government ("State Budget,") local governments, and the consolidated general government under the provisions of the Budget Code (No. 2440-IIs of December 18, 2009) and the annual budget laws. ${ }^{2}$

Under Decree No. 241, article 61.e of April 20, 2011 the Fiscal Forecasting Department (FFD) of the MOF is assigned responsibility for collecting, processing, and disseminating information on general government's finances in accordance with the budget classification system. As part of the reform of public sector accounting in Georgia, in 2008 the existing budget classification was replaced with the economic classification of the Government Finance Statistics Manual 2001 (GFSM 2001). GFS, compiled on a cash basis in accordance with the methodology of the GFSM 2001, are an integral part of fiscal policy formulation. GFS are published on the MOF's website and reported to the IMF for publication in the IMF's International Financial Statistics (IFS) and Government Finance Statistics Yearbook (GFSY).

\subsubsection{Data sharing and coordination among data-producing agencies are adequate.}

Formal and informal arrangements exist for the exchange of data with other data producing agencies (both inside and outside the MOF.) On a formal basis - through a letter signed by the Minister of Finance — data are obtained from other government agencies, and local governments. The letter defines the required data, the level of detail, the periodicity and timeliness, and the format of the data transmission. Also, through a letter signed by the Head of FFD, data are obtained from other departments in the MOF. While management of the MOF clearly demonstrates the commitment to improve data quality through bi-lateral meetings and collaboration with other data producing agencies, there is no arrangement for regular meetings of all technical staff responsible for macroeconomic statistics. Such meetings provide a comprehensive arena for exchanging information on current and forthcoming projects for statistical development, promoting cross-sectoral data consistency crucial for macro-economic policy making, and coordinating work programs to avoid duplication of effort, ensure coherent application of methodology at all stages of data collection, and enhance effectiveness. No specific mechanisms exist to maintain close liaison between the FFD and the users of the fiscal statistics.

\footnotetext{
${ }^{2}$ The budget and other laws are available on the MOF's website: http://www.mof.ge .
} 


\section{Recommendation:}

Establish periodic, regular meetings with the technical data compilers of macroeconomic statistics at the NBG and GEOSTAT.

\subsubsection{Individual reporters' data are to be kept confidential and used for statistical purposes only.}

Confidentiality of the data is not normally applicable to general government units. The General Administrative Code (2181 of June 25, 1999) states that all central government units should make their information public (i.e., to any public or private sector entity) no later than ten days after the request, unless such information is declared as being secret according to the Law of Georgia on Official Secrecy (No. 455-Is of October 29, 1996).

\subsubsection{Statistical reporting is ensured through legal mandate and/or measures to encourage response.}

By decrees of the Minister of Finance, the source data producing departments in the MOF provide data to the FFD for GFS compilation. Mechanisms exist for reporting of local government data to the Local Government Division in the MOF's Budget Department.

The providers of source data are aware that their data are used by the FFD for GFS compilation and dissemination.

\subsection{Resources}

0.2.1 Staff, facilities, computing resources, and financing are commensurate with statistical programs.

The number of staff is adequate for the compilation and dissemination of cash-based GFS. Staff retention is high. Three staff members in the FFD compile GFS.

Knowledge of the GFSM 2001 methodology is very good, and two staff members have attended the IMF's GFS training courses on the GFSM 2001 methodology. In other MOF departments, knowledge of the GFSM 2001 methodology is also good. The FFD provided internal training on the economic and functional classifications of the GFSM 2001 when the budget classification was replaced in 2008 with the GFSM 2001 classifications.

Sufficient computer resources are allocated. All fiscal data compilation and dissemination by the MOF are automated. The FFD staff members each have a computer. The MOF is accommodated in a relatively new building with more than adequate office furniture and equipment.

Funding is secure and senior management advised that additional funding will be made available for future expansion of GFS as accrual accounting is introduced under the accounting reforms for public sector accounting. 


\subsubsection{Measures to ensure efficient use of resources are implemented.}

There are no formal processes for the review of staff performance. When necessary, the MOF seeks outside expert assistance to evaluate methodologies and compilation systems; for example, accounting and GFS advice have been an integral part of the accounting reform.

No separate cost information on the compilation of GFS is available as the allocation of resources is part of the overall management process of the MOF.

\subsection{Relevance}

\subsubsection{The relevance and practical utility of existing statistics in meeting users' needs are monitored.}

The use of GFS is largely limited to users within government and international organizations. GFS is an integral part of the budget process and fiscal forecasting and policy making. Although there is regular contact with users in the MOF, the NBG, GEOSTAT, and the IMF, there is no formal consultation with external users. There has been little contact with external users since the MOF commenced dissemination of GFS on their website, as data and methodological requirements have generally been met by material on the website. However, the MOF promptly and readily responds to users' requests.

No special studies are undertaken to identify emerging data requirements. The MOF monitors developments in international statistical and accounting standards.

\section{Recommendation:}

Introduce a structured and periodic process of consultation with users.

\subsection{Other quality management}

\subsubsection{Processes are in place to focus on quality.}

The GFS are compiled from accounting data which are subject to the application of the budget law and accounting standards, audit, and review by the parliament.

Particular attention is placed on the quality of accounting data. The ongoing reform of public sector accounting included the adoption in 2008 of the GFSM 2001 classification as the budget classification for central and local governments. This program will see the changing of accounting standards and procedures to adopt the International Public Sector Accounting Standards (IPSASs) by 2020. Adoption of the IPSASs includes the implementation of accrual accounting. 


\subsubsection{Processes are in place to monitor the quality of the statistical program.}

The MOF uses various means to monitor the quality of GFS. Central government and local governments use the same chart of accounts, which enhances the consistency of the data reported. Annual data for central government and local governments are audited by the Chamber of Control against published accounting standards.

The FFD verifies the quality of the monthly source data by comparing the data with those of the previous period. Large changes in trends are also investigated. The FFD relies on the professional judgment of the staff working with the GFS data.

There are no surveys using estimates. Quality control processes for GFS compilation have not been formally documented.

\subsubsection{Processes are in place to deal with quality considerations in planning the statistical program.}

Quality considerations are taken into account in the work program planning process; for example, the ongoing accounting reform which includes the full implementation of the GFSM 2001 methodology.

The FFD made a trade-off between timeliness and accuracy in the case of GFS for the general government sector, with data being released two months, rather than the preferred one month, after the reference month. GFS for the central government are released one month after the reference month.

There are no systematic arrangements in place to obtain feedback from users of GFS on the quality of the statistics.

\section{Assurances of integrity}

\subsection{Professionalism}

\subsubsection{Statistics are produced on an impartial basis.}

There are no specific laws that establish the professional independence of those responsible for GFS compilation. Fiscal data are compiled under the budgetary laws primarily for purposes of budget monitoring and fiscal policy analysis, and for reporting to international organizations in accordance with international standards. These laws and standards establish detailed procedures to be followed for all aspects of data collection and processing and hence ensure the production of fiscal data on an impartial basis. The GFS compilers cannot change any of the source data provided by the Treasury and other MOF Departments, unless such changes are the result of revisions.

Recruitment is based on relevant expertise and educational qualifications and in accordance with The Law of Georgia on the Public Service (No. 1022 of October 31, 1997). Staff 
retention is very good. Two out of three GFS staff members have attended the IMF's GFS courses on the GFSM 2001 and on-the-job training is provided internally.

\subsubsection{Choices of sources and statistical techniques, as well as decisions about dissemination, are informed solely by statistical considerations.}

The GFS compilers are free of political influence in the choice of the most appropriate data sources and methods for compiling GFS, and changes in the statistical procedures are made on the basis of technical rather than political criteria. Data sources are selected according to both the basis of recording and the availability of the information needed to compile and disseminate fiscal statistics.

Selection of statistics for publication or other dissemination is in accordance with the recommendations of the GFSM 2001 and the timing of release follows the requirements of the SDDS.

\subsubsection{The appropriate statistical entity is entitled to comment on erroneous interpretation and misuse of statistics.}

Apart from international organizations, use of GFS is very limited outside the government sector in Georgia. Generally, erroneous interpretation and misuse of statistics are rare. Nevertheless, GFS compilers are allowed to provide expert advice on technical aspects of GFS and to respond to public misinterpretation of statistics. Data provided to the GEOSTAT and the NBG for dissemination in their media are not accompanied by any explanatory material to avoid misinterpretation. Extensive explanatory material is provided by the MOF when the State Budget is tabled in Parliament.

\subsection{Transparency}

\subsubsection{The terms and conditions under which statistics are collected, processed, and disseminated are available to the public.}

The current compilation of fiscal data takes place under the provisions of the Budget Code (No. 2440-IIs of December 18, 2009) and annual budget laws, as it is done mainly for budget monitoring and management purposes. Information about this law, like all other government laws, is freely available to the public. GFS published by GEOSTAT and the NBG are sourced to the MOF.

\subsubsection{Internal governmental access to statistics prior to their release is publicly identified.}

The MOF provides GFS to the NBG two to three days prior to the simultaneous release of GFS on the MOF's and NBG's websites. This is to enable the NBG to prepare the National Data Summary Page. Generally, there is no other internal government access prior to the release of GFS. However, in the event that GEOSTAT requires the data for input to their statistics, they are prohibited from publishing any GFS ahead of the MOF's release. These arrangements are not publicized. 


\section{Recommendation:}

Publicly identify the arrangements with the NBG and GEOSTAT for internal government access to GFS prior to their release.

\subsubsection{Products of statistical agencies/units are clearly identified as such.}

The MOF releases GFS on its website and provides data to both the GEOSTAT and NBG for release in their products. The GEOSTAT and NBG source GFS to the MOF.

\subsubsection{Advance notice is given of major changes in methodology, source data, and statistical techniques.}

Methodological changes are usually announced in advance in the Budget Law and other laws for the corresponding year. Major changes, such as the accounting reform, are announced in advance on the MOF's website.

\subsection{Ethical standards}

\subsubsection{Guidelines for staff behavior are in place and are well known to the staff.}

There is no specific code of conduct for the compilation of GFS. However, all state employees are governed by a code of conduct according to the Law of Georgia on Public Service (No. 1022 of October 31, 1997), which also includes penalties for violations. This Law was disseminated to all staff when it was promulgated. When employees sign their employment contracts, they are referred to the existence of this law. The MOF has its own internal code of conduct (The Home Rule of the Central Apparatus of the Ministry of Finance of Georgia) approved under the decree of the Minister of Finance of October 10, 2007.

\section{Methodological soundness}

\subsection{Concepts and definitions}

2.1.1 The overall structure in terms of concepts and definitions follows internationally accepted standards, guidelines, or good practices.

Compilation of monthly, quarterly, and annual fiscal data follows the analytic framework prescribed by the annual budget laws. The annual budget laws are consistent with the analytic framework and methodology of the GFSM 2001.

Georgia is in the process of reforming public sector accounting. The strategy for the reform set out a phased plan for the migration to the full GFSM 2001 methodology, and the adoption 
of the IPSASs. ${ }^{3}$ In 2007 the functional classification of the GFSM 2001 was implemented and, in the 2008 budget, the budget classification was replaced with the GFSM 2001 economic classification and applied to central governments' cash-based accounting data in 2008 and to local governments' data in 2009. There is to be a phased transition to full accrual accounting by 2020 as the IPSASs are incrementally introduced. The transition to accrual-based GFS will follow the transition to full accrual IPSASs. Where there are differences between IPSASs and the GFSM 2001, it is planned to set up the system so that it will produce both IPSASs and GFSM 2001-compliant reports.

In 2011 eight pilot organizations are to prepare financial statements on a modified cash basis. This will be extended in 2012 to all central government organizations and LEPLs, other than public corporations, that will be required to prepare consolidated financial statements compliant with the cash-based IPSAS and include, as voluntary additional disclosure, modified cash information.

\section{$2.2 \quad$ Scope}

\subsubsection{The scope is broadly consistent with internationally accepted standards, guidelines, or good practices.}

\section{General government sector}

The institutional coverage of reported data in Georgia consists of central government, two autonomous republics, and local governments (67 administrative districts, towns, and cities) and the consolidated general government. Budgetary central government includes all ministries and budgetary organizations that are covered by the State Budget. There are no extrabudgetary funds. The two territories, Abkhazian Autonomous Republic and the Tskhinvali Region (the former South Ossetia Autonomous Region), which are not controlled by the central authorities, are excluded from the general government of Georgia.

\section{LEPLS}

There are a large number of entities set up by central and local governments as LEPLs whose institutional sector status is uncertain. Some 3,000 of 5,000 plus LEPLs are schools. A detailed sectorization of LEPLs has not been done so it is not known to which sector (general government, nonprofit institutions serving households, public nonfinancial corporations, or public financial corporations) units belong. Many LEPLs report to a line ministry, or to a local government. Many receive funding from the central budget, others have own-source revenue, and others are completely self financing. Some LEPLs also have the power to borrow.

\footnotetext{
${ }^{3}$ The Ministerial Decree November 2009 cancels the decree \#101 on the "Accounting Reform Strategy" of the Minister of Finance of Georgia, $10^{\text {th }}$ of February 2006. The 2006 decree included the migration to the GFSM 2001 methodology. The 2009 decree focuses on the implementation of the IPSASs.
} 
The data available on LEPLs' revenue and expenses varies. In the majority of cases the only data captured in the budget reporting system on LEPLs are the transfers to them from the State Budget or local government budgets. A minority of LEPLs are accounted for inside the State Budget, like a budgetary organization. In these cases all revenue, including ownaccount revenue and the final composition of expenditures, is captured by the budget execution data. There are others who, although they use the central Treasury Services for their accounting, are not inside the State Budget, and own-account revenue and expenditure details are not captured in budget execution data. The majority are completely independent in their accounting arrangements and operate their finances through commercial bank accounts, so that the only information captured by budget execution data is transfers to them from central or local governments' budgets.

\section{GFS coverage of stocks and flows}

Cash-based GFS is compiled and disseminated for central government, local government, and the consolidated general government. The MOF compiles monthly, quarterly, and annual data. The Statement of Sources and Uses of Cash and detailed tables on revenue, expense, transactions in assets and liabilities, and the functional classification of outlays are compiled. A partial balance sheet, showing liabilities only, is prepared for central government.

In addition, the MOF compiles and disseminates data for central government debt in accordance with the recommendations of the SDDS. Domestic debt covers loans from the NBG, securities issued by the central government, and some, but not all, old debt from the Soviet era. Information on the latter is not always available. External debt covers bilateral and multilateral loans and two Eurobond issues. Government guaranteed debt is not included in central government debt, but is separately disclosed as a memorandum item in the tables.

\subsection{Classification/sectorization}

The institutional sectors are defined in accordance with the recommendations of the GFSM 2001. The sectorization of the LEPLs has been an ongoing problem and will require further external technical assistance in order for it to be resolved. GFS are prepared for each of the subsectors of general government (central government and local government) and for the consolidated general government. 
The GFSM 2001 economic and functional classifications have been adopted as the budget classification. The central government units have used the new classification in the preparation of their cash-based accounting data from 2008 and the local governments from 2009. The following tables are compiled:

- $\quad$ Statement of Sources and Uses of Cash

- Revenue

- $\quad$ Expense

- Transactions in assets and liabilities

- $\quad$ Partial balance sheet (liabilities only for central government)

- $\quad$ Outlays by functions of government

- Transactions in financial assets and liabilities by sector

Liabilities are correctly classified as domestic or foreign according to the residence of the other party to the instrument.

In the case of LEPLS that are schools, the treatment of the issue of school vouchers is not in accordance with the recommendations of the GFSM 2001. The government has a 'student voucher' form of financing so that, in principle, the flow of funds is from the government to students (households) and then to the school LELPs. In practice, the flow of funds is direct from government to the LEPLs. In the GFS, the transfer is classified as a miscellaneous current transfer to schools. The students (households) that are in fact a party to the transaction do not appear in the actual accounting records because of administrative arrangements. Such payments should be rerouted so that the government is seen to be making the payment to the students (households), who are then deemed to make payments of the same amount to the schools. The issue of the school vouchers is a transfer - social assistance benefits.

\section{Recommendation:}

Review and update the sectorization of the LEPLs.

\subsection{Basis for recording}

\subsubsection{Market prices are used to value flows and stocks.}

Transactions are valued on the basis of the amount of receipts and payments in cash.

In accordance with the GFSM 2001, loans are valued at nominal value. Securities are not valued at market value, as recommended by the GFSM 2001, but at nominal value.

Amounts denominated in foreign currency are converted to Georgian Lari using the official exchange rate, as provided by the NBG, on the day of the transaction and, in the case of debt stocks, at the balance date. 


\section{Recommendation:}

Value securities at current market prices.

\subsubsection{Recording is done on an accrual basis.}

All transactions are recorded on the basis of cash received or paid.

The Treasury, in the MOF, currently has information on accrued interest and accounts receivable and payable. The next phase of the accounting reform will require central government units in 2012 to prepare financial data on a modified cash basis: i.e., financial statements on a cash basis with voluntary disclosures of some accrual items. The strategy for the accounting reform includes the full implementation of accrual accounting by 2020 .

\subsubsection{Grossing/netting procedures are broadly consistent with internationally accepted standards, guidelines, or good practices.}

Government finance transactions are correctly recorded in accordance with the grossing/netting procedures recommended in the GFSM 2001. Tax refunds are correctly classified as (negative) revenue transactions.

\section{Accuracy and reliability}

\subsection{Source data}

3.1.1 Source data are obtained from comprehensive data collection programs that take into account country-specific conditions.

Comprehensive and timely data are available for budgetary central government, local governments and the consolidated general government.

\section{Central government operations}

For central government reporting, a Treasury Single Account (TSA) system has been established and cash planning and management introduced. Georgia is in the process of reforming public sector accounting. The reform includes a phased plan for the migration to the full GFSM 2001 methodology. In 2007 the functional classification of the GFSM 2001 was implemented and, in the 2008 budget, the budget classification was replaced with the GFSM 2001 economic classification and applied to central governments' cash-based accounting data in 2008 and to local governments' data in 2009. There is to be a phased transition to full accrual accounting by 2020 as the IPSASs are incrementally introduced. Central government agencies ${ }^{4}$ will be required from 2012 to prepare cash financial statements with voluntary disclosures of modified cash information. In addition to the cash

\footnotetext{
${ }^{4}$ A list of central government agencies is available in the budget documentation.
} 
data, the Treasury currently has information on accrued interest and accounts receivable and payable.

\section{Central government debt}

Central government debt, sufficient to meet the requirements of the GFSM 2001, is available monthly. Domestic debt is provided by the Treasury and e External debt by the Foreign Relations Department of the MOF. Debt information is available by type of instrument, sector of the counterparty, and country of the creditor. For external debt, the data are available in creditor currency, US dollars, and Georgian Lari. Information on arrears is available and is separately disclosed in the GFS published tables.

\section{Local government}

Timely cumulative year-to-date and annual data on local governments' revenues, expenditures, and financing are available from the Budget Department's Local Government Division. Local governments are required to use the budget classification in the preparation of their data.

\subsubsection{Source data reasonably approximate the definitions, scope, classifications, valuation, and time of recording required.}

\section{General government operations}

The central and local government data are compiled in accordance with budget law. As the budget law is consistent with the recommendations of the GFSM 2001, source data are fully consistent with the GFSM 2001. The budget classification is based on the GFSM 2001 economic classification with additional detail built into the chart of accounts to address fiscal policy analytical requirements. The functional classification is the COFOG classification. Function is determined by the organizational classification of government agencies. The Treasury also prepares data for the consolidated general government.

\section{Central government debt}

Domestic and external debt source data are consistent with the requirements of the GFSM 2001 and the SDDS.

\subsubsection{Source data are timely.}

Source data for compiling GFS for the general government and its subsectors are extremely timely. Central and local government data are available within 15-20 days after the end of the reference month. Central government debt data are available approximately 15 days after the end of the reference period.

Cash flow data are provided monthly on a cumulative year-to-date basis. As the months and quarters are calculated from the cumulative data, the months sum to the quarters, and the 
quarters to the year. Regular contact is maintained with the Treasury and any discrepancies are investigated in consultation with the Treasury.

The fiscal year ends December 31. Fiscal data are compiled and audited within three months of the end of the year then submitted to Parliament for approval. Parliament approves the data within three months. Once approval is received, preliminary GFS are replaced with the final, audited data.

\subsection{Assessment of source data}

3.2.1 Source data-including censuses, sample surveys, and administrative records-are routinely assessed, e.g., for coverage, sample error, response error, and nonsampling error; the results of the assessments are monitored and made available to guide statistical processes.

The GFS are compiled from complete administrative records for transactions and debt stocks. The GFS compilers routinely assess the accuracy of the source data from the various departments of the MOF. Data inconsistencies and out-of-trend values are confirmed with the reporting departments, and documented.

\subsection{Statistical techniques}

\subsubsection{Data compilation employs sound statistical techniques to deal with data sources.}

GFS are compiled from comprehensive source data. Preliminary data are subsequently replaced by final audited data for each period.

\subsubsection{Other statistical procedures (e.g., data adjustments and transformations, and} statistical analysis) employ sound statistical techniques.

GFS are compiled from a comprehensive actual data and do not need any other statistical procedures.

\subsection{Assessment and validation of intermediate data and statistical outputs}

\subsubsection{Intermediate results are validated against other information, where applicable.}

The same GFS data are published on the MOF's and GEOSTAT's websites. No validations of intermediate government finance data are carried out, as no similar data are published elsewhere. Instead, validation of GFS compilation is done against the original source data (e.g., against the Treasury Department's data provided to the FFD). 


\subsubsection{Statistical discrepancies in intermediate data are assessed and investigated.}

Data are from accounting systems that are subject to cross-checks for accuracy.

Reported financial flow data on liabilities are reconciled with changes in the corresponding debt stock data.

\subsubsection{Statistical discrepancies and other potential indicators of problems in statistical outputs are investigated.}

There are no statistical discrepancies as GFS are compiled from Treasury records, and outputs are verified against the original source data.

\subsection{Revision studies}

3.5.1 Studies and analyses of revisions are carried out routinely and used internally to inform statistical processes (see also 4.3.3).

Reliability of source data is continuously assessed. Revisions to final budget execution data, and hence GFS, are rare, and occur only when an accounting error is detected. A GFS time series is maintained and any revisions are documented, so information can be retrieved for revision studies. However, as revisions are rare, no studies of revisions are carried out.

\section{Serviceability}

\subsection{Periodicity and timeliness}

\subsubsection{Periodicity follows dissemination standards.}

The periodicity of fiscal sector statistics meets or exceeds the SDDS periodicity requirements. GFS are released monthly, quarterly, and annually for central government and the consolidated general government. Central government debt is released quarterly and annually.

\subsubsection{Timeliness follows dissemination standards.}

The timeliness of fiscal sector statistics meets or exceeds the SDDS timeliness requirements. GFS for central government are released within one month of the reference month and for general government within two months of the end of the reference month. Central government debt data are released within two months of the reference quarter.

\subsection{Consistency}

\subsubsection{Statistics are consistent within the dataset.}

As quarterly and annual data are the sum of the months, concepts, definitions, and classifications are the same for all periodicities. GFS compiled by the FFD from consistent 
sources (e.g., those data compiled from the Treasury Department's records on revenues, expenditure and financing) are internally consistent. The cash deficit/surplus is equal to financing and major aggregates are equal to the sum of their components. Total expense and the net acquisition of nonfinancial assets according to the economic classification correspond with that in the functional classification of expenditure. Transfers paid by one level of government are equal to transfers received by another level of government.

Domestic financing is reconcilable with the change in domestic debt. Foreign financing data are reconcilable with the changes in foreign debt.

\subsubsection{Statistics are consistent or reconcilable over a reasonable period of time.}

GFS are compiled from budget execution data which follow the annual budget laws. Since 2008, the budget classification is fully consistent with the GFSM 2001 economic classification. An historical time series has been reconstructed on the basis of the new classification. Annual data back to 2002 are available on the MOF's website.

No official explanations of changes in trends, etc., are disseminated with the data, but the FFD can explain them, if users inquire.

\subsubsection{Statistics are consistent or reconcilable with those obtained through other data sources and/or statistical frameworks.}

National accounts and balance of payments statistics are compiled from general government data provided by the MOF to the GEOSTAT, and monetary and financial statistics are compiled from NBG records. All these data are largely consistent or reconcilable with GFS. The MOF, the NBG, and GEOSTAT have no formal mechanism in place for the reconciliation of the datasets.

\subsection{Revision policy and practice}

\subsubsection{Revisions follow a regular and transparent schedule.}

Ad hoc revisions to cumulative year-to-date data are made when needed. With the move to the TSA and a fully automated accounting system, revisions occur infrequently and generally are small. In the event of large revisions, the revisions are identified and recorded in the appropriate month. Users, on request, are advised of any such revisions.

Preliminary annual data are replaced by final audited data according to a regular, wellestablished and transparent schedule, as required by law.

\subsubsection{Preliminary and/or revised data are clearly identified.}

Preliminary data published in the GEOSTAT and NBG bulletins are clearly identified. However, preliminary data on the MOF website are not identified. Data provided by the FFD to users, within government and international organizations, are identified as preliminary. A footnote is added to tables to advise the revision of data when final data are available. 


\subsubsection{Studies and analyses of revisions are made public (see also 3.5.1).}

Studies and analysis of revisions are not undertaken by the FFD as revisions are rare.

Reasons for revisions are investigated and documented by the FFD, and are only made public when individual users enquire about the reasons for the revisions.

\subsection{Data accessibility}

\subsubsection{Statistics are presented in a way that facilitates proper interpretation and meaningful} comparisons (layout and clarity of text, tables, and charts).

The GFS are disseminated on the MOF's website in accordance with the requirements of the SDDS, and with a time series. The FFD is seeking management approval to release more detailed data on the MOF's website. Additional data are available on request. No commentary is provided with the disseminated tables.

GFS tables are available on the GEOSTAT's website, fiscal data are available in the National Summary Data Page on the NBG's website, and highly aggregate summary fiscal data are included in the NBG's bulletins.

GFS for Georgia are also published by the IMF in their IFS and GFSY publications.

\subsubsection{Dissemination media and format are adequate.}

The GFS are disseminated on the MOF's and GEOSTAT's websites in a format (Excel files) that facilitates re-dissemination. Additional data are available free of charge in paper and/or electronic formats.

\subsubsection{Statistics are released on a preannounced schedule.}

In accordance with the requirements of the SDDS, the MOF releases data as per the advance release calendar publicized on the MOF's website.

\subsubsection{Statistics are made available to all users at the same time.}

The GFS are released on the MOF's and NBG's websites simultaneously in accordance with the preannounced advanced release calendar on the MOF's website.

\subsubsection{Statistics not routinely disseminated are made available upon request.}

Detailed GFS, not released on the MOF's website, are made available to users on request. Although the availability of additional statistics is not made known on the MOF's website, national users are aware of the procedures for obtaining additional data. 


\subsection{Metadata accessibility}

5.2.1 Documentation on concepts, scope, classifications, basis of recording, data sources, and statistical techniques is available, and differences from internationally accepted standards, guidelines, or good practices are annotated.

Budget documentation and SDDS metadata provide information about the methodology used to collect and process the data. The SDDS metadata is regularly reviewed and updated. The budget documentation is available on the MOF's website and the SDDS metadata on the IMF's website. Reference is also made to the GFSM 2001. Methodological guidelines for central government debt are set out in the Law of Georgia on Public Debt.

\subsubsection{Levels of detail are adapted to the needs of the intended audience.}

Budget documentation and SDDS metadata are available to the public from the MOF's and IMF's websites, respectively. These are the two main sources of information on the GFS metadata.

\subsection{Assistance to users}

\subsubsection{Contact points for each subject field are publicized.}

Although the GFS data are sourced to the MOF in the products of the GEOSTAT or NBG, no contact person is publicized. Users (outside government) of GFS disseminated by the FFD know who to contact for enquiries. Otherwise, users contact either the FFD or any other MOF department for the specific data they require. The MOF provides prompt and knowledgeable service and support to users.

\section{Recommendation:}

Provide users with contact points and material to raise awareness on the use of GFS.

5.3.2 Catalogs of publications, documents, and other services, including information on any charges, are widely available.

The MOF does not have any catalogues of publications, documents, or other services. 
Table 5. Data Quality Assessment Framework (July 2003): Summary of Results for Government Finance Statistics

(Compiling Agency: Ministry of Finance )

\begin{tabular}{|c|c|c|c|c|c|c|}
\hline \multicolumn{7}{|c|}{$\begin{array}{l}\text { Key to symbols: NA = Not Applicable; } O=\text { Practice Observed; LO = Practice Largely Observed; LNO = Practice Largely Not } \\
\text { Observed; NO = Practice Not Observed; SDDS = Complies with SDDS Criteria }\end{array}$} \\
\hline \multirow{2}{*}{ Element } & \multirow{2}{*}{ NA } & \multicolumn{4}{|c|}{ Assessment } & \multirow{2}{*}{ Comments } \\
\hline & & $\mathbf{O}$ & LO & LNO & NO & \\
\hline 0.1 Legal and institutional environment & & \multirow{3}{*}{$\mathrm{X}$} & $\mathrm{X}$ & & & $\begin{array}{l}\text { No periodic, regular meetings of technical staff of the data producing } \\
\text { agencies. }\end{array}$ \\
\hline 0.2 Resources & & & & & & \\
\hline 0.3 Relevance & & & $\mathrm{X}$ & & & No formal consultation with users. \\
\hline 1.1 Professionalism & & \multirow[t]{2}{*}{$\mathrm{X}$} & & & & \multirow{3}{*}{$\begin{array}{l}\text { The public are not made aware of internal government access prior to } \\
\text { release of GFS. }\end{array}$} \\
\hline 1.2 Transparency & & & $\mathrm{X}$ & & & \\
\hline 1.3 Ethical standards & & $\mathrm{X}$ & & & & \\
\hline \multicolumn{7}{|l|}{ 2. Methodological soundness } \\
\hline 2.1 Concepts and definitions & & $\mathrm{X}$ & & & & \multirow{2}{*}{$\begin{array}{l}\text { Sectorization of LEPLs requires review. } \\
\text { Securities are valued at nominal value. }\end{array}$} \\
\hline 2.2 Scope & & $\mathrm{X}$ & & & & \\
\hline 3.2 Assessment of source data & & $\mathrm{X}$ & & & & \\
\hline 3.3 Statistical techniques & & $\mathrm{X}$ & & & & \\
\hline $\begin{array}{l}3.4 \text { Assessment and validation of intermediate data and } \\
\text { statistical outputs }\end{array}$ & & $\mathrm{X}$ & & & & \\
\hline 3.5 Revision studies & & $\mathrm{x}$ & & & & \\
\hline \multicolumn{7}{|l|}{ 4. $\quad$ Serviceability } \\
\hline 4.1 Periodicity and timeliness & & $\mathrm{X}$ & & & & \\
\hline 4.2 Consistency & & $\mathrm{X}$ & & & & \\
\hline 4.3 Revision policy and practice & & $\mathrm{X}$ & & & & \\
\hline \multicolumn{7}{|l|}{ 5. Accessibility } \\
\hline 5.1 Data accessibility & & $\mathrm{X}$ & & & & \\
\hline 5.2 Metadata accessibility & & & $\mathrm{X}$ & & & $\begin{array}{l}\text { Methodology is available from legislation on the MOF website. Link } \\
\text { is on the MOF website to SDDS metadata. }\end{array}$ \\
\hline 5.3 Assistance to users & & & $\mathrm{X}$ & & & $\begin{array}{l}\text { No contact points or material available to raise awareness on the use } \\
\text { of statistics. }\end{array}$ \\
\hline
\end{tabular}

CInternational Monetary Fund. Not for Redistribution 


\section{Monetary Statistics}

\section{Prerequisites of quality}

\subsection{Legal and institutional environment}

\subsubsection{The responsibility for collecting, processing, and disseminating the statistics is clearly specified.}

The NBG is the sole official agency designated to compile monetary statistics for Georgia. NBG's functions and powers are established by the Organic Law on the National Bank of Georgia. Article 3 (paragraph 3) of this law defines NBG's responsibility for “compiling and disseminating Georgia's financial and external sector statistics following international standards and methodology." Article 33 (section Informational Support of Execution of Monetary and Statistical Functions of the National Bank) ${ }^{-}$of the same law authorizes the NBG to request statistical and accounting reports, including confidential information, from the financial sector. Article 45 of the Organic Law authorizes the NBG to "request and receive from both public and private entities all statistical reports, accounting data, and other data (including confidential ones) necessary to perform the functions assigned to the NBG."

Chapter 12, Article 6 of the Regulation on the NBG's Activities confers responsibility for collection and processing of monetary data on the Macroeconomic and Statistics Department (MESD) of the NBG. The department comprises four divisions: the Macroeconomic Research Division (MRD), the Monetary Policy Division (MPD), the Monetary Statistics Division (MSD), and the Balance of Payment Division (BoPD). Of these four divisions, the MSD is responsible for compiling monetary and financial data.

Article 29 of the Law of Georgia on Activities of Commercial Banks requires that all banks operating in Georgia prepare and submit to the NBG reports in such a form and detail and with such a frequency as the NBG's regulations prescribe.

The MSD is responsible for reviewing and improving the statistical methodology and disseminating financial and external sector statistics as well as data within the SDDS framework.

\subsubsection{Data sharing and coordination among data-producing agencies are adequate.}

NBG's structural units exchange data and information via email. Computers within the department are linked by a local network. NBG's local network is protected from outside by the CISCO security appliance and the Threat Management Gateway. Staff from different NBG's departments did not have open access to shared drives of other departments. During the mission Information Technology (IT) Department of the NBG established a shared drive to facilitate information and data exchange between the MESD and the BSD. 
The NBG uses an Excel-based framework for the MFS compilation. Commercial banks transmit their data to the NBG over the Internet. Transmitted data are encrypted. Collected data are backed-up on a daily basis. Currently, the back-up server is located on-site in a remote building at a distance of about 100 meters away from the NBG's main administrative building. The mission was informed that the NBG was installing a remote back-up server at an off-site location about $15-20 \mathrm{~km}$ from the NBG headquarters. The server will ensure that no data will be lost in case of fire or a natural disaster.

Banks submit their daily balance sheets to the Banking Supervision Department (BSD) of the NBG. In addition, they provide the MSD with 54 supplementary reports for statistical purposes on a monthly basis. The MPD compiles daily monetary aggregates and aggregates on liquidity of the banking system and submits them to the MSD. The MSD posts the aggregates on the NBG's website. ${ }^{5}$

Bi-lateral meetings and arrangements for collaboration on data issues are maintained with other data producing agencies to promote a proper understanding of data requirements, to avoid duplication of effort, and to take into account reporting burden (e.g., by discussing changes to administrative processes before they take place.) To ensure efficient data sharing and coordination, the NBG and the GEOSTAT signed in 2010 a Memorandum of Understanding (MoU), which contains a set of rights and responsibilities for both of agencies to facilitate the exchange of information between these agencies. However, there is no arrangement for regular meetings of all technical staff responsible for macroeconomic statistics (NBG, MOF, and GEOSTAT). Such meetings provide a comprehensive arena for exchanging information on current and forthcoming projects for statistical development, promoting cross-sectoral data consistency crucial for macro-economic policy making, coordinating work programs to avoid duplication of effort, ensure coherent application of methodology at all stages of data collection, and enhance effectiveness.

\section{Recommendation:}

Conduct pre-established, regular meetings, such as one per year, to improve communication among data compilers at NBG, GEOSTAT, and MOF, by discussing issues of common interest, avoid duplication of efforts, and ensure the consistency of macroeconomic statistics (national accounts, monetary, fiscal, and external sector).

\footnotetext{
${ }^{5}$ The MSD also compiles monetary aggregates (MAs) at the end of each month. The MAs compiled by the MSD differ from those compiled by the MPD because MAs compiled by the MPD do not include accrued interest for deposits included into the definition of broad money.
} 
0.1.3 Individual reporters' data are to be kept confidential and used for statistical purposes only.

The NBG does not disclose confidential data of individual institutions or transactions. Article 20 (paragraph 1) of the Organic Law on the National Bank of Georgia establishes a legal framework for protection of information and confidentiality and states that "no present or former member of the Board of the National Bank and no employee or auditor of the National Bank of Georgia and the Georgian Financial Monitoring Office shall be entitled to permit access of an unauthorized person to confidential information, disclose, or publicize such information or use it for personal gain." The same law (Article 20, paragraph 3) stipulates that information on accounts and/or transactions of individuals and legal entities may be disclosed only by the decision of a court. A similar provision is specified in Article 17 of Law of Georgia on Activities of Commercial Banks.

The Staff Manual of the NBG addresses the obligation of NBG's staff to protect confidential information in Article 3.2.

Article 202 of the Criminal Code of Georgia envisages administrative, financial, and criminal sanctions for breach of confidentiality.

The NBG disseminates aggregated data only. Access to individual data is available to all MSD staff.

\subsubsection{Statistical reporting is ensured through legal mandate and/or measures to encourage response.}

The National Bank of Georgia has the legal authority to collect data from credit institutions as required for compiling statistics and to enforce mandatory reporting provisions as necessary. The authority is established by the Organic Law on the NBG, the Law of Georgia on Activities of Commercial Banks, and NBG's regulations and instructions.

As stated earlier, Article 33 (section Informational Support of Execution of Monetary and Statistical Functions of the National Bank) of the Organic Law on the NBG authorizes the NBG to collect statistical and accounting reports (including confidential ones) from the financial sector as it deems necessary to perform NBG's responsibilities under this law.

Article 29 of the Law of Georgia on Activities of Commercial Banks requires that banks submit to the NBG reports defined by the NBG norms. Article 30 of the same law envisages a wide range of sanctions and penalties for noncompliance and misreporting. Similar provisions are specified in NBG's Directive 242/01 of December 25, 2009 and Directive 92/01 of June 25, 2010. 
Financial institutions systematically comply with their reporting obligation, and there were no cases of nonreporting during the past years.

NBG's Directive 184 On Statistical Reporting Forms for Georgian Commercial Banks and Compiling Procedures of July 17, 2008 sets out specific requirements for compiling and reporting statistical forms by commercial banks, their periodicity, and timeliness.

NBG's directives contain detailed instructions and explanations on the preparation of statistical reports by credit institutions and their submission to the NBG. Meetings, seminars, and consultations with representatives of reporting institutions are held on an ad hoc basis. Their purpose is to respond to questions on the compilation of data and other information report forms to ensure that these are completed in accordance with the specified requirements. Draft new report forms and amended compilation instructions are shared with data reporters for comments. Data reporters also participate in regular meetings with the BSD where they can provide feedback to the BSD on data reporting requirements and obtain clarification on data reporting issues.

\subsection{Resources}

\subsubsection{Staff, facilities, computing resources, and financing are commensurate with statistical programs.}

The MSD compiles monetary statistics for Georgia. At the end of September 2011, the MSD had seven full-time staff assigned to compile and disseminate monetary statistics. The staff has university degrees in economics and accounting. Their experience ranges from six months for two newly appointed staff to 9 and 17 years for two senior staff. Key staff has long work experience in monetary statistics, and all staff periodically participates in seminars, conferences, and trainings organized by international organizations and other central banks. The NBG considers that staff numbers are adequate for compilation and dissemination of monetary statistics.

Funding is provided for statistical products within a short-term planning horizon of one year. The MESD prepares an annual budget of expenditures, which covers departmental needs (software, hardware, operational travel, stationery, etc.). Every department submits its budget of expenditures to the Finance and Accounting Department (FAD). The FAD incorporates budget needs of all departments into the NBG's unified budget.

Article 19 of the Organic Law on the NBG stipulates that remuneration of NBG's employees shall be comparable to the average wages across the Georgian banking system.

Computer resources appear adequate for performing the designated tasks. Each staff member at the MSD is assigned a desktop computer. 


\subsubsection{Measures to ensure efficient use of resources are implemented.}

The NBG implements specific measures to ensure efficient use of resources. The NBG has established a performance appraisal procedure for its staff. The appraisal is conducted every three years and is used as a basis for personnel decisions: salary increases or decreases, promotions, etc.

\section{$0.3 \quad$ Relevance}

\subsubsection{The relevance and practical utility of existing statistics in meeting users' needs are monitored.}

User requirements are monitored annually by means of user surveys. In addition, data users can provide their comments and feedback to the NBG using contact information on the NBG's website or a phone number specified both on the NBG's website and in the NBG's Bulletin of Monetary and Banking Statistics (BMBS).

The MESD conducts regular discussions with other NBG's departments involved in the design and implementation of monetary policy. These departments are internal users of monetary statistics and are in position to identify emerging data needs.

As stated earlier, the NBG staff periodically participates in statistical seminars and trainings organized by international organizations and other central banks.

\subsection{Other quality management}

\subsubsection{Processes are in place to focus on quality.}

The NBG recognizes that official statistics must have confidence of users. The NBG's management and MSD staff ensures that the quality of compiled and disseminated data is in compliance with key parameters of quality standards such as methodological soundness, accuracy and reliability, serviceability, and accessibility. To demonstrate their commitment to data quality, the NBG website provides information on various aspects of data quality such as reporting forms and guide and revision policies.

Data reported by ODCs are subject to validation checks at the collection and processing stages.

The NBG and banks are subject to annual mandatory audits (Article 59 of the Organic Law on the NBG and NBG's Directive 134/01 On Rules about External Audit for Commercial Banks). 
0.4.2 Processes are in place to monitor the quality of the statistical program.

The NBG has established a process to routinely monitor the quality of statistical data. In case problems are identified, the MSD works with banks to bring the quality of reported data in line with the standards recommended in the Monetary and Financial Statistics Manual (MFSM) and the Monetary and Financial Statistics Compilation Guide (MFSCG).

The MSD has access to expert guidance through established contacts with experts of international organizations, including the Fund. The process of compiling monetary statistics is continually reviewed and assessed in order to improve data quality requirements.

\subsubsection{Processes are in place to deal with quality considerations in planning the statistical program.}

One of the main goals of the work programs of the statistical divisions of the NBG is to focus on high quality statistics by extensive use of international standards. Taking into account the findings from the internal audit, the statistical programs and processes are revised and updated. Timeliness of data is considered one of the main priorities, as recognized by the recent SDDS subscription.

Feedback from users on quality standards and on new and emerging data requirements is taken into account in the work program planning process. The NBG receives comments from data users by distributing a questionnaire. Data users can also contact the NBG by telephone and email posted on the NBG's website and the $B M B S$.

\section{Assurances of integrity}

\subsection{Professionalism}

\subsubsection{Statistics are produced on an impartial basis.}

The NBG's independence is guaranteed by the Constitution of Georgia (Article 95, paragraph 4) and by the Organic Law on the National Bank of Georgia. Article 4, paragraph 1 of the Organic Law on the National Bank of Georgia states that the National Bank shall be independent in its activity. Legislative, executive, and other authorities shall not interfere in its activity or monitor its activity except for cases set forth by the Constitution of Georgia and the Organic Law.

The NBG is professionally independent. The NBG uses professional considerations and established methodological principles when compiling statistics. Staff of the NBG is free from political or other influences in choosing the most appropriate sources and methods.

Recruitment and promotion of staff are based on skills and expertise in relevant areas. Hiring to the NBG is regulated by the Law on Civil Service. Vacancies for open-ended positions are 
posted on the website of the Public Service Bureau and are open for everyone. Applicants are required to be citizen of Georgia, be fluent in Georgian, and have a university degree in a relevant discipline. Applicants for positions in the MSD must have a university degree in economics, finance, or accounting. The NBG has a three-month probationary period policy for newly hired employees.

Staff is promoted based on performance. All promotion proposals shall be approved by the president of the NBG.

Research and analysis are encouraged and published on the NBG website.

\subsubsection{Choices of sources and statistical techniques, as well as decisions about dissemination, are informed solely by statistical considerations.}

Balance sheets of the NBG and all commercial banks are the basic source for compiling monetary data. All commercial banks follow a standard chart of accounts. Reporting forms are designed to meet the requirements of the MFSM methodology and to follow best international practices. NBG's staff takes steps to ensure that the statistical methodology and source data applied for compilation of monetary statistics are consistent with the source data applied for BOP, GFS, and national accounts statistics.

Monetary data are disseminated following established procedures and are in line with SDDS requirements and the advance release calendar (ARC) posted on the NBG's website.

\subsubsection{The appropriate statistical entity is entitled to comment on erroneous interpretation and misuse of statistics.}

Public Relations Division of the NBG monitors financial press and mass media on a regular basis. Cases of misinterpretations or misuse of monetary statistics are brought to the attention of the publisher with a request to make appropriate corrections in the publication.

Provision of metadata in the $B M B S$ is also intended to prevent misinterpretation or misuse of monetary statistics.

In order to prevent misinterpretation of monetary statistics, journalists usually consult with the MSD's specialists regarding the content of information to be published.

\subsection{Transparency}

\subsubsection{The terms and conditions under which statistics are collected, processed, and} disseminated are available to the public.

The NBG's website provides a broad description of the terms, condition and dissemination practices of statistics. The relevant laws and legislative acts are posted in Georgian and 
English on the NBG's website. Copies of the legal documents can be obtained from the contact point. The NBG's website contains an ARC for major macroeconomic and financial data dissemination.

Georgia participates in the IMF's SDDS. Its metadata on monetary statistics are posted on the IMF's Dissemination Standards Bulletin Board (DSBB). The NBG's website provides a link to the country page on the DSBB.

Electronic versions of the relevant laws and legislative acts are available to the public in Georgian and English on the NBG's website. Copies of legal documents can be obtained from the contact point. The NBG's website contains an ARC for major macroeconomic and financial data dissemination.

\subsubsection{Internal governmental access to statistics prior to their release is publicly identified.}

There is no internal government access to the data before they are released to the public.

\subsubsection{Products of statistical agencies/units are clearly identified as such.}

The NBG's website and the $B M B S$ present monetary statistics compiled by the NBG and some macroeconomics statistics compiled by other agencies. Data compiled by the NBG are clearly identified. Both the $B M B S$ and the NBG's website include references to the source of statistics provided by other agencies.

The NBG provides the GEOSTAT with tables with monetary data to be published in the GEOSTAT's monthly Social and Economic Situation of the Republic of Georgia, where the NBG is identified as the source for such data.

\subsubsection{Advance notice is given of major changes in methodology, source data, and statistical techniques.}

There is currently no established procedure in place of NBG's giving an advance notice of major changes in the methodology, source data, and statistical technique. Major changes in source data and statistical techniques are announced and explained when a new data are published.

\section{Recommendation:}

Provide advance notice of major changes in methodology, source data, and statistical techniques, for example, within the press release of the previous period. 


\subsection{Ethical standards}

1.3.1 Guidelines for staff behavior are in place and are well known to the staff.

The NBG's Staff Manual identifies rules and standards of ethical conduct for NBG's staff. The Manual is available to all employees and establishes rights, responsibilities, and disciplinary actions for failure to meet standards prescribed by the Manual. ${ }^{6}$

\section{Methodological soundness}

\subsection{Concepts and definitions}

2.1.1 The overall structure in terms of concepts and definitions follows internationally accepted standards, guidelines, or good practices.

The concepts and definitions used by the MSD to compile the central bank survey and the ODC survey are broadly consistent with the guidelines of the MFSM. The ODCs survey covers commercial banks only. The depository corporations survey (DCS) is based on the balance sheets of the NBG and the sectoral balance sheet of commercial banks.

The NBG compiles the following main monetary aggregates:

- $\quad$ Reserve Money: currency outside the NBG, required and excess reserves of commercial banks with the NBG in national and foreign currency.

- $\quad$ Cash in Circulation: notes and coins outside the NBG.

- $\quad$ MO: cash in circulation excluding cash in vaults of commercial banks.

- $\quad$ 1: $M 0$ plus transferable deposits in national currency excluding deposits of commercial banks and the government sector.

- $\quad$ M2: M1 plus time deposits in national currency excluding deposits of commercial banks and the government sector.

- $\quad$ M3: M2 plus foreign currency deposits excluding deposits of commercial banks and the government sector.

\subsection{Scope}

2.2.1 The scope is broadly consistent with internationally accepted standards, guidelines, or good practices.

The ODCs survey covers commercial banks only. Data on credit unions, which represent less than one percent of total assets of the financial system, are collected by the NBG but not

\footnotetext{
${ }^{6}$ There was not any misconduct or violations of rules specified by the Manual in recent years.
} 
included into the coverage of the ODCs. As of end September 2011, Georgia's depository corporations sector comprised the NBG and 19 commercial banks. Banks in liquidation are not included into coverage of ODCs survey. ${ }^{7}$ Commercial banks report balance sheets, financial statements, special reporting forms for supervisory purposes, and statistical reporting forms to the NBG. Data reported by commercial banks to the NBG cover headquarters and domestic branches.

There are 18 credit unions in Georgia which accept deposits from their own members. Since their assets are very small (less than one percent of the total assets of the financial system), they are not included in the ODCs survey. Credit unions report to the NBG's Non-Banking Institutions Supervision Department (NBISD).

All other financial corporations (except exchange bureaus) - such as insurance corporations, microfinance organizations, and the stock exchange - also report to the NBG's NBSD. Data are used for supervision purposes only.

Going beyond the scope of monetary statistics, the NBG plans to compile the other financial corporations (OFC) survey with the accounts of insurance corporations representing the bulk of the OFC subsector.

\subsection{Classification/sectorization}

2.3.1 Classification/sectorization systems used are broadly consistent with internationally accepted standards, guidelines, or good practices.

Sectorization of monetary statistics broadly follows the recommendations of the MFSM and the BPM5. Charts of accounts for the NBG and commercial banks do not provide for distinction between residents and nonresidents (except for resident and nonresident commercial banks). The definition of residency is provided in the NBG's Guidelines for Filling the Monthly Statistical Data Reporting Forms F4 on Loans and in the Tax Code of Georgia.

\footnotetext{
${ }^{7}$ For instance there is only one bank in liquidation, which assets are very small (less than one percent).
} 
The share of other assets and other liabilities within the balance sheet of the NBG is around two percent; and within the aggregated balance sheet of ODCs is around 13 and 25 percent, respectively. The high ratio for other assets and liabilities in the balance sheets of commercial banks is related to commercial banks' capital, provisions for loans, and fixed assets (primarily buildings). Currently, NBG's prudential norms require 12 percent capital adequacy while in fact an average capital adequacy ratio for commercial banks amounts about 16.2 percent.

Sectorization of domestic positions is mainly consistent with the MFSM recommendations and is presented in the DCS as follows: general government, central government, local government, nonfinancial corporations, households, and other private sector. However, OFCs are not presented separately as the MFSM recommends. Nonprofit institutions (NPIs) are not classified either. Financial instruments with both OFCs and NPIs are classified with Other Nonfinancial Corporations (ONFC) in the central bank survey (CBS) and the ODCS. However, amounts in these accounts are not considerable.

Classification of financial instruments in the monetary statistics largely follows the recommendations of the MFSM. Instruments are classified in the source data by type, currency denomination (national and foreign), and by maturity (short-term and long term) for loans. However, part of debit card deposits, check book deposits, credit guarantee deposits, deposits for letters of credit, and deposits for other payment documents are classified as Other Items Net in DCS and not as Deposits Included in Broad Money as the MFSM recommends. ${ }^{8}$ As of end August 2011, the share of these deposits in M2 and M3 was about 7 and 3 percent respectively.

Accrued interests are classified together with the outstanding amount of assets or liabilities for most of financial instruments. However, accrued interest for some financial instruments such deposits and loans to nonresidents, deposits and loans to central and local government, deposits and loans to OFCs and NPIs are not classified together with the outstanding amount of respective deposits or loans.

The NBG does not include deposits of nonfinancial corporations with the NBG in the definition of monetary base as the MFSM recommends. The mission was informed that amounts in those accounts were very small (less than one percent) and those accounts would be removed from NBG's balance sheet soon.

Repurchase agreements are classified as collateralized loans as the MFSM recommends.

\footnotetext{
${ }^{8}$ Those issues were raised by the MFS technical assistance mission in 2009.
} 
Financial derivatives are recorded off- balance sheet. However, their volume is not considerable.

\section{Recommendations:}

Include into the definition of broad money debit card deposits, check book deposits, credit guarantee deposits, deposits for letters of credit, and deposits for other payment documents.

Separate positions on financial instruments with OFC's and NPI's from positions with ONFC. Depending on governance structure and financing sources classify NPI's either as part of the government or as 'Other Resident Sectors'.

Classify accrued interest for deposits and loans to nonresidents, deposits and loans to central and local government, deposits and loans to OFCs and NPIs together with the outstanding amount of respective deposits or loans.

Include in monetary statistics data on positions on financial derivatives consistent with recommendations of the MFSM and the MFSMCG.

\subsection{Basis for recording}

2.4.1 Market prices are used to value flows and stocks.

Accounting rules at the NBG broadly follow recommendations of the International Financial Reporting Standards (IFRS). The practices are set out in the table below. 
Table 6. Valuation Methods in the National Bank of Georgia and Commercial Banks

\begin{tabular}{|c|c|c|c|}
\hline $\begin{array}{l}\text { Financial } \\
\text { instrument }\end{array}$ & National valuation method at the NBG & $\begin{array}{l}\text { National valuation } \\
\text { method at ODCs }\end{array}$ & MFSM 2000 Guidance \\
\hline Monetary Gold & London gold market price & --- & At end-period market price \\
\hline SDR holdings & $\begin{array}{l}\text { At end-period exchange rate. Exchange rate is } \\
\text { obtained from IMF's website. }\end{array}$ & --- & At end-period exchange rate \\
\hline Deposits & At book value & At book value & At book value \\
\hline Loans & At book value & & At book value \\
\hline $\begin{array}{l}\text { Securities other than } \\
\text { shares (assets) }\end{array}$ & $\begin{array}{l}\text { The NBG has three types of securities: i) } \\
\text { securities held to maturity, ii) securities } \\
\text { available for sale, and iii) securities for } \\
\text { trading. Securities held to maturity are valued } \\
\text { at amortized cost (acquisition cost plus } \\
\text { accruals); securities available for sale and } \\
\text { securities for trading are valued at the latest } \\
\text { available market price. The NBG usually uses } \\
\text { quotation from Bloomberg. }\end{array}$ & Fair value & $\begin{array}{l}\text { At end period market price or } \\
\text { market price equivalent }\end{array}$ \\
\hline $\begin{array}{l}\text { Securities other than } \\
\text { shares (liabilities) }\end{array}$ & At book value & At book value & $\begin{array}{l}\text { At end period market price or } \\
\text { market price equivalent }\end{array}$ \\
\hline $\begin{array}{l}\text { Shares and other } \\
\text { equity (assets) }\end{array}$ & Market prices & $\begin{array}{l}\text { Commercial banks use } \\
\text { two methods to value } \\
\text { shares: (i) Fair value, (ii) } \\
<20 \% \text { fair value, }>20 \% \\
\text { historical cost* }\end{array}$ & $\begin{array}{l}\text { At end period market price or } \\
\text { market price equivalent }\end{array}$ \\
\hline $\begin{array}{l}\text { Shares and other } \\
\text { equity (liabilities): }\end{array}$ & & & \\
\hline $\begin{array}{l}\text { (i) Funds contributed } \\
\text { by owners }\end{array}$ & (i) At nominal amount & (i) At nominal amount & $\begin{array}{l}\text { (i) At nominal amount of the } \\
\text { proceeds from the initial and } \\
\text { subsequent issuance of } \\
\text { ownership shares }\end{array}$ \\
\hline (ii) Retained earnings & (ii) At nominal amount & (ii) At nominal amount & (ii) At nominal amount \\
\hline $\begin{array}{l}\text { (iii) General and } \\
\text { special reserves }\end{array}$ & (iii) At nominal amount & (iii) At nominal amount & (iii) At nominal amount \\
\hline $\begin{array}{l}\text { (iv) Valuation } \\
\text { adjustment }\end{array}$ & (iv) At nominal amount & (iv) At nominal amount & (iv) At nominal amount \\
\hline $\begin{array}{l}\text { (v) Current-year } \\
\text { results }\end{array}$ & (v)At nominal amount & (v)At nominal amount & (v) At nominal amount \\
\hline SDR allocation & At end period exchange rate & --- & At end period exchange rate \\
\hline Financial derivatives & At market prices & Fair value & $\begin{array}{l}\text { At end period market price or } \\
\text { market price equivalent }\end{array}$ \\
\hline $\begin{array}{l}\text { Foreign currency } \\
\text { denominated } \\
\text { positions }\end{array}$ & At end-period exchange rate & $\begin{array}{l}\text { At end-period exchange } \\
\text { rate }\end{array}$ & $\begin{array}{l}\text { At end period exchange rate. } \\
\text { (The mid-point between the } \\
\text { buying and selling rate of } \\
\text { exchange should be used). }\end{array}$ \\
\hline \multicolumn{4}{|l|}{ Nonfinancial assets } \\
\hline Nonmonetary gold & On inventory cost $* *$ & --- & At end-period market price. \\
\hline Fixed assets & On cost method *** & IFRS & $\begin{array}{l}\text { According to national } \\
\text { accounting standards. }\end{array}$ \\
\hline
\end{tabular}

* According to the IFRS (standards 27, 28, and 39). Banks have an option to value investments more than 20 percent in market value but in practice they value them in historical cost.

** These are gold coins. The NBG record them in the balance sheet on inventory cost (cost of production + transportation).

*** Recorded as cost of assets plus depreciation 


\subsubsection{Recording is done on an accrual basis.}

The accounts of the NBG and those of commercial banks are recorded on an accrual basis. Interest accrued but not yet due is mainly recorded together with the outstanding amount of financial assets and liabilities.

Transactions are recorded on settlement day (time of delivery), but using the price of the transaction date (change of ownership).

\subsubsection{Grossing/netting procedures are broadly consistent with internationally accepted standards, guidelines, or good practices.}

Assets and liabilities of the NBG and commercial banks are presented on a gross basis. Claims on particular transactors are not netted against liabilities to those transactors. Whenever a data category in a sectoral survey is shown on a net basis, the underlying gross positions are also shown. In the financial statements, loans are recorded on a gross basis at nominal values with provisions for loan losses as a negative asset item netting from the total of loans. When compiling monetary statistics, the MSD brings the provisions for loan losses to the liability side under Other Liabilities, presenting the loans at their nominal value.

Accounts in overdraft are recorded and reported as loans to the corresponding sector.

When producing the ODCs survey, the MSD consolidates the intrasectoral accounts of the commercial banks in Other Items Net. The DC survey consolidates the accounts of the NBG with the accounts of ODCs, also in Other Items Net.

\section{Accuracy and reliability}

\subsection{Source data}

\subsubsection{Source data are obtained from comprehensive data collection programs that take into} account country-specific conditions.

All financial institutions operating in Georgia must be licensed by the NBG, enabling it to keep its register up-to-date. Data sources for the DCS are balance sheets of the NBG and commercial banks. Commercial banks provide the NBG with supplemental statistical reports. All banks submit their reports regularly in compliance with NBG's regulations. Reports are submitted on a daily, weekly, monthly, quarterly, and annual basis. Report forms are being continually evaluated and revised when needed, to keep them current with market and legislative changes.

Currently, the NBG works on implementing a new comprehensive statistical data collection system (Sebstat). The Sebstat is expected to automate data collection, processing, and dissemination processes. The Sebstat will also have a central database with access restricted to users from NBG's different departments. 


\subsubsection{Sources data reasonably approximate the definitions, scope, classifications,} valuation, and time of recording required.

The chart of accounts of the NBG and commercial banks and supplementary reporting forms submitted by commercial banks to the NBG constitute the main source data for compiling monetary statistics. All commercial banks follow the same chart of accounts.

Commercial banks sectorize nonfinancial corporations (NFC) into private and state-owned based on the Statistical Register available to them online. A corporation is deemed to be state-owned if more than half of its capital belongs to the government. Sectorization of legal entities by residency is based on the information from the Georgia Revenue Service (GRS). ${ }^{9}$ The GRS uses the Tax Code to define residency. The Tax Code does not give a definition of residency for legal entities consistent with the MFSM. Moreover, there are some shortcomings in sectorization of resident and nonresident individuals in commercial banks. In particular, residency for individuals is based on the foreign citizenship and not on the center of economic interest as the MFSM recommends.

The MSD does not conduct any inspections to monitor how commercial banks comply with $M F S M$ requirements.

The balance sheet of the NBG is audited by an external well-known audit firm selected by the Parliament of Georgia (Article 59 of the Organic Law on the NBG). The 2010 audit was conducted by Deloitte. The financial statements were approved on March 30, 2011.

\section{Recommendation:}

Introduce a clear statistical definition of residency to ensure that all institutional units are sectorized on residents and nonresidents consistent with the MFSM. Conduct regular trainings/consultations with data compilers to improve the quality of source data.

\subsubsection{Source data are timely.}

The MSD receives the source data for the NBG's balance sheet on the next day following the end of reference month. ODCs submit their balance sheets and financial statements to the NBG within 7 and 10 days respectively. This timeline permits compilation of the analytical accounts of the NBG and ODCs within the SDDS prescribed standards by the fifth and twentieth day of the month, respectively.

\footnotetext{
${ }^{9}$ All legal entities must be registered in the GRS. The GRS is in charge with tax collection.
} 


\subsection{Assessment of source data}

3.2.1 Source data-including censuses, sample surveys, and administrative records-are routinely assessed, e.g., for coverage, sample error, response error, and nonsampling error; the results of the assessments are monitored and made available to guide statistical processes.

The NBG has established a computerized monitoring system to detect internal inconsistencies in data reported by each bank. However, this system does not allow for monitoring out-of-trend movements, which the MSD staff implements manually.

The MSD reviews and analyzes statistical data reported by banks. First, the MSD reviews balance sheets and financial statements; then the MSD and the BSD cross-check the data for internal consistency. In case misreporting or errors are detected, the NBG sends data back for revision and correction. Compilers' queries and questions are addressed via email or phone.

\subsection{Statistical techniques}

\subsubsection{Data compilation employs sound statistical techniques to deal with data sources.}

The DCS is based on actual accounting records of the NBG and commercial banks; therefore, no estimations are necessary. Electronic processing of all data minimizes the risk of mistakes. Data reported by commercial banks are usually complete, and the MSD does not need to estimate missing information. In case banks report their data with a delay, the NBG uses data from the previous month.

Supplemental information provided together with the monthly balance sheets in general allows for an adequate sectorization of institutional units and classification of financial instruments in compliance with recommendations of the MFSM.

3.3.2 Other statistical procedures (e.g., data adjustments and transformations, and statistical analysis) employ sound statistical techniques.

Since data used for DCS compilation are complete and based on the balance sheets of the institutions, there is no need for data adjustments or transformations.

\subsection{Assessment and validation of intermediate data and statistical outputs}

\subsubsection{Intermediate results are validated against other information, where applicable.}

Balance sheet data and other supplemental data reported to the MSD are cross-checked with the data reported to other NBG's departments, primarily to the BSD. 


\subsubsection{Statistical discrepancies in intermediate data are assessed and investigated.}

Data are regularly monitored to investigate statistical discrepancies and to ensure data accuracy. When a large movement is noticed in the submitted data, the MSD contacts the reporting institution for clarifications.

\subsubsection{Statistical discrepancies and other potential indicators of problems in statistical outputs are investigated.}

The NBG is committed to investigate any significant discrepancies of major aggregates and stock vs. flow data to ensure accuracies.

All large movements in data series are subject to investigation and validation.

\subsection{Revision studies}

3.5.1 Studies and analyses of revisions are carried out routinely and used internally to inform statistical processes (see also 4.3.3).

As a general practice, monetary statistics are final upon release.

\section{Serviceability}

\subsection{Periodicity and timeliness}

\subsubsection{Periodicity follows dissemination standards.}

The CBS, the ODCS, and the DCS are disseminated on a monthly basis through the NBG's website and its monthly publication Bulletin of Monetary and Banking Statistics. Monetary aggregates are disseminated on a daily and monthly basis. This periodicity fully complies with SDDS requirements.

\subsubsection{Timeliness follows dissemination standards.}

Dissemination of monetary statistics follows the ARC. The CBS is disseminated by the seventh day after the end of reference month. The ODCS and the DCS are disseminated by the twentieth day of the following month. Timeliness of dissemination of monetary statistics is consistent with SDDS requirements.

\subsection{Consistency}

\subsubsection{Statistics are consistent within the dataset.}

The NBG's and commercial banks' records for claims on and liabilities to are largely consistent with each other. The mission was provided with records on these positions and could verify the consistency of positions by main instruments. 


\subsubsection{Statistics are consistent or reconcilable over a reasonable period of time.}

Monetary data are presented in consistent historical series since 2001. For some monetary aggregates consistent data are available since 1995 when monetary statistics started being compiled. When changes in source data or methodology are introduced, the historical data are revised as far back as possible. If any breaks occur in the time series, footnotes explaining them are added.

\subsubsection{Statistics are consistent or reconcilable with those obtained through other data sources and/or statistical frameworks.}

Data on net foreign assets derived from monetary statistics are reconcilable with data on net foreign assets derived from balance of payments statistics and with data on international investment position (IIP).

There is a small difference in the definition of reserve assets. The MSD includes the stock of Russian Rubles in reserve assets, while the BoPD does not. This difference has an insignificant weight in the total reserve assets (200 US\$ currently). Another difference relates to the use of exchange rates. BoPD uses the exchange rates of the last day of the month, while MSD uses the last working day.

Data derived from monetary statistics differ from corresponding measure from IIP data. The main reason for these differences is that monetary statistics do not include in the definition of foreign liabilities foreign capital invested in local banks in the form of shares and other equity while the IIP definition of foreign liabilities does. ${ }^{10}$

The NBG conducted data cross-checks with the MOF and found that data on net credit to the central government (NCCG) derived from the MFS were not consistent with data derived from the Government Finance Statistics compiled by the MOF. The NBG posted a methodological note explaining those differences on the NBG's website.

\subsection{Revision policy and practice}

\subsubsection{Revisions follow a regular and transparent schedule.}

Commercial banks' data are final when first released and are not subject to revisions except if errors are detected. In this case, revisions are explained in footnotes and comments in upcoming releases. Annual data of the NBG are preliminary, pending closing of the NBG's books for the reference month. Data become final after their first release.

\subsubsection{Preliminary and/or revised data are clearly identified.}

\footnotetext{
${ }^{10}$ A methodological note explaining these differences was published during the mission.
} 
When applicable data are clearly identified as provisional or revised in all NBG's publications. As mentioned above, MFS are normally final when first released

\subsubsection{Studies and analyses of revisions are made public (see also 3.5.1).}

Revisions of monetary aggregates and other monetary data are explained through footnotes to the corresponding tables in statistical publications.

\section{Accessibility}

\subsection{Data accessibility}

5.1.1 Statistics are presented in a way that facilitates proper interpretation and meaningful comparisons (layout and clarity of text, tables, and charts).

Monthly time series for monetary statistics are disseminated on the Statistics page of the NBG's website in Excel and in the BMBS (posted on the Publications page). A number of analytical charts are included in the $B M B S$. In addition to the $B M B S$, the NBG issues Monthly Review, Inflation Report (quarterly), Financial Stability Report (yearly), and Annual Report. All these publications contain tables on monetary statistics at a different level of detail.

The structure of the surveys compiled by the NBG for the central bank and the banking sector is consistent with the structure of the central bank, other depository corporations, and depository corporation's surveys, respectively, as recommended by the MFSM.

\subsubsection{Dissemination media and format are adequate.}

The NBG disseminates monthly monetary statistics in Georgian and in English on the NBG's website and in the $B M B S$. Monetary statistics are accompanied with press releases. Data posted on the NBG's website provide historical series from 1995 onwards. The structure of the NBG's website and links to the Statistics page are clear.

Nonpublished but nonconfidential time series are available upon request.

\subsubsection{Statistics are released on a preannounced schedule.}

An ARC that includes release dates for monetary statistics is posted on the NBG's website. Monetary statistics are released in accordance with the timetable in the calendar.

The ARC on the NBG's website contains release dates for (i) financial sector's statistics, (ii) exchange rates statistics, and (iii) external sector statistics.

\subsubsection{Statistics are made available to all users at the same time.}

Monetary statistics are released simultaneously to all users, in accordance with the ARC, through press releases, the $B M B S$, and the NBG's website. 


\subsubsection{Statistics not routinely disseminated are made available upon request.}

Additional (nonconfidential) information is available upon request. Users can request additional information through either the contact point listed on the NBG's website or the Press Office, which will forward the inquiries to the relevant department for response.

\subsection{Metadata accessibility}

5.2.1 Documentation on concepts, scope, classifications, and basis of recording, data sources, and statistical techniques is available, and differences from internationally accepted standards, guidelines, or good practices are annotated.

Data on monetary statistics published in the BMBS and posted on the NBG's website include comprehensive methodological notes. The NBG updates methodological notes when necessary.

In addition, metadata are available from Georgia's SDDS webpage posted on the IMF's $D S B B$. The metadata on the $D S B B$ were last updated in May 2010.

\subsubsection{Levels of detail are adapted to the needs of the intended audience.}

The NBG's publications and electronic data posted on its website provide different levels of detail to meet users' needs. Methodological comments are published in the $B M B S$, the Statistical Bulletin, and the Annual Report of the NBG. They include notes on the revised data, changes in the methodology, and any changes in the structure of the accounting and/or statistical frameworks.

\subsection{Assistance to users}

\subsubsection{Contact points for each subject field are publicized.}

Contact information (e-mail addresses and telephone numbers) are available on the NBG website. Assistance and support are provided to users who can submit queries by addressing the contact point or the Press Office of the NBG.

\subsubsection{Catalogs of publications, documents, and other services, including information on any charges, are widely available.}

The NBG website provides users with considerable amount of information about electronic and hard copy publications and documents. The NBG publications can be obtained free of charge from the contact point upon request. 
Table 7. Data Quality Assessment Framework: Summary of Results for Monetary Statistics

(Compiling Agency: National Bank of Georgia)

\begin{tabular}{|c|c|c|c|c|c|c|}
\hline \multicolumn{7}{|c|}{$\begin{array}{l}\text { Key to symbols: NA = Not Applicable; } \mathrm{O}=\text { Practice Observed; LO = Practice Largely Observed; LNO = Practice Largely Not } \\
\text { Observed; NO = Practice Not Observed; SDDS = Complies with SDDS Criteria }\end{array}$} \\
\hline \multirow{2}{*}{ Element } & \multirow{2}{*}{$\mathbf{N A}$} & \multicolumn{4}{|c|}{ Assessment } & \multirow{2}{*}{ Comments } \\
\hline & & $\mathbf{O}$ & $\mathbf{L O}$ & LNO & NO & \\
\hline \multicolumn{7}{|l|}{ 0. $\quad$ Prerequisites of quality } \\
\hline 0.1 Legal and institutional environment & & & $\mathrm{X}$ & & & \multirow{4}{*}{$\begin{array}{l}\text { Meetings among data producing agencies (NBG, GEOSTAT, and } \\
\text { MOF) do not follow a regular schedule, such as one per year, which } \\
\text { would improve communication by discussing issues of common } \\
\text { interest on a pre-established, regular basis. }\end{array}$} \\
\hline 0.2 Resources & & $\mathrm{X}$ & & & & \\
\hline 0.3 Relevance & & $\mathrm{X}$ & & & & \\
\hline 0.4 Other quality management & & $\mathrm{X}$ & & & & \\
\hline \multicolumn{7}{|l|}{ 1. $\quad$ Assurances of integrity } \\
\hline 1.1 Professionalism & & $\mathrm{X}$ & & & & \multirow{3}{*}{$\begin{array}{l}\text { There is not advance notice of major changes in methodology, } \\
\text { Source data, and statistical techniques. }\end{array}$} \\
\hline 1.2 Transparency & & & $\mathrm{X}$ & & & \\
\hline 1.3 Ethical standards & & $\mathrm{X}$ & & & & \\
\hline \multicolumn{7}{|l|}{ 2. Methodological soundness } \\
\hline 2.1 Concepts and definitions & & $\mathrm{X}$ & & & & \multirow{4}{*}{$\begin{array}{l}\text { Deposits on debit cards, check book, credit guarantee are not included } \\
\text { In Broad Money. Accrued interests are not classified together with the } \\
\text { Outstanding amount of assets or liabilities for all financial } \\
\text { instruments. OFCs and MPIs are classified together with ONFC and } \\
\text { ODS. Financial derivatives are recorded off-balance sheet. }\end{array}$} \\
\hline 2.2 Scope & & $\mathrm{X}$ & & & & \\
\hline 2.3 Classification/sectorization & & & $\mathrm{X}$ & & & \\
\hline 2.4 Basis for recording & & $\mathrm{X}$ & & & & \\
\hline \multicolumn{7}{|l|}{ 3. $\quad$ Accuracy and reliability } \\
\hline 3.1 Source data & & & $\mathrm{X}$ & & & \multirow{5}{*}{$\begin{array}{l}\text { Residency criteria for legal entities are based on Tax Code, which } \\
\text { does not give definition of residency for legal entities consistent with } \\
\text { the MFSM. }\end{array}$} \\
\hline 3.2 Assessment of source data & & $\mathrm{X}$ & & & & \\
\hline 3.3 Statistical techniques & & $\mathrm{X}$ & & & & \\
\hline $\begin{array}{l}\text { 3.4 Assessment and validation of intermediate data and } \\
\text { statistical outputs }\end{array}$ & & $\mathrm{X}$ & & & & \\
\hline 3.5 Revision studies & & $\mathrm{X}$ & & & & \\
\hline \multicolumn{7}{|l|}{ 4. $\quad$ Serviceability } \\
\hline 4.1 Periodicity and timeliness & & $\mathrm{X}$ & & & & \\
\hline 4.2 Consistency & & $\mathrm{X}$ & & & & \\
\hline 4.3 Revision policy and practice & & $X$ & & & & \\
\hline \multicolumn{7}{|l|}{ 5. Accessibility } \\
\hline 5.1 Data accessibility & & $\mathrm{X}$ & & & & \\
\hline 5.2 Metadata accessibility & & $\mathrm{X}$ & & & & \\
\hline 5.3 Assistance to users & & $\mathrm{X}$ & & & & \\
\hline
\end{tabular}




\section{Balance of Payments Statistics}

\section{Prerequisites of quality}

\subsection{Legal and institutional environment}

\subsubsection{The responsibility for collecting, processing, and disseminating the statistics is clearly specified.}

The NBG is the sole official agency designated to compile the balance of payments statistics for Georgia. NBG's functions and powers are established by the Organic Law on the National Bank of Georgia. Article 3, paragraph 3, of this law defines NBG's responsibility for "compiling and disseminating Georgia's financial and external sector statistics following international standards and methodology." Article 45 of the Organic Law authorizes the NBG to "request and receive from both public and private entities all statistical reports, accounting data, and other data (including confidential) necessary to perform the functions assigned to the NBG."

Article 2 of the NBG Law define the external sector statistics as comprising of the balance of payments, international investment position, external debt, and official international reserves statistics.

The Macroeconomic and Statistics Department (MESD) of the NBG is responsible for compiling monetary and balance of payments statistics. The department comprises four divisions: the MRD, the MPD, the MSD, and the Balance of Payment Division (BoPD). Of these four divisions, the BoPD is responsible for compiling external sector statistics, except for reserve assets, which are disseminated by MPD.

\subsubsection{Data sharing and coordination among data-producing agencies are adequate.}

The NBG shares data with the GEOSTAT and the MOF in the process of compiling financial and external sectors statistics. The MOF provides the NBG with government and government-guaranteed external debt and financial services related to such debt. GEOSTAT shares with the NBG data on external trade (goods and services), the stocks and flows of FDI, portfolio and other investments for other sectors. Data on services are provided also by other governmental agencies.

Procedures are in place to provide for the effective and timely flow of source data to the NBG. Data are exchanged electronically in a timely fashion. To ensure efficient data sharing and coordination, in 2010 the NBG and GEOSTAT signed a Memorandum of Understanding $(\mathrm{MoU})$, which contains a set of rights and responsibilities for both agencies to facilitate the exchange of information between these agencies. Following the MoU requirements, the NBG and GEOSTAT created a working group that has regular quarterly meetings to discuss FDI 
inflows to Georgia. The meetings are held 2-3 days prior to publishing FDI data to confer positions of GEOSTAT and NBG.

Bi-lateral meetings and arrangements for collaboration on data issues, e.g., between GEOSTAT and NBG on data sources for the balance of payments, are maintained with other data producing agencies to promote a proper understanding of data requirements, to avoid duplication of effort, and to take into account reporting burden (e.g., by discussing changes to administrative processes before they take place.) However, there is no arrangement for regular meetings of all technical staff responsible for macroeconomic statistics. Such meetings provide a comprehensive arena for exchanging information on current and forthcoming projects for statistical development, promoting cross-sectoral data consistency crucial for macro-economic policy making, coordinating work programs to avoid duplication of effort, ensure coherent application of methodology at all stages of data collection, and enhance effectiveness.

NBG's structural units exchange data and information via email. Computers within the MESD are linked by a local network. However, there is no centralized database with limited access granted to authorize staff in relevant departments. ${ }^{11}$ A centralized database can facilitate efficient data sharing and coordination between NBG departments particularly with regard to high frequency data. Because balance of payments and IIP statistics are compiled on a less frequent basis (quarterly), the absence of a centralized database has not hampered the efficient sharing of data within the NBG used for compiling balance of payments and IIP statistics.

NBG's local network is protected from outside by the CISCO security appliance and the Threat Management Gateway.

The BoPD utilizes an Access and Excel based framework for the compilation of external sector statistics. Financial and nonfinancial corporations transmit their data to the NBG via email. Transmitted data are encrypted. Collected data are backed-up on a daily basis. Currently, the back-up server is located in a separate building around 50 meters away from the NBG's main administrative facilities. The mission was informed that the NBG is installing a remote back-up server in an off-site location about 15-20 km away from the NBG headquarters. The server will ensure that no data will be lost in case of fire or natural disaster.

\section{Recommendation:}

${ }^{11}$ During the mission the Information Technology IT Department of the NBG established a shared drive to facilitate information and data exchange between the MESD and the Banking Supervision Department (BSD). 
Conduct pre-established, regular meetings, such as one per year, to improve communication among data compilers at NBG, GEOSTAT, and MOF, by discussing issues of common interest, avoid duplication of efforts, and ensure the consistency of macroeconomic statistics (national accounts, monetary, fiscal, and external sector).

\subsubsection{Individual reporters' data are to be kept confidential and used for statistical purposes only.}

The NBG does not disclose confidential data of individual institutions or transactions. Article 20 (paragraph 1) of the Organic Law on the National Bank of Georgia establishes a legal framework for protection of information and confidentiality and states that "no present or former member of the Board of the National Bank and no employee or auditor of the National Bank of Georgia and Georgian Financial Monitoring Office shall be entitled to permit access of an unauthorized person to confidential information, disclose, or publicize such information or use it for personal gain.” The same law (Article 20, paragraph 3) stipulates that information on accounts and/or transactions of individuals and legal entities may be disclosed only by the decision (ruling) of a court.

The Staff Manual of the NBG addresses the obligation of NBG's staff to protect confidential information in Article 3.2. In addition, Article 202 of the Criminal Code of Georgia envisages administrative, financial, and criminal sanctions for breach of confidentiality.

The balance of payments aggregation and dissemination procedures ensure that information not be published in a manner likely to enable the identification of a particular person or organization.

\subsubsection{Statistical reporting is ensured through legal mandate and/or measures to encourage response.}

Statistical reporting is ensured through legal mandate by the NBG according to Article 45 of the NBG's Organic Law (see 0.1.1).

The Organic Law of the NBG, the Law of Georgia on activities of commercial banks, and NBG's regulations and instructions establishes a legal basis for NBG's data collection and data reporting by banks to the NBG.

As stated earlier, Article 33 of the Organic Law on the NBG authorizes the NBG to collect statistical and accounting reports (including confidential) from the financial sector as it deems necessary to carry out NBG's responsibilities under this Law. 
Article 29 of the Law of Georgia on activities of commercial banks obligates banks to submit to the NBG reports defined by the NBG norms. Article 30 of the same Law envisages wide range of sanctions and penalties for noncompliance and misreporting. The similar provisions are specified in NBG's directives 242/01 (December 25, 2009) and 92/01 (June 25, 2010). Financial institutions systematically comply with their reporting obligation, and there were no cases of nonreporting during the past years.

NBG's directive 184 on statistical reporting forms for Georgian commercial banks and procedures on their compiling (July 17, 2008), set out specific requirements for compiling and reporting statistical forms by commercial banks, their periodicity, and timeliness.

NBG's directives contain detailed instructions and explanations on the preparation of statistical reports by credit institutions and their submission to the NBG. Meetings, seminars, and consultations with representatives of reporting institutions are held on an ad hoc basis. Their purpose is to respond to questions on the compilation of data and other information that will ensure that these are completed in accordance with the specified requirements. Draft new report forms and amended compilation instructions are shared with data reporters for comments. To create goodwill among reporters, they are consulted when forms or reporting requirements are introduced or revised.

\section{$0.2 \quad$ Resources}

\subsubsection{Staff, facilities, computing resources, and financing are commensurate with statistical programs.}

There are two divisions within the Macroeconomics and Statistics Department of the NBG, responsible for Monetary Statistics and Balance of Payments Statistics. The NBG employs, as of September 2011, 386 people. Staff qualification and computer resources are adequate to perform the required tasks. NBG is financially independent and self-sufficient to meet its statistical obligations. The BoPD of the MSD is responsible for compiling the external sector statistics, including the balance of payments and IIP. The Balance of Payments Division employs six staff members, two of which are young professionals, in charge of the balance of payments, IIP, and external debt statistics compilation, analysis, dissemination, and forecast. Recently, compilers attended the External Debt Statistics Courses, ITRS, and CDIS seminars organized by the IMF.

Certain tasks are conducted with significant pressure (or delayed) by the staff responsible for compiling balance of payments statistics, for example, the data validation work on the ITRS and the processing of private nonfinancial corporations external debt data, collected by GEOSTAT. In addition, there are limited staff resources for a timely implementation of new international standards related to external sector statistics, such as the implementation of the sixth edition of the Balance of Payments and International Investment Position Manual 
(BPM6) and the forthcoming new guides on international reserves and foreign currency liquidity and external debt. However, the overall quality of the balance of payments statistic and IIP is sound, even with limited staff resources.

\subsubsection{Measures to ensure efficient use of resources are implemented.}

The NBG implements specific measures to ensure efficient use of resources. The NBG established a performance appraisal procedure for its staff. The appraisal is conducted every three years and is used as a basis for personnel decision: salary increases or decreases, promotions, etc.

Funding is provided for statistical projects within a planning horizon of one year. The MESD prepares an annual budget of expenditures, which covers departmental needs. Every department submits its budget to the Finance and Accounting Department (FAD) who produces the NBG's single budget.

\section{$0.3 \quad$ Relevance}

\subsubsection{The relevance and practical utility of existing statistics in meeting users' needs are monitored.}

User requirements are monitored annually by means of user surveys. Several groups of statistics users are consulted bilaterally: government agencies, financial corporations, other market participants. In addition, data users may provide their comments and feedback to the NBG through the contact point in the NBG's website (www.nbg.gov.ge).

Compilers of external sector statistics regularly participate in statistical meetings and seminars organized by international and regional organizations.

\subsection{Other quality management}

\subsubsection{Processes are in place to focus on quality.}

The Management is sensitive to data quality. To demonstrate their commitment to data quality, the NBG website provides information on various aspects of data quality such as reporting forms and guide and revision policies. The NBG's medium-term activity plan emphasizes the improvement of quality, including all dimensions of data quality.

Moreover, the BoPD has actively initiated consultations with the IMF and other central banks with the view of improving the quality of the statistical data through training and technical assistance. The focus on quality covers all levels of the organization including senior management. 
Accuracy of data is given priority by the management and the staff. Consistency checks are performed on a quarterly basis with regard to both input and output data received from monetary statistics and banking supervision. A recent initiative for a new IT application to enable electronic reporting together with the in-job training demonstrates NBG's commitment to maintain a high quality.

\subsubsection{Processes are in place to monitor the quality of the statistical program.}

The NBG data compilers have frequent meetings and consultations with data providers. Data obtained from parallel sources are checked for consistency. During 2007-2008, the BoPD had access to the guidance and technical assistance of IMF Regional Statistics Advisor on the quality of statistics and on strategies for improving data production. NBG managers are informed on the quality achieved for ongoing statistical activities.

\subsubsection{Processes are in place to deal with quality considerations in planning the statistical program.}

One of the main goals of the work programs of the statistical divisions of the NBG is the focus on high quality statistics by extensive use of international standards. Taking into account the findings from the internal audit, the statistical programs and processes are revised and updated. The NBG management recognizes the trade-offs between quality and timeliness of statistical data. Timeliness of data is considered one of main priorities, as recognized by the recent SDDS subscription.

The NBG implemented the ITRS system in 2009 to ensure a sound compilation program. The results of verifications procedures are shared with the compilers from GEOSTAT on a regular basis to inform statistics process. Feedback from users on quality standards and on new and emerging data requirements is taken into account in the work program planning process. The recent decision to increase the ITRS threshold is one of the results of such consultation process.

\section{Assurances of integrity}

\subsection{Professionalism}

\subsubsection{Statistics are produced on an impartial basis.}

The NBG's independence is guaranteed by Constitution of Georgia (Article 95, paragraph 4) and by the Organic Law on the National Bank of Georgia. Article 4, paragraph 1, of the Organic Law on the National Bank of Georgia states that the National Bank shall be independent in its activity. Legislative, executive, and other authorities shall not interfere in its activity or monitor its activity except cases afforded by Georgian Constitution and this Organic Law. 
The NBG itself has a strong professional independence, including the use of professional considerations and scientific principles in connection with compiling statistics. Staff of the NBG is free from political or other influences in choosing the most appropriate sources and methods.

Recruitment and promotion of the staff are based on relevant skills, performance, and expertise in the relevant areas. Appointing and promoting staff require an approval of the President of the NBG. The NBG hires the new staff on the basis of "The Law on Civil Service." The permanent positions are posted on the website of the Public Service Bureau indicating clearly required qualification and are open for everybody.

Research and analysis (including rationale for the choice of methodologies) are encouraged and resulted in elaborated publication of the external sector data, including sources and methods, starting in 2007.

\subsubsection{Choices of sources and statistical techniques, as well as decisions about dissemination, are informed solely by statistical considerations.}

The choice of sources and statistical techniques for the compilation of the balance of payments statistics is based solely on statistical considerations made by the NBG staff. NBG staff generally follows the requirements of manuals prepared by the IMF Statistics Department, including the International Reserves and Foreign Currency Liquidity: Guidelines on Data Template (2001), External Debt Statistics: Guide for Compilers and Users (2003), and the fifth edition of the Balance of Payments Manual.

Balance of payments statistics is disseminated only on the basis of statistical considerations. Dissemination practices are posted on the NBG's website. For each component of balance of payments, the work has been started on preparing the internal compilation guidelines.

\subsubsection{The appropriate statistical entity is entitled to comment on erroneous interpretation and misuse of statistics.}

Staff of the NBG is encouraged to comment on miss-interpretation of data. To provide assistance to users, contact information is provided on the NBG website.

The Public Relations Division monitors the financial press and mass media on a regular basis. Cases of misinterpretations or misuse of external sector statistics are brought to the attention of the publisher with a request to make appropriate corrections in its publication. Provisions of metadata in the quarterly and annual publications are also intended to prevent misinterpretation or misuse of balance of payments statistics.

In order to prevent misinterpretation of external sector statistics journalists occasionally consult with the BoPD's specialists regarding the matter of information to be published. 


\subsection{Transparency}

1.2.1 The terms and conditions under which statistics are collected, processed, and disseminated are available to the public.

NBG publications and website reproduce material from the statistical law and other relevant documents about the terms and conditions under which official statistics are compiled and disseminated. The Organic Law on the National Bank of Georgia is available on NBG website. The relevant laws and legislative acts are available to the public in Georgian and English on the NBG website. Copies of the legal documents can be obtained from the contact point.

Georgia participates in the IMF's SDDS. Its metadata on external sector statistics are posted on the IMF's Dissemination Standards Bulletin Board (DSBB). The NBG's website provides a link to the country page on the DSBB.

\subsubsection{Internal governmental access to statistics prior to their release is publicly identified.}

There is no internal government access to data before release.

\subsubsection{Products of statistical agencies/units are clearly identified as such.}

NBG's statistical and general publications clearly identify the data producing agency's product. The Annual Report, the annual Financial Stability Report, the publication on the Balance of Payments of Georgia, the quarterly Inflation Report and the monthly Monetary and Fiscal Review of the NBG include comprehensive descriptive and analytical commentary in respect of economic and financial data.

The NBG provides to the GEOSTAT tables with external sector data to be published in the GEOSTAT's monthly Socio-Economic Situation of the Republic of Georgia, where the NBG is identified as the source for such tables.

\subsubsection{Advance notice is given of major changes in methodology, source data, and statistical techniques.}

There is no advance notice of major changes in methodology, source data, and statistical techniques. 


\section{Recommendation:}

Provide advance notice of major changes in methodology, source data, and statistical techniques, for example, within the press release of the previous quarter.

\subsection{Ethical standards}

\subsubsection{Guidelines for staff behavior are in place and are well known to the staff.}

The NBG's Staff Manual identifies rules and standards of ethical conducts for NBG's staff. The Manual is available to all employees and establishes rights, responsibilities, and disciplinary actions for failure to meet standards prescribed by the Manual. Staff is aware of this Manual.

\section{Methodological soundness}

\subsection{Concepts and definitions}

2.1.1 The overall structure in terms of concepts and definitions follows internationally accepted standards, guidelines, or good practices.

The balance of payments statistics are compiled in conformity with the guidelines of the $B P M 5$ and elements of the BPM6.The balance of payments is a statistical statement that records transactions with rest of the world. Current, capital, and financial accounts of the balance of payments statement are defined according to the guidelines of the BPM5, and the current account balance in principle is equal (with sign reversed) to the net capital and financial account balance. Resident institutional units are those that have a center of economic interest in Georgia.

Transactions are identified using BPM5 concepts and definitions. Foreign direct investment transactions are defined by applying the 10 percent or more of ownership rule. Reserve assets are defined considering the concept of monetary authorities' effective control and availability for use.

The detailed balance of payments and IIP data are compiled and disseminated according to the framework prescribed by BPM5 and are presented in both a time series format and in a reconciliation format. 


\section{$2.2 \quad$ Scope}

2.2.1 The scope is broadly consistent with internationally accepted standards, guidelines, or good practices.

Georgia's balance of payments and IIP statistics broadly cover all transactions and positions of resident institutional units vis-à-vis the rest of the world, except for regions not controlled by the Georgian government. The criterion of residence is generally determined by the principles established in the BPM5. In cases where administrative complexities give rise to measurement issues, the NBG makes strong efforts to estimate the transactions and positions on a residency basis. Geographic, institutional units, and financial instruments coverage are:

- Geographic Coverage: The economic territory of Georgia consists of the geographic territory administrated by the government of Georgia, including Georgian embassies, consulates and representative offices abroad. Representative offices of foreign institutions on the territory of Georgia are treated as nonresidents. However, data do not cover the territories of Abkhazian Autonomous Republic and Tskhinvali Region (former South Ossetian Autonomous Region), a part of Georgian territory not controlled by the central authorities.

- Institutional units Coverage: In principle, all resident institutional units undertaking foreign transactions are covered, although the international investment activity of households may not be fully captured by existing sources and methods.

- $\quad$ Financial instrument coverage: FDI includes flows of inward (outward) investment by foreign (Georgian) companies in their subsidiaries (with a foreign paid-in capital ratio of 10 percent or more), such as initial capitalization, capital increase, loan capital (excluding loans between financial companies), and reinvested earnings. The portfolio investments include equity securities, bonds and notes, and money market instruments.

The NBG estimates: unrecorded and shuttle trade; travel expenditures; compensation of Georgian employees abroad; compensation of foreigners working in Georgia; workers' remittances; and migrants transfers. Estimates for shuttle trade are made according to special survey on shuttle trade. The survey was conducted in 2006. Average travel expenditure per visitor is also estimated based on a survey conducted in 2006.

\subsection{Classification/sectorization}

\subsubsection{Classification/sectorization systems used are broadly consistent with internationally accepted standards, guidelines, or good practices.}

The balance of payments classification system applied by the NBG closely follows that recommended in BPM5 and subsumes a primary breakdown between credit and debit and 
assets and liabilities. Data are further classified by functional categories. The main elements of balance of payments classifications are as follows:

\section{Current Account}

1. Goods

2. Services

3. Income

4. Current transfers

\section{Capital and Financial Account}

1. Capital account

2. Direct investment

3. Portfolio investment

4. Financial derivatives

5. Other investment

6. Reserve assets

The sectorization used to compile Georgia's balance of payments conforms to the methodology recommended in the BPM5 (four institutional sectors in the reporting country: monetary authorities, general government, banks, and other sectors).

\section{$2.4 \quad$ Basis for recording}

\subsubsection{Market prices are used to value flows and stocks.}

Following the international standards, FDI and portfolio investment are valued at market prices. Book values are used when market values are not available. Other investment transactions are valued at nominal value. The stocks of external assets and liabilities denominated in other currencies are converted to US dollars at the official exchange rate fixed of the NBG at the end of the reference period. Where financial transaction estimates are derived from stock data, the value of the transaction excludes revaluation (price and exchange rate) and other changes in volume.

\subsubsection{Recording is done on an accrual basis.}

In general, Georgia's balance of payments and IIP statistics are compiled on an accrual basis with minor exceptions. For each interest bearing instrument, interest is calculated on an accrual basis according to the interest term (rate, timing) of the particular instrument. Dividends are recorded when payment is made, not as of the date payable, due to the difficulties in obtaining this information. (This is a common problem in many countries and, considering the limited resources available, it should not be a priority for improving the quality of the external sector statistics.) 


\subsubsection{Grossing/netting procedures are broadly consistent with internationally accepted standards, guidelines, or good practices.}

In line with the recommendations of $B P M 5$, current and capital account transactions are recorded on a gross basis while financial account transactions are recorded on a net basis, and separately for the individual asset and liability components.

\section{Accuracy and reliability}

\subsection{Source data}

\subsubsection{Source data are obtained from comprehensive data collection programs that take into account country-specific conditions.}

The main data sources are : financial and monetary statistics compiled in the NBG; the database of Single Administrative Documents (DSAD) (database of customs declarations) of export-import of goods provided by the Revenue Service (former Customs Department) to GEOSTAT; data from ministries and other government institutions; regular surveys of enterprises (including the survey on External Economic Activities) and households conducted by the GEOSTAT, ad-hoc surveys, and information disseminated by mass-media.

The balance of payments data compilation program is broadly sufficient to compile the balance of payments statistics, covering four institutional sectors. The program is based on data from direct reporting of enterprises and banks, surveys, administrative data, and information from press. Data sources are subject to constant improvement. However, there is room for improvement on the international transactions reporting system (ITRS) and the private nonfinancial external debt compilation system. In particular, the quality of the ITRS data can be improved by conducting training activities with data reporters. The balance of payments compilers have plans for conducting such activities, which have not taken place yet due to the limited time available. The quality of the private nonfinancial external debt compilation system can be improved by increasing the coverage of data.

The coverage of reporting banks in the ITRS is integrated with the bank register maintained by the bank supervisory authorities. Sufficiently detailed information is available for both transactions via banking accounts. However, cash transactions are not covered by ITRS system at this stage, although the impact on the quality of the balance of payments statistics is minimal.

Reporting instructions request explanations about transactions that are above a given reporting threshold (as means of verification that they have been correctly classified in reports submitted by banks). In addition, reporting instructions emphasize the need to minimize the number and value of transactions that are not classified by category. Finally, 
reporting instructions do not permit netting of balance of payments transactions (e.g., credits net of debits).

For transactions that fall below the reporting threshold, a sample survey of banks and nonbanking institutions with accounts abroad is not conducted periodically to obtain information in order to classify the low-value transactions across the balance of payments components.

The structure of the reporting system for banks and enterprises with accounts abroad is consistent with the accounting practices employed by banks and enterprises and thus data can be readily extracted from the operational records. The ITRS report forms are designed in a way that makes them easy to complete and appropriate for computer processing and have also been pilot-tested with a sample of respondents.

Merchandise trade data are collected from the database of custom declarations provided by the GEOSTAT. Data on services are collected from the quarterly nonfinancial enterprises survey of external economic activity carried out by GEOSTAT, several governmental agencies, and the banking sector. Data on direct investment abroad are collected through reports of resident banks submitted to the NBG quarterly. Data on direct investment in the country (also abroad) are obtained through: (i) quarterly nonfinancial enterprises survey of external economic activity; (ii) quarterly reports of resident banks; (iii) information on privatization receipts provided by the Ministry of Economy and Sustainable Development (balance of payments data); and (iv) information from press.

Data on portfolio and other investment are collected from: (i) a quarterly nonfinancial enterprises survey of foreign economic activity carried out by GEOSTAT; (ii) quarterly reports from resident banks on balance sheets, claims and liabilities of commercial banks on nonresidents, long-term loans of commercial banks received from nonresidents and its service, assets and liabilities of commercial banks with respect to financial derivatives, on the share of foreign capital in the banking system, on investments in commercial banks' equity capital, list of shareholders of commercial banks; (iii) balance sheet, foreign exchange position, and data on disbursement and service of the IMF loans from the NBG; (iv) administrative data from the Ministry of Finance on external government debt and government guaranteed debt and its service, international grants, balances on banking accounts abroad of the government institutions; (v) data on microfinance organizations that are cross-checked with nonbanks supervision data; and (vi) data for the insurance companies from the Insurance Supervision Service.

The survey frame for the quarterly nonfinancial enterprises survey on external economic activity is prepared based on a survey list created from the survey results on external economic activity conducted in recent years, on a business register, business survey, data on privatization, ITRS, and customs declaration data. Included are enterprises from the business 
register that indicate share of nonresidents in the equity; the survey frame is supplemented by enterprises that are identified through the ITRS, and those from the enterprise survey that indicate existence of external liabilities, privatization or customs declarations data that are omitted from other sources. The survey aims to cover all enterprises performing external economic activities. The enterprise register has improved substantially in recent years, but some difficulties still remain. The most relevant of these difficulties refer to the data collection process and particularly affect construction activities (power stations, hotels, etc.). To deal with this issue and complement the enterprise register data, GEOSTAT has established direct contacts with several ministries (Ministry of Energy and Natural Resources, Ministry of Economy and Sustainable Development, Ministry of Agriculture, Ministry of Labor, Health and Social Affairs) that provide updated information on new established business entities with nonresidents share. In case of hotels assistance is provided by the Ministry of Economy and Sustainable Development of Georgia and also by the Ministry of Finance and Economy of A/R of Adjara.

The financial press and research papers are monitored for information on international transactions that need to be taken into account in the balance of payments compilation system. International standards, guidelines, and practices are also monitored for changes that need to be taken into account in the balance of payments compilation system.

\section{Recommendations:}

The quality of the ITRS data can be improved by conducting training activities with data reporters. The private nonfinancial external debt compilation system needs strengthening.

For transactions that fall below the reporting threshold, a sample survey of banks and nonbanking institutions with accounts abroad should be conducted to obtain information to classify the low-value transactions across the balance of payments components.

The quality of the private nonfinancial external debt compilation system should be improved by increasing the coverage of data.

3.1.2 Source data reasonably approximate the definitions, scope, classifications, valuation, and time of recording required.

Source data drawn from surveys and ITRS generally meet the methodological standards and guidelines for compiling balance of payments statistics. The forms and instructions that serve to collect source data are consistent with the concepts and definitions of the BPM5.

Pilot tests are conducted to ensure that data collected will allow compilation of estimates according to international guidelines. For example, two pilot tests were conducted before the 
introduction of the ITRS, one pilot test on data for one day and another using data for two weeks. The pilot test used data from five banks.

The accuracy of the data received from enterprises survey is yet to be satisfactory because enterprises are not obliged to report by law. Nonetheless, GEOSTAT staff work with reporting enterprises to resolve major issues and guarantee the quality of external sector statistics. A new statistical law is under discussion, which may include penalties for nonresponse or low quality data reporting. Currently, the response rate is 80-90percent, which is in line or higher than other countries.

Administrative records used to compile balance of payments statistics provide reasonable approximations of the methodological requirements of the balance of payments.

\section{Current Account}

- Goods: DSAD is the main information source on trade of goods. The following additional information is obtained from corresponding sources: natural gas imported and transited; electricity exported, imported, and transited; and fuel delivered to ports (airports and sea ports).

- Services: Transportation: freight of imported goods is derived from the conversion of imports in c.i.f. prices into f.o.b. prices. Besides the above mentioned estimates of the value of transport services connected with import of goods, the data are obtained from other sources as well. These are: Georgian Railway Ltd, the ports and airports of Georgia. Also, indirect estimates are carried out based on the information obtained from Department of Borders Defense about transportation means and persons entering and leaving the country.

- Travel: The data on travel are compiled on the basis of the regular household survey. Additional information about business travel is collected from government structures, as well as from the banking sector.

- Other services: The data on other services such as consultation, construction, financial and others are collected from the enterprises receiving such services. The data on diplomatic missions of Georgia abroad are obtained from Ministry of Foreign Affairs of Georgia. Information on financial services is obtained from the MOF, GEOSTAT and the Statistical Service of the NBG; information on insurance services is provided by the insurance companies. 
- Income

- Compensation of employees: The estimations of compensation of employees are mainly based on the household survey data. Income of residents employed in international organizations is also estimated. In calculation, number of employees and their remuneration are used.

- Investment income: Income on investment is calculated based on data from various sources: National Bank on interest payments in banking sector; other income payments and receipts (debit and credit) are calculated based on commercial banks and enterprises; report of MOF on interest payments on the state debt and debt under state guarantee;

- Current transfers: These include mainly technical assistance which is provided to the country by governments of other countries and international organizations. The data are obtained from the reports of MOF, international organizations and foundations which provide technical and humanitarian assistance to Georgia and have their offices on the territory of Georgia. Ministry of Foreign Affairs of Georgia presents the data on membership fees to various international organizations.

\section{Capital account}

- Capital transfers: Are calculated based on information provided by Division of Grants and Humanitarian and Technical Assistance of the MOF, as well as by other information sources.

- Migrants' transfers: The data are calculated based on information obtained from sample surveys carried out by GEOSTAT. For estimates, information of Border Police (former Department of Borders Defense) of Georgia is used regarding the persons entering and leaving the country.

\section{Financial Account}

The data on direct and portfolio investment on the banking sector are compiled from reports of commercial banks. Data for other sectors are estimated based on the enterprise survey. Data on insurance companies are obtained from the Insurance Supervision Division of the NBG.

Information on other investment is compiled according to commercial banks data. Additional sources come from the MOF and the enterprise survey.

Reserve assets are calculated from the NBG balance sheets. 


\subsubsection{Source data are timely.}

The source data are timely for compiling and disseminating balance of payments statistics according to the SDDS requirements. Data from the banking sector are provided on 20th day after the end of reference period. Data from GEOSTAT are received monthly for merchandise trade, one month after the reference period. Data on external government debt, debt under government guarantee, and grants received by the government are provided by the MOF one month after the reference period. The data from surveys conducted by GEOSTAT are submitted to the BoPD 70-75 days after the end of the reference period. The information from the household survey on income of Georgian citizens working abroad and on nonresidents in Georgia is received 65-70 days after the end of the reference period.

\subsection{Assessment of source data}

3.2.1 Source data-including censuses, sample surveys, and administrative records-are routinely assessed, e.g., for coverage, sample error, response error, and nonsampling error; the results of the assessments are monitored and made available to guide statistical processes.

Source data are validated and incorporated in the balance of payments statistics database as they are received from reporters. The NBG data on the banking sector is considered to be sound.

Adjustments are made, especially concerning reinvested earnings and dividends. Where applicable, data sources are checked against other available sources. The information received from the MOF on the external government and government guaranteed debt is reconciled with the MOF operational data. For data on FDI, temporal consistency is sought by checking reports over corresponding periods of time and by matching stock at the beginning of the period and transactions data.

NBG collects financial sector data from all banks, microfinance institutions, and insurance companies. The quarterly nonfinancial enterprises survey of external economic activity carried out by GEOSTAT serves as source for compiling other sectors' data.

Regarding private nonfinancial corporations external debt, a loan-by-loan database provided by GEOSTAT contains the necessary information to calculate transactions (including accrued interest), exchange rate changes, and other changes. 


\subsection{Statistical techniques}

\subsubsection{Data compilation employs sound statistical techniques to deal with data sources.}

Statistical techniques used to compile balance of payments and IIP statistics are sound, except of the calculation of C.I.F./F.O.B. prices on imports. On imports, the NBG recalculates C.I.F. to F.O.B. prices of imported goods by applying a 10 percent ratio on imports: 8 percent as transportation costs and 2 percent as insurance costs. However, these coefficients are not based on a sound method, such as a survey among major importers to estimate transportation and insurance costs. NBG is working on a methodology for converting valuations from C.I.F. to F.O.B. basis. The new methodology will be completed in 2012, according to BoPD staff. It will take into consideration the geographical composition, volumes, and means of transportation for imports.

The data are further compared with those of the principal trading partner countries. On the basis of mirror comparisons of partner data adjustment coefficients are determined for export and import data for Georgia. The export-import data are further complemented by goods for processing, repair on goods, and goods procured in ports by carriers.

On services, the value of transportation services is derived from the difference between C.I.F. and F.O.B. of imported goods as 8 percent. The NBG estimates the import of travel services by residents studying, working or receiving treatment abroad.

On income, estimates for compensation of Georgian employees working in foreign countries are made taking into account the results of the household survey and through the electronic remittances data.

On current and capital transfers, estimations of workers' remittances are made following the same method as for estimations of compensations of employees. Migrants' transfers are calculated on the basis of the number of emigrants/immigrants and the average value of real estate that could be sold.

Data editing procedures are followed by BoPD staff at the various levels of data categorization. Data are also routinely compared with corporations reports and press reports. The applied software allows for automated computerized checks that reduce processing errors.

\section{Recommendation:}

The calculation of the adjustment for C.I.F./F.O.B. prices on imports should be based on a sound method, such as a survey among major importers to estimate transportation and insurance costs. 


\subsubsection{Other statistical procedures (e.g., data adjustments and transformations, and} statistical analysis) employ sound statistical techniques.

Missing data on a quarterly basis are filled using the previous quarter reporting. For debt due that has been rescheduled, a GEOSTAT report form provide for the change in the terms of debt due undergoing refinancing/rescheduling. Using this information, a new debt creation is recorded and the original debt extinguished.

\subsection{Assessment and validation of intermediate data and statistical outputs}

\subsubsection{Intermediate results are validated against other information, where applicable.}

Intermediate results are validated against other independent data sources. FDI transactions are followed through the financial press. A list of the main FDI enterprises is kept updated. Where available, data are also cross-checked with regulatory prudential information.

\subsubsection{Statistical discrepancies in intermediate data are assessed and investigated.}

The behavior of series is cross-checked with related series/indicators.

Reported data on investment income payments and receipts are regularly assessed in relation to the corresponding stock data in the international investment position statistics. Reported financial flow data are reconciled with changes in the corresponding stock data collected for external debt and for other elements of the international investment position.

\subsubsection{Statistical discrepancies and other potential indicators of problems in statistical outputs are investigated.}

Statistical discrepancies and other problems in statistical outputs are investigated. The NBG makes logical control and analysis of all received information. Data are also verified with the information available from the BIS banking statistics and the results of the Coordinated Portfolio Investment Survey. Staff monitors developments in the errors and omissions. The size of errors and omissions is acceptable and has a random pattern.

\subsection{Revision studies}

\subsubsection{Studies and analyses of revisions are carried out routinely and used internally to} inform statistical processes (see also 4.3.3).

Analyses and studies of revisions are carried out on a routine basis to improve sources and statistical techniques, although they are not documented. For example, studies may assess the initial estimates against revised or final data over a given period of time and comprise: (i) 
studies of scale (frequency of revision and number of time series revised) and (ii) studies of direction and magnitude of revisions. Studies may also investigate the sources of errors, omissions, and fluctuations in the data.

\section{Recommendation:}

Document analyses and studies of revisions and make them known to users if findings impact the analysis, such as significant differences between preliminary and final data.

\section{Serviceability}

\subsection{Periodicity and timeliness}

\subsubsection{Periodicity follows dissemination standards.}

Balance of payments and IIP data are disseminated quarterly, following the SDDS.

\subsubsection{Timeliness follows dissemination standards.}

Quarterly balance of payments data are published 90 days after the end of the reference period, in accordance with the SDDS.

\subsection{Consistency}

\subsubsection{Statistics are consistent within the dataset.}

Concepts, definitions, and classifications for producing quarterly and annual balance of payments statistics are the same. The sum of the quarterly statistics and the annual statistics are consistent. Over the long run, the net errors and omissions item has not been large and has been stable over time. Balance of payments and IIP data are consistent with external debt and international reserves data.

Financial transactions data are reconcilable with changes in the international investment position and a table explaining the reconciliation (e.g., transactions, exchange rate, price, and other changes) is disseminated on an annual basis.

\subsubsection{Statistics are consistent or reconcilable over a reasonable period of time.}

Consistent balance of payments statistics are available since 1995. When major methodological changes are introduced, historical time series are reconstructed. 
Detailed methodological notes identify and explain the main breaks and discontinuities in the balance of payments component time series, their causes, as well as adjustments made to maintain consistency over time. For example, a break in the series exists in Dec 2001 and a methodological note was published explaining the main reasons for the break in the balance of payments component time series and their causes. A recent update of the 2000-2001 balance of payments statistics concluded a multiple years' work on presenting balance of payments statistics according to the BPM5 framework. Source data do not allow for reestimation of statistics prior to 2000, i.e. the 1995-1999 series. (This situation is common in many countries undertaking significant improvements in their statistical systems. Consistent time series for the period 2000-to date are considered reasonable for sound analyses of the Georgian external sector.)

\subsubsection{Statistics are consistent or reconcilable with those obtained through other data sources and/or statistical frameworks.}

The balance of payments statistics are reconcilable with monetary and financial statistics and with data on the external debt. There is a small difference in the definition of reserve assets. The MSD includes the stock of Russian Rubles in reserve assets, while the BoPD does not. This difference has an insignificant weight in the total reserve assets (200 US\$ currently). Another difference relates to the use of exchange rates. BoPD uses the exchange rates of the last day of the month, while MSD uses the last working day. As for the comparison between the IIP and foreign assets and liabilities in the other depository corporations survey (ODCS), a discrepancy exits in the definition of foreign liabilities. The ODCS does not include foreign capital in the form of shares and other equity in the definition of foreign liabilities. ${ }^{12}$

Balance of payments statistics are consistent with national accounts statistics. As for public external debt, there are small differences between NBG and MOF statistics. These differences are: ${ }^{13}$

- $\quad$ Arrears on principal are excluded from loans and recorded in other liabilities (arrears).

- $\quad$ Arrears on interest and accrued penalty that are omitted from MOF data are recorded as arrears (this case is for two countries)

- Accrual interest not yet due is excluded from MOF data, while included in NBG data on external debt.

- In MOF data government Eurobonds are recorded in nominal values, while in NBG data are at market value.

\footnotetext{
${ }^{12}$ A methodological note explaining these differences was published during the mission.

${ }^{13}$ A methodological note explaining these differences was published during the mission.
} 
- In some cases minor differences are caused by rounding of decimals of exchange rate.

\subsection{Revision policy and practice}

\subsubsection{Revisions follow a regular and transparent schedule.}

The revision policy for balance of payments statistics is as follows:

- Regular revisions of quarterly data are included in the balance of payments each quarter and can affect data up to three quarters;

- Regular revisions of annual data are included in the balance of payments once a year and may affect quarterly and annual data up to three years.

\subsubsection{Preliminary and/or revised data are clearly identified.}

Preliminary data are identified in footnotes. ${ }^{14}$ Users are not informed whenever data are revised. A detailed explanation of the revisions, when significant, has not been always available, according to the users survey. Users interviewed specifically mentioned recent revisions in foreign direct investment data.

\section{Recommendation:}

Inform users whenever data are revised, providing detailed explanation of the revisions, when significant.

\subsubsection{Studies and analyses of revisions are made public (see also 3.5.1).}

Analyses of differences between the revised and preliminary data are not published for major aggregates to allow an assessment of the reliability of the preliminary data. However, in the relative short time series available (from 1995) analyses between the revised and preliminary data did not show any relevant findings to merit publication.

\footnotetext{
${ }^{14}$ Footnotes were incorporated during the mission.
} 


\section{Accessibility}

\subsection{Data accessibility}

5.1.1 Statistics are presented in a way that facilitates proper interpretation and meaningful comparisons (layout and clarity of text, tables, and charts).

The balance of payments statistics are disseminated in US dollars following the standard components of the BPM5. Data are disseminated by the NBG through a press release and on the website http://www.nbg.gov.ge/index.php? $\mathrm{m}=353 \& \operatorname{lng}=\mathrm{eng}$.

The annual balance of payments publication includes charts, graphics, and explanatory notes, related to the IIP, the balance of payments, and external debt, and contains commentaries on current period developments.

\subsubsection{Dissemination media and format are adequate.}

Balance of payments and IIP data are released on the NBG's website (in Georgian and English). Data are also published in annual reports both available in Georgian and English on the NBG's website and in hard copy. The annual report on the Balance of Payments of Georgia has been released since 2009. (http://www.nbg.gov.ge/index.php?m=353\&lng=eng)

Data are available in downloadable format (Excel). This makes them easy for users to obtain data for their own manipulation and analysis. In addition, data include standard (detailed) and analytic (short) presentations of the balance of payments and IIP statistics. Long time-series are regularly disseminated (from 1995, i.e. the year Georgia started compiling balance of payments and IIP statistics.)

\subsubsection{Statistics are released on a preannounced schedule.}

Georgia is announcing in advance the dates on which balance of payments and IIP data are released. An advance release calendar is accessible on the NBG website (http://www.nbg.gov.ge/index.php?m=367).

\subsubsection{Statistics are made available to all users at the same time.}

Data are simultaneously released to all users of statistical information.

5.1.5 Statistics not routinely disseminated are made available upon request. 
Additional data series that do not contain confidential information are provided upon request. Users are informed of nonpublished data series that are available upon request, such as loans, cash, and deposits by currency, loans by country; and nominal prices of bonds. ${ }^{15}$

The decision on the disclosure of requested information is taken considering the confidentiality of individual data. Therefore, requests for data are considered by the NBG on case-by-case basis and are dependent on confidentiality considerations.

\subsection{Metadata accessibility}

5.2.1 Documentation on concepts, scope, classifications, basis of recording, data sources, and statistical techniques is available, and differences from internationally accepted standards, guidelines, or good practices are annotated.

Notes on data sources and compilation methods are available on the NBG website and in the annual report on the Balance of Payments of Georgia. Methodological notes are posted both in Georgian and in English. Methodology, compilation practices, and data sources are also published in the IMF Balance of Payments Statistics Yearbook and in the national page of the IMF's Data Standards Bulletin Board (DSBB). A link to the DSBB can be found in the NBG website.

\subsubsection{Levels of detail are adapted to the needs of the intended audience.}

Detailed methodological notes are available, as described in the previous Section 5.2.1. Less specialized users benefit from brief explanations of the datasets comprising the external sector statistics in Georgia, including how they relate to each other. ${ }^{16}$

The level of detail in the data is adequate for both general and specialized users. All prescribed components are disseminated, including assets and liabilities data on direct investment, portfolio investment (broken down into equity and debt), other investment, and reserve assets.

\section{$5.3 \quad$ Assistance to users}

\subsubsection{Contact points for each subject field are publicized.}

\footnotetext{
${ }^{15} \mathrm{BoPD}$ published a note describing the available, nonpublished data during the mission.

${ }^{16}$ Brief explanations were prepared by the BoPD and published during the mission.
} 
Statistics users have available a contact number on the NBG website. Arrangements have been established within the NBG to ensure that any queries received are directed to the relevant person, including BoPD staff.

5.3.2 Catalogs of publications, documents, and other services, including information on any charges, are widely available.

A list of NBG publications containing statistics is available on the NBG website (http://www.nbg.gov.ge/index.php? $\mathrm{m}=308$ ). New publications are announced via press releases. 
Table 8. Data Quality Assessment Framework: Summary of Results for Balance of Payments Statistics

(Compiling Agency: National Bank of Georgia)

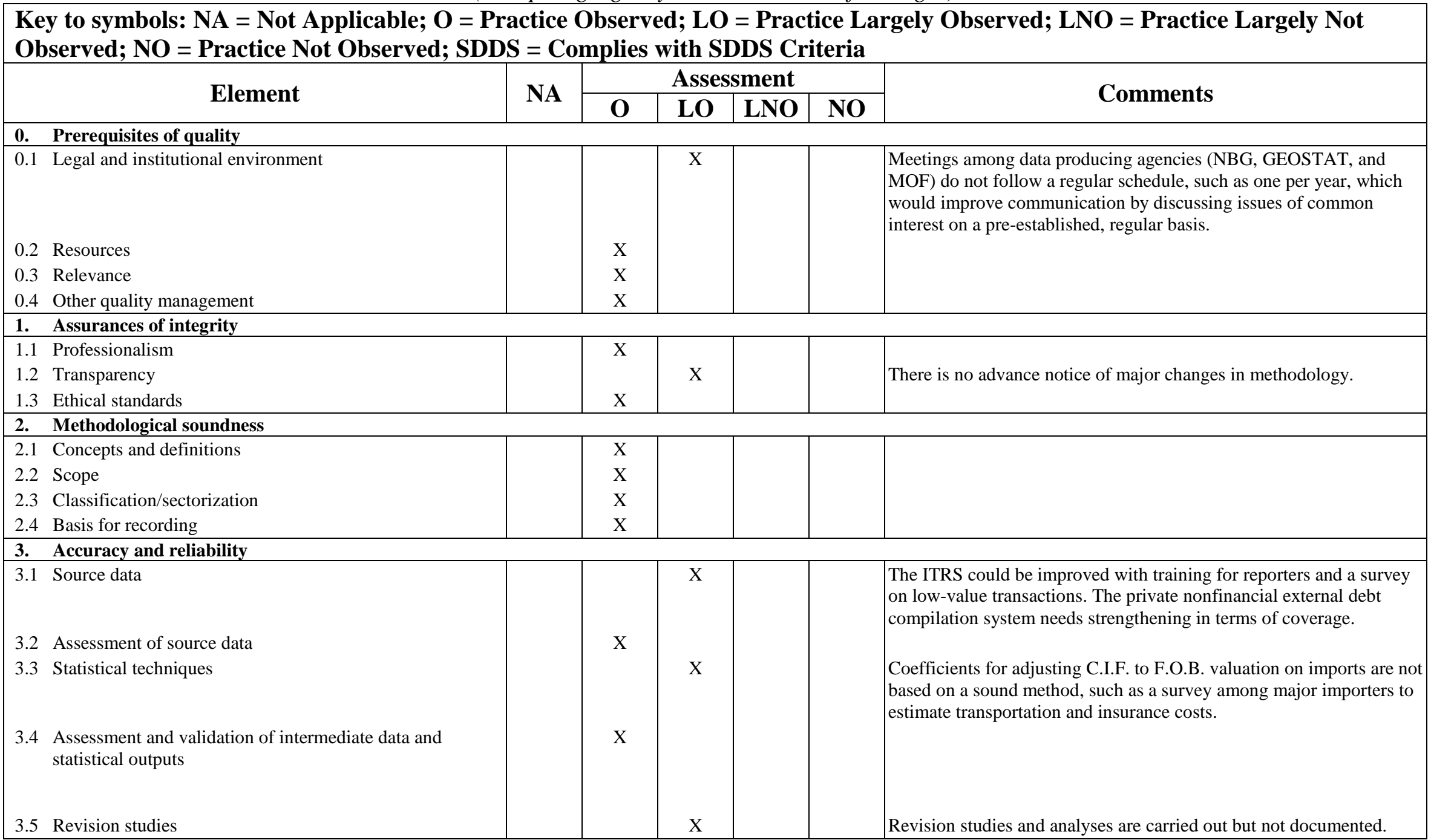


Table 8. Data Quality Assessment Framework: Summary of Results for Balance of Payments Statistics

(Compiling Agency: National Bank of Georgia)

Key to symbols: NA = Not Applicable; O = Practice Observed; LO = Practice Largely Observed; LNO = Practice Largely Not

Observed; NO = Practice Not Observed; SDDS = Complies with SDDS Criteria

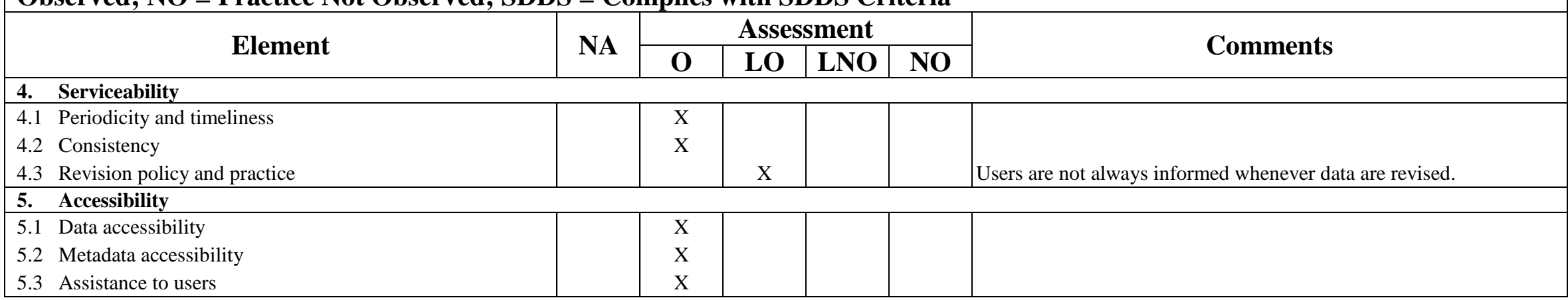

